\title{
Towards developing a systematic knowledge trend for building energy consumption prediction
}

DOI:

https://doi.org/10.1016/j.jobe.2020.101967

\section{Document Version}

Accepted author manuscript

Link to publication record in Manchester Research Explorer

\section{Citation for published version (APA):}

Qiao, Q., Yunusa-Kaltungo, A., \& Edwards, R. (2021). Towards developing a systematic knowledge trend for building energy consumption prediction . Journal of Building Engineering, 35, [101967].

https://doi.org/10.1016/j.jobe.2020.101967

\section{Published in:}

Journal of Building Engineering

\section{Citing this paper}

Please note that where the full-text provided on Manchester Research Explorer is the Author Accepted Manuscript or Proof version this may differ from the final Published version. If citing, it is advised that you check and use the publisher's definitive version.

\section{General rights}

Copyright and moral rights for the publications made accessible in the Research Explorer are retained by the authors and/or other copyright owners and it is a condition of accessing publications that users recognise and abide by the legal requirements associated with these rights.

\section{Takedown policy}

If you believe that this document breaches copyright please refer to the University of Manchester's Takedown Procedures [http://man.ac.uk/04Y6Bo] or contact uml.scholarlycommunications@manchester.ac.uk providing relevant details, so we can investigate your claim.

\section{OPEN ACCESS}




\title{
Towards developing a systematic knowledge trend for building energy consumption prediction
}

Qingyao Qiao, Akilu Yunusa-Kaltungo*, Rodger E. Edwards

Department of Mechanical, Aerospace and Civil Engineering (MACE), University of Manchester, M13 9PL, UK

E-mail addresses: qingyao.qiao@ postgrad.manchester.ac.uk (Q.Qiao)

akilu.kaltungo@manchester.ac.uk (A. Yunusa-Kaltungo)

rodger.edwards@manchester.ac.uk (RE Edwards)

Corresponding author: $(*)$

\begin{abstract}
:
The rapid depletion of natural sources of energy, coupled with increasing global population has triggered the emergence of various techniques and strategies for building energy consumption prediction. According to information from existing body of knowledge, this paper systematically brings to fore the application areas of building energy consumption prediction (i.e. well-established and emerging), the relationships between these areas and the ways in which authors integrate the current spate of techniques. Based on direct implications of buildings on global energy consumption and $\mathrm{CO}_{2}$ emissions, this information makes it possible to identify trends, strengths and limitations in this context, thereby enabling the centralisation of activities required for future studies. This study follows several welldocumented guides for conducting logical reviews of primary articles concerning main topics of building energy consumption prediction within popular online databases. The definition of articles' search keywords as well as inclusion/exemption factors were governed by a combination of principles stipulated by Preferred Reporting Items for Systematic Reviews and Meta-Analyses (PRISMA) and Procedures for Performing Systematic Reviews (PPSR). In comparison to existing review articles in the studied field, the current study is novel in the sense that it provides a very holistic view to building energy consumption prediction, thereby minimising the need to consult multiple individualised studies that are limited to specific techniques, data sets, regions or types of buildings. Another unique feature of this study is its interrelationship network of articles which depicts a quick glance at some of the most influential studies as well as underrepresented areas, thereby aiding research planning, future directions and cross-disciplinary collaborations.
\end{abstract}




\section{Keywords}

Building energy; energy consumption; prediction; sustainability; systematic and metaanalysis

\section{Introduction}

The population of the world has experienced an unprecedented growth from 2.53 billion in 1950 to 7.16 billion in 2011. Based on the current growth rate of $1.2 \%$ per year, the world population is anticipated to reach 14.4 billion within the next 60 years [1]. This rapid growth in population, has led to a corresponding rise in global primary energy consumption (3701Mtoe in 1965 to 13511 Mtoe in 2017). At the current population growth rate, it is predicted that there could be a total depletion of all current primary energy sources in less than 134 years [2].

Buildings represent an immense proportion of global energy consumption and carbon dioxide (CO2) emissions, due to rising human demands for housing and quality of living standards [3]. As a consequence, building and transport related activities are gradually becoming the main energy consumption sectors globally. In 2017, buildings construction and maintenance represented $36 \%$ of global energy usage and $39 \%$ of total CO2 released [4], [5]: this proportion could be significantly greater in highly industrialised nations. For instance, the UK's domestic and services industries accounted for an estimated 44\% of cumulative energy in 2018 [6]. Similarly, building energy usage in China rose by a magnitude of 1.7 between 2000 and 2014, and is predicted to represent 35\% of cumulative national energy usage by 2020 [7]. The criticality of stable and reliable energy can never be overemphasised, which is perhaps why policymakers and governments across the world are continuously implementing regulations, policies and in some cases incentives that are aimed at promoting building energy saving initiatives. In the United Kingdom for instance, Climate Change Act of 2008 established a legal framework for reducing CO2 emissions by $34 \%$ by 2020 and a further $80 \%$ by 2050 [8]. While such Acts and targets are immensely crucial drivers for change, their actualisation significantly hinges on the reliability of building energy usage predictions. In recent decades, a number of theoretical (statistic methods and artificial intelligence methods) [9] and practical (EnergyPlus, TRNSYS, eQuest, DOE-2) [10] analysis tools have been developed and applied to varying levels of success in this field. 
While existing building energy consumption prediction approaches have significantly enhanced the understanding of energy trends as well as aided forecasting, the ever-increasing complexity of the energy systems associated with modern day buildings have made it imperative to continuously seek smarter and more reliable approaches. The complexity of prediction is further compounded by variations in occupant behaviour [11] with regards to the use of electrical appliances and/or devices, geographical location of buildings, age of buildings, function of building, etc.[12]. Owing to the rising popularity of building energy studies, coupled with the advent of high-power computational technologies, existing body of knowledge is adequately furnished with a spate of articles in this area but very few of them are solely based on knowledge trends development through detailed literature reviews of building energy consumption prediction, except for those by Amasyali and EI-Gohary [13], Wei et al.[14], Ahmad et al.[15] as well as Lim and Zhai [16].

Amasyali and EI-Gohary [13] reported a study based upon data-driven building energy usage prediction models. The study [13] primarily focused on investigating scope of predictions, data features, data pre-processing methodologies, roles of machine learning based prediction algorithms and evaluation performance measures. The study advocates the need to further focus on longer term building energy usage forecasts of residential buildings through better understanding of lighting patterns [13]. Similarly, Wei et al. [14] reviewed the emerging datadriven methods applied in building energy analysis for a range of archetypes and granularities, whereby the basic concepts, merits and demerits of existing applications of building energy analyses were discussed. The study [14] generated three core findings. The initial finding advocates that current data-driven frameworks should be streamlined to specific energy demands. The second finding highlights that building energy analyses need to encompass energy applications at varying scales as well as using several weather conditions. The third and final finding recommends the integration of multiple target indices into existing datadriven frameworks. Ahmad et al. [15] studied the forecasting mechanisms for electrical energy usage of buildings especially those that involved artificial intelligence (AI) techniques such as support vector machine (SVM) and artificial neural networks (ANN). The study [15] further highlighted the superior performance of hybrid methods such as least square-SVM (LSSVM) over the independent application of traditional ANN and/or SVM when predicting building electrical energy usage. Lim and Zhai [16] also provided a detailed review of commonly used mechanisms and techniques for building stock energy forecasting, whereby 
specific emphasis was placed on comparing the strengths and weaknesses of existing primary stochastic engineering building stock energy models.

Although all classes of existing articles (literature reviews, case studies, short communications, editorials and regular articles) provide some insights on prevailing as well as previous status of building energy consumption prediction research, the approaches adopted for the reviews therein can be described as opinionated since they rarely explain the criteria used for selecting the included primary studies. Additionally, traditional literaturebased studies offer little or no information about the timelines covered and the statistical distribution of primary studies (also referred to as meta-analysis), which is crucial to the understanding of energy consumption since outcomes may sometimes vary according to authors' geographical locations. Based on these premises, the current study aims to adequately compensate for the existing gaps through logical and well-structured classification of the findings of existing studies [17]. A systematic review (SR) attempts to identify and interpret contributions of existing studies that concern the investigated title, thereby synthesising existing work on the basis of fairness, precision and reliability. In contrast to standard literature reviews, SRs need considerably more efforts as well as provide further details about the specific impacts of certain principles across macroscopic settings and empirical methods. On the one hand, if several comparable studies generate consistent results, SRs offer proof that such principles are robust and transferable. On the other hand, if the findings from studies are inconsistent, sources of discrepancies are easily identified. With regards to quantitative studies, a systematic review can be used to detect the actual effects through meta-analytic techniques [18], which may be challenging or impossible through individual primary studies alone or standard literature reviews.

Based on a rigorously defined research protocol, the systematic review performed here examines all types of prediction methods (physical, statistical, artificial intelligence-based and hybrid methods) associated with building energy consumption prediction over 3 decades. Additionally, the classification of the prediction methods provides information such as overall developmental trends within the study area, building designs considered, temporal granularities, forms of energy usage forecasted, data structures, feature types, sample sizes, optimisation and improvement approaches considered within individual primary studies. The 
remaining parts of this paper are structured thus; Section 2 provides the procedural details of the systematic review of building energy consumption prediction. Section 3 summarises widely applied prediction methods as well as explains the data classification approach adopted here, including a highlight of the advantages and disadvantages of individual methods. Section 4 describes the synthesisation of major findings from included articles, particularly the data properties, data preprocessing and accuracy of the prediction methods. Finally, Section 5 provides the concluding remarks and future considerations.

The contributions provided by this systematic literature review are two-fold: firstly, it helps to identify the general developmental trends of building energy usage forecasting/prediction, based on logical but thorough examination of all related articles from 4 databases. Secondly, the extracted data and statistics provide a knowledge repertoire which offers guidance for future research, especially in the identification of opportunities that can enhance the accuracy and robustness of prediction outcomes.

\section{Review Methodology}

The SR is performed in line with both PRISMA and PPSR methodologies provided by Sharma and Oremus [19] and Kitchenham [17] respectively. PRISMA and PPSR are characterised by detailed items checklist and phase flow diagrams that enable transparent reporting during SRs and meta-analyses.

\subsection{The research question}

Formulating a representative research question is a fundamental step for adequately performing SRs. With regards to building energy consumption prediction, several of the existing regulations, instruments and guideline are still at development stages. This implies that some prediction procedures are sometimes determined based on personal experience and preference. In simpler terms, personal understanding of the interrelationships that exist between different prediction methods, building types as well as input parameters would be the most uncertain part of prediction. Therefore, tracking the totality of developmental history and trends of building energy consumption prediction offers a great opportunity for ascertaining research direction. Unfortunately, such holistic and all-encompassing reviews are very rare within existing body of knowledge, thereby necessitating the harmonisation of numerous independent studies. Based on this premise, the following research question was formulated for this study: 
"To what extent do existing building energy consumption prediction literature reviews address the multi-dimensionality of knowledge management trends?"

\subsection{Identification of relevant articles}

The research area of energy consumption monitoring and prediction is quite diverse and widely studied across various disciplines. In order to create a representative spectrum of studies, 6 well-known multidisciplinary electronic databases (Web of Science, InSpec, Compendex, Geobase, GeoRef, Scopus) are used to generate the reviewed articles. Web of Science (WoS) and Scopus being two of the most comprehensive academic information management system broaden the wider reach of review while Engineering Village (which is made up of 4 engineering-specific databases) were used to complement each other. The review primarily comprised of several classes of inputs especially published journal articles, conference articles, conference proceedings, book chapters, dissertations as well as articles in press. The systematic search starts with identifying very important keywords. In order to enhance good coverage of articles but at the same time optimise the selection of directly linked articles, a combination of the SPIDER and PICO approaches suggested by Cooke et al. [18] was applied for defining the following keywords:

“building” AND “energy consumption” AND “prediction” AND “ageing” OR “existing” OR "retrofit" OR "old".

The selected keywords indicated that this SR particularly focuses on existing buildings rather than new buildings. The rationale behind this class of buildings is due to the peculiar challenges associated with older buildings with regards to energy consumption prediction, due to their lack of up-to-date or totally unavailable data. Furthermore, since the term "existing" might not be comprehensive enough to capture all the relevant articles, alternative but related words such as "ageing" "retrofit" and "old" were included within the search string so as to enhance search quality.

\subsection{Study Selection}

While keywords are universally recognised as incredibly strong tools for guiding articles search within databases, their ability to adequately represent the interest of a reviewer is always a function of their origin. For instance, some authors misdefine keywords or even omit them completely, which raises the possibility of extracting several unrelated articles during reviews. Therefore, an additional layer of filtration is often required for further assessment of actual relevance. Additionally, the inclusion of all primary studies is 
unreasonable, inefficient and could also lead to bias. Therefore, the definition of key inclusion criteria is imperative for the exclusion of irrelevant studies. The inclusion criteria defined for this systematic review are:

i. $\quad$ Language of publication must be English language due to its global prevalence;

ii. Research focus of article must be on building energy consumption prediction;

iii. Full text of article must be available.

Table 1 shows the review protocol that was adopted for this study, which also summarizes the search string and exclusion.

Articles that meet these three basic criteria were further screened for eligibility. For instance, when conducting inter-database search for articles using the same keywords, there is always a possibility of creating duplicates, triplicates and quadruplicates that must be screened out since their contributions to knowledge is same. Figure 1 depicts the procedure used for streamlining the articles generated at different stages of the review. A total of 2493 articles were initially generated from all 6 databases, of which 181 of them were inaccessible. An additional 1835articles were further excluded due to the misalignment of their core contents with the review context. The remaining 457 full-text accessible articles were then transferred into Mendeley reference management software, whereby 217 articles were identified and excluded due to duplicates, triplicates, quadruplicates and non-English text. Finally, 240 articles were retained for detailed contents review and eventual analysis.

\section{Classification of methods for building energy consumption prediction}

A comprehensive classification and reasonably standard nomenclature of prediction methods would ease the ability of readers or researchers to build a holistic building energy performance analysis knowledge network. Currently, there is a lack of uniform and clear consensus on the classification of prediction methods, which may lead to misconceptions and a corresponding lack of deep understanding of the peculiarities of individual prediction methods. For instance, Amasyali and El-Gohary [13], as well as Runge and Zmeureanu [20] simply classified methods as physical or data-driven while Suganthi and Samuel [21] applied 12 sub-categories for their classification. This broad classification of articles and techniques rarely reflect the key features of the individual methods. In addition, contradictory definitions of prediction methods could be observed across several review articles. For instance, Grillone et al. [22] deemed hybrid method (grey model or grey-box model) that making use of data- 
driven techniques to optimize the results obtained with deterministic (physical based) methods, while subtle difference existed in [8], [13], [23]-[28] which simply defined hybrid methods as combination of physical models and data-driven approaches. According to [29] however, any combination of different methods can be regarded as a hybrid method. Simply designating hybrid methods as grey models can potentially lead to significant misinterpretation when such classifications are compared to the earlier grey prediction model introduced by Deng [30] over 4 decades ago, which had a primary aim of predicting system behaviours.

Based on inspirations from earlier works by Wei et al. [14], Bourdeau et al. [27] and Robert et al. [26], prediction approaches should have at least four basic classifications, namely; physical, statistical, AI and hybrid methods. The data-driven methods in their reviews [14], [26], [27] were fundamentally grouped into statistical and AI methods, due to the fact that both classes primarily investigate the relationships that exist between input and output data. However, while statistical methods mechanically seek to establish the input-output data relationships, artificial intelligence methods apply special characteristics such as self-learning, self-adjusting and generalization abilities to achieve similar outcomes more efficiently. In order to foster clarity and conciseness, Table 2 summarises the merits and demerits of the different classes of prediction methods described herein.

\subsection{Physical methods}

Physical methods (also referred to as engineering, deterministic or white-box approaches) [33], [34] are mainly based on the application of physical laws for modelling building systems and their associated components, as well as estimating thermal dynamics and energy patterns. The increased understanding of the characteristics of physical methods over the past decades has contributed to the creation of several building energy simulation platforms including EnergyPlus, DOE-2, eQuest and DesT. In addition to the relative simplicity of obtaining details of a building's performance through physical methods, impact of changes to a building can also be swiftly and clearly assessed from the relationships that exist between inputs and outputs. Physical methods are also good at simulating energy consumption throughout the life cycle of a building, which in turn offer asset owners and/or operators the highest degrees of flexibility with regards to implementing cost-effective improvement strategies. Such methods are more applicable at building design stages rather than predicting the performance of existing buildings. Furthermore, in terms of handling diverse predictive 
situations as well as assessing new technologies for energy conservations, physical methods are far more flexible than statistical and AI method [16].

Despite the aforementioned advantages of physical methods, the possibility of significant deviations between predicted results and real-life situations is still considered a limitation. Such deviations are also referred to as performance gaps, which may be influenced by various factors as summarised by Lahrech et al. [35] and Simon [36]. The most prominent factors include uncertainties in building design parameters, uncertainties in operational data used for modelling, estimation errors as well as limitations in the underlying models [35], [36].

\subsection{Statistical methods}

Statistical methods (also known as statistical regression or regression methods) [9] mainly focus on estimating the relationships between variables. More specifically, statistical methods enable researchers understand the impacts of independent variables on the dependent variables by estimating the minimum mean square error (MMSE) for a given set of independent variables. The most common statistical methods are linear regression, stepwise regression, locally estimated scatterplot smoothing (LOESS), ordinary least squares regression (OLSR), multivariate adaptive regression splines (MARS) and logistic regression. Statistical methods are arguably the most widely applied for building energy prediction in practice, due to computational ease, speed and reasonable degree of accuracy [37]. Despite their ability to quickly generate predictive energy consumption data, this class of building energy prediction approaches have been criticized for their inability to adequately establish the nature of relationships between inputs and outputs, which necessitates thorough scrutiny of the influence of assumptions made during results generation. Studies have shown that statistical methods can accurately predict medium to long term energy consumption patterns of buildings [38]. Although reasonably acceptable, their performance with regards to short term prediction is less accurate [39]. The relative simplicity of implementation coupled with acceptable predicting performance outcomes of statistical methods is perhaps a fundamental reason for their widespread application as benchmarking tools for more advanced and complicated prediction methods [27].

\subsection{Artificial Intelligence (AI)}


During the last decade, the breakthroughs in computational technology has significantly elevated the capabilities of artificial intelligence (AI) methods. The concept of AI was initially coined by John McCarthy in 1956 who defined AI as the science and engineering of making intelligent machines [40]. Machine learning (ML) and neural networks (NNs) are two very common methods for automating intellectual tasks [41]. ML consists of applying mathematical and statistical approaches to automatically learn from experience[42]. ML algorithms are often categorised as supervised, unsupervised and semi-supervised algorithms. $\mathrm{NN}$ explores the prospects of techniques that can adequately mimic the operations of the human brain. The most representative and commonly used NNs are ANN and their deep learning derivatives.

\subsubsection{Machine learning (ML)}

\subsubsection{Supervised machine learning algorithms}

Supervised machine learning algorithms can utilise what has been learned in the past to new data using labelled samples to predict future events [42]. The most common supervised algorithms are SVM, DT, ensemble algorithms, Bayesian methods.

\section{Support vector machine (SVM)}

SVM can be described as a kernel-based machine learning technique [15]. Assuming a set of training samples, each of which belongs to one or more classes, SVM training algorithm can adequately allocate the new sample(s) into the appropriate categories by functioning as a nonprobability binary linear classifier. The trained samples are represented by space points and the possible classes are distinguished by notable gaps. Consequently, new samples are mapped into the created spaces and simultaneously allocated to their respective categories, based on their relative positions from the gaps. While SVM outperforms other methods on the basis of linearly separable problems, it has also been criticized for the difficulties associated with data training and interpretation [43], [44].

\section{Decision trees}

Decision trees [45] are often considered one of the most popular amongst machine learning approaches. Their functioning is mainly based on application of tree-like structures to allocate datasets into several preconceived groups or target values [46]. Classification, boosted and regression trees are considered the most popular forms of decision trees. The most notable strengths of decision trees are their relative ease of interpretation and nonparametric nature. However, they have also been described as being susceptible to overfitting 
problems as well as having high affinity for local minima. Another problem with decision trees is their lack of online learning capabilities.

\section{Ensemble algorithms}

Ensemble methods [28] are combinations of multiple learning algorithms, whereby the individual algorithms can be trained separately and their predictions combined in ways that depict an overall prediction. The main purpose of ensemble algorithms is to determine which of the weaker models can be combined as well as the best means by which such combinations can be performed [47], [48]. Random forest, bootstrapped aggregation, gradient boosting machines, boosting, stacked generalization and adaBoost [49] are some of the most notable examples of ensemble algorithms. While the combination approach adopted by ensemble algorithms allows for the strengths of certain individual algorithms to compensate for the weaknesses of others thereby improving overall prediction accuracy, tuning the different methods to ensure compatibility is often very challenging.

\section{Bayesian algorithms}

Bayesian methods [50] are explicitly based on the application of Bayes' theorem for solving classification and regression problems. Gaussian Naive Bayes, Naive Bayes, Bayesian network, Bayesian belief network and multinomial Naive Bayes are common examples of Bayesian algorithms. While Bayesian methods are universally recognized for their data processing speeds and training ease, the presence of correlated input variables is known to cause immense difficulties during analysis. This is often due to the fundamental assumption that the resultant output category is always a function of independent input variables, which is seldom the case under practical applications. Therefore, the performance of Bayesian methods (especially naïve Bayes) is best when the correlation attributes is minimal but could be unreliable when the number of variables is large.

\subsubsection{Unsupervised machine learning algorithms}

In contrast with supervised learning, unsupervised machine learning algorithms explore how to infer a function of describing hidden structures from unlabelled data [42]. The most common unsupervised algorithms are clustering algorithms and dimensionality reduction algorithms. 
Clustering algorithms [51] are used to establish pattern similarities so that data that exhibit similar characteristics can be classified into their corresponding target groups. Popular examples of clustering algorithms include hierarchical, expectation maximization, k-medians and k-means clustering approaches. Clustering algorithms are most suited for identifying linear correlations between data classes but their applications can be highly restricted by the non-linearities, noise, multi-dimensionality and significant variabilities often associated with real-life data. This is perhaps why several studies have explored alternative approaches for determining cluster compositions and efficiency [52].

\section{Dimensionality reduction algorithms}

Similar to clustering methods [53], dimensionality reduction methods are principally based on the utilisation of underlying data structure to summarise and/or explain data characteristics, but with significantly fewer information. This implies that dimensionality reduction algorithms can be useful for the visualisation, simplification or interpretation of highly dimensional data, prior to feeding such data into a typical supervised learning framework. Partial least squares regressions (PLSRs), principal components regressions (PCRs) and principal component analysis (PCA) are some of the most commonly used dimensionality reduction algorithms. Most dimensionality reduction approaches are multivariate statistical analysis tools that pose the capabilities to transform original interrelated variables onto alternative and new subspace with significantly lower dimensionality. The resultant subspace would then represent a set of uncorrelated variables that retained the maximum variations that exists in the original data set, thereby making them suitable for handling large datasets but less effective when dealing with non-linearities.

\subsubsection{Semi-supervised machine learning algorithms}

Semi-supervised machine learning algorithms (SSMLA) fall between supervised and unsupervised learning classes, thereby utilising both labelled and unlabelled data [54]. The most common examples of semi-supervised algorithms are generative models, low-density separation and graph-based methods.

\section{Generative Models}

Generative models assume that all data (whether labelled or not) are produced by the same underlying model [55]. This assumption ensures that the parameters of the underlying model can be used to associate the unlabelled data with the learning purpose, and the label of the unlabelled data can be regarded as the actual parameters of the model. The main advantages 
of generative models are simplicity, ease of implementation and its ability to outperform other methods under limited labelled data scenarios. However, a key challenge often associated with SSMLAs is that the model assumptions must be accurate, that is, the hypothetical generative model must match the real data distribution, otherwise the use of unlabelled data will reduce the generalization performance. Unfortunately, it is often difficult to make accurate model assumptions in advance under real-life situations, unless sufficient and reliable domain knowledge exists [55].

\section{Low-Density Separation}

The fundamental concept of low-density separation methods (LDSMs) is quite similar to that of support vector machine. LDSMs consider applying various possible label assignments to unlabelled samples. This implies that attempts are made to use each unlabelled sample as a positive or negative example, after which one in all samples are divided into hyperplanes with maximal spacing. Once the partitioned hyperplane is determined, the final label assignment of the unlabelled samples the becomes the predicted result [56].

\section{Graph-Based Methods}

Graph-based methods [55] map the data set into a graph whereby each sample within the data set corresponds to a node on the graph. If the similarity between two samples is very high (or the correlation is strong), then there is an edge between the corresponding nodes, and the strength of the edge is proportional to the similarity (or correlation) between the samples. The node corresponding to the labelled sample is regarded as dyed, and the node corresponding to the unlabelled sample has not been dyed. Therefore, semi-supervised learning corresponds to the process of "colour" spreading or spreading on the graph. Graph-based methods have the advantage of clear concepts and easy to explore the nature of the algorithm through matrix operation analysis. However, this method occupies a lot of memory space during calculations, and it is difficult to directly process large-scale data. In addition, it may be necessary to recalculate when receiving new samples [57].

\subsubsection{Neural Networks (NNs)}

\section{Artificial neural network (ANN)}

ANN owes its origin to biological neural networks of the human central nervous system and was initiated by McCulloch and Pitt [58]. ANN is primarily a sub-set of pattern identification techniques that can be used to visualise regression and/or classification challenges. A typical 
ANN can be characterized by several hundreds of algorithms that possess wide variations that can be applied to different practical challenges. Some of the most frequently applied ANN approaches include Hopfield network, multi-layer perceptron, perceptron, and radial basis function networks (RBFN) [59]. The main advantages of ANN include: superior ability to solve non-linear problems that are associated with highly dimensional datasets, handling large and incomplete datasets (including those containing random noise) and self-adaption to dynamic scenarios [60]. Besides self-adaptation, self-organisation and real-time learning, basic ANN-based models are relatively easy to construct. A typical ANN model comprises of several simple processing elements that are joined via a complicated layer structure that allows the model to evaluate complicated tasks which are often characterised by multiple inputs and outputs. Figure 2 shows a typical ANN-based model with multiple inputs (IP) and several target outputs (TM). However, just like any other tool and technique, ANN has also had it fair share of criticism especially due to its requirement for large amounts of data, computational expense during data training as well as the difficulties associated with the selection of meta-parameters and network topology.

\section{Deep learning}

Deep learning methods [61] are updated forms of ANN that require more computer power than the traditional ANNs. In comparison with standard ANNs, deep learning methods apply far more complex neural networks and the most common types are AotuEncoder [62], recurrent neural network (RNN) [63], convolutional neural network (CNN) [64] and Generative adversarial network (GAN) [65]. In addition to their earlier stated characteristics, deep learning networks generally share very similar advantages and disadvantages with ANNs but better emphasise the depth of the model structure. On the one hand, a deeper model means better nonlinear prediction capability and can learn more complicated transformation, thereby allowing the model fit more complex input data. On the other hand, the more layers a model has, the fewer tasks required to be handled for each layer. Therefore, the model can better learn input data layer by layer.

\subsection{Hybrid methods}

Just as ensemble methods are based on the fusion of multiple learning algorithms, hybrid methods [66] also combine several methods, although their fusion approaches vary. For ensemble methods, the individual sub-models are homogeneous while hybrid methods combine completely different or heterogeneous machine learning methods to improve the 
quality of reasoning as well as boost the adaptivity of the entire solution [33]. Besides the lack of in-depth knowledge about hybrid methods within existing literature, their perceived drawbacks are often attributed to the risk of overfitting and computational intensiveness. When sufficient amount of data are available, more complex methods generally provide more accurate prediction result [22]. However, the extent to which data amounts influence the performance (including accuracy, speed and complexity) of hybrid methods has not been studied in detail, which implies that it is yet to be fully founded as to whether hybrid methods will always outperform other individualised prediction methods. This systematic review shows that hybrid methods have been applied in 32 of the captured case studies and Table 3 clearly depicts the main functions of the respective hybrid methods as well as their submethods.

\section{Extraction of data and synthesis of major findings from included article}

Comprehensive and accurate statistics can help to accurately grasp the development trend of building energy usage to a large extent. Correspondingly, it should be reminded that due to the increasing complexity of the thermal environment of buildings, professional knowledge and rich practical experience are still indispensable even if various advanced and efficient prediction approaches are applied. In this section, this kind of experience will be summarized in detail.

\subsection{Overview of included articles}

Core developments in building energy consumption prediction research can be traced back to 2001. Figures 3 and 4 show the number of relevant articles published annually between 2001 and 2013. Interestingly, the SR conducted here revealed that the articles search sensitivity and precision is not always a function of the database size. For instance, Engineering Village databases, especially Compendex and InSpec, returned the highest percentage as well as volume of relevant primary articles in comparison to significantly larger databases such as WoS and Scopus. This finding could help save significant amounts of research time and efforts in the future. Research outputs in this field have been limited till 2010. However, exponential rises in total energy consumption due to building operational activities also led to publication surge from less than ten articles to about 20 articles per year for the next 4 year, until 2018 when output rates doubled to almost 40 articles. It is adjudged that the experienced growing trends could have been influenced by the implementation of initiatives such as the Kyoto Protocol [98]. as well as the growing expenditures or contributions of various 
governments on education (including research) since 2009 as shown in Figure 5. Additionally, Figure 6 provides a distribution of articles by country, where it can be observed that the two biggest economies in the world (United States of America and China) contribute the most but contributions from other developing countries is also very significant. For instance, India and Malaysia are contributing immensely which may be attributed to their currently erratic and inadequate electric power supply shortage [99].

Only 24 of the 240 included articles qualified as literature review articles, which is not a representation of the global focus on building energy usage prediction. A further breakdown of the 24 literature review articles showed that 50\% of them (articles [9], [13], [14], [22], [23], [25], [27]-[29], [93], [94], [95]) typically focused on the application of statistical and AI methods for building energy consumption prediction, which is a further attestation to their well-established popularity. The articles mainly iterated the advantages, disadvantages and application areas of the most common classes, with keen emphases on building types, temporal granularity of prediction, types of energy usage predictions and the characteristics of the training/testing data ([13], [23], [27]). Additionally, 4 review articles ([15], [20], [60], [103]) targeted ANN-based applications. A summary of their major findings revealed that Mohandes et al. [103], Runge and Zmeureanu [20] investigated the practicability of ANNs in analysing issues related to building energy, while Georgiou et al. [60] gave a brief review of the basic theory of ANNs as well as their specific applications to building energy management, systems control and energy prediction. Additionally, Ahmad and Hassan [15] reviewed the use of building electrical energy consumption prediction methods that were primarily based several artificial intelligence (AI) approaches especially ANN, SVM and their fusion. The 4 review articles by Kavgic et al. [8]; Liam and Zhai [16]; Li and Wen [10] as well as Yang et al. [104] were compilations of research outputs that applied physical methods. Kavgic et al. [8] compared as well as summarised the possible advantages and disadvantages of both top-down and bottom-up methods, with particular emphasis on the current stochastic building stock energy models. In general, their study [8] offered useful insights on the challenges and possible future directions of stochastic building stock energy modelling. The physical methods review by Yang et al. [104] on the other hand examined the relationship between building energy usage and thermal comfort especially the implications of such relationships on wider energy and environmental challenges such as socio-economic, carbon footprints and fuel mix. Liam and Zhai [16] provided a comparison of the performance of five distinct applications of bottom-up physical models on the UK building 
stock. Li and Wen [10] tried to harmonise building operation and control mechanisms by providing a holistic review of whole building and building critical components modelling approaches. Some of the most intriguing highlights of the study are its details on how to achieve energy savings through short-term weather forecasting and diverse model-based optimal control methods.

Two review articles by Yildiz et al. [9] and Menedez et al. [105] respectively examined the application of statistical methods for building energy prediction. Yildiz et al. [9] presented various electricity load estimating models, with keen emphasis on regression models. Menezes et al. [105] however compared the benchmarking figures published in the 2nd and 3rd editions of CIBSE Guide F against actual power loads measured in UK office buildings. Rylatt et al. [106] reviewed current bottom-up methods to predict domestic energy requirements and introduced novel GIS tools to extract the plan form of dwellings from digital maps. Asadi et al. [107] performed a review of indoor environmental quality (IEQ) as well as energy usage within several buildings, based on occupant behaviours.

Eight of the 240 primary articles were case studies that investigated the impacts of climate change on the energy performance of buildings. Based on the climate change data from UKCIP02, the heating and cooling demand for the 2020s, 2050s, and 2080s in UK office buildings and housing stock was investigated [108]. For residential buildings in the UK, despite global warming being predicted to lead to increased energy demand in the summer, heating demand will still dominate cooling demand by the 2080s [109]. The fall in heating demand for office building is predicted to approximately cover the rise in cooling demand. Natural ventilation alone may fail to supply sufficient summer cooling especially for most existing office buildings that do not comply with the 2002 version of the Building Regulations or more recent versions [108]. Taking climate change and building age into consideration, a similar conclusion with regards to heating and cooling demand was drawn by Waddicor et al. [110], using IPCC predictive weather files to predict the future energy patterns of office blocks within Torino, Italy. Based on IPCC weather file, Daly et al. [111] investigated the influence of climate change on energy usage of commercial buildings across various Australian cities. The comparative study revealed slight changes (i.e. between $-0.6 \%$ and $+8.3 \%$ in heating demand and an increase from $9.1 \%$ to $25 \%$ in cooling demand) [111]. The building energy consumption during the 2020s, 2050s, and 2080s was simulated in [112]-[114], whereby a drop in heating demands with corresponding rises in cooling 
demands were observed for all cases. According to Wong et al [115] the cooling loads of Hong Kong's residential sector during 2009-2100 would be $6.1 \%-9.8 \%$ more than $1979-2008$ due to additional heat gained by the building envelope [115]. Full details of the scope, data properties, data sources, data sizes, temporal granularities, prediction algorithms, and performance metrics of the individual prediction models discussed within all articles are provided in Appendix A.

Figure 7 shows a detail breakdown of the information presented in Appendix A, where further classifications according to prediction approach and building types are provided. The existing methods cover residential, commercial, education \& research and other buildings (1 article for mixed building, 8 articles for building sector and 8 not available). According to Figure 7(b), the use of physical methods was skewed towards residential buildings. This is mainly due to the challenges and time-intensiveness often encountered when using physical methods to evaluate the complexities and non-linearities associated with the indoor environment of commercial and educational buildings. Moreover, commercial buildings often have large amounts of historical energy consumption data available, which makes them the preferred target of artificial intelligence, statistical, and hybrid methods. In order to ease the determination of optimum data sampling frequency trends for existing studies, the temporal granularities of the studies are also shown in Figure 8, where it is observable that more than $50 \%$ of energy usage prediction research data were obtained on daily basis. Additionally, Figure 9 showed that predicted energy usage is mainly based on 4 categories - total energy consumption (18\% of primary articles), heating and cooling load (28\% of primary articles), electricity consumption (35\% of primary articles) and others (19\% of primary articles).

\subsection{Data properties and data pre-processing}

The recent proliferation of smart buildings, metering devices, sensors and sophisticated data acquisition devices is continuously enhancing the ability of researchers to amass building energy data at high frequencies. Irrespective of the field of study, the accuracy of prediction or forecasting activities is heavily dependent on the reliability and volume of datasets fed into the model. For building related studies, additional parameters such as data quality, geographic diversity, forecast horizon, customer segmentation and forecast origin also influence prediction performance [116]. This makes it crucial to ascertain the peculiarities of building energy prediction data as well as their processing regimes. 


\subsubsection{Data properties}

Figure 10 shows a distribution of primary studies according to the types of data upon which their research was founded, which reveals that $61 \%$ (87) of studies were based on primary/real data, while $23 \%$ (33) and 10\% (14) applied simulated and benchmarking datasets respectively.

The amount of the datasets applied for training, validation, and testing varies between 3 days [117] and 30 years[118]. In this review, the sizes of datasets are divided into 6 categories according to duration, as shown in Figure 11. Most of the primary studies applied between 1 month and 1 year, with approximately $25 \%$ collecting data for at least one year. Additionally, nine of the studies [38], [78], [79], [81], [82], [119]-[122] considered did not provide details on timeframe applied, owing to sole reliance on simulated datasets.

\subsubsection{Data pre-processing and features selection}

The primary building data acquired through experiments and/or surveys are often raw, incomplete and crucial features may be embedded in uncorrelated background noises, which could cause errors and inaccurate final results. Hence, some degree of pre-processing is required before model training. Data pre-processing can help improve the quality of data as well as boost accuracy of prediction outcomes. Cleaning, filtering, integration, normalization, reduction and transformation of datasets are common activities associated with data preprocessing. If accurately implemented, data smoothening and noise frequency bands identification can help identify and/or delete outliers, thereby helping to aiding the achieve the following objectives: data format standardisation, abnormal data clearing, error correction and duplicate data clearing. Once the raw data has been treated, the next step is data integration, which involves combining data from multiple sources so that redundant features can be identified and excluded prior to training. By removing non-discriminative features as well as reducing dimensionality of the dataset, computational efficiency and model performance can be significantly enhanced.

Based on the findings from this review, the most commonly used building energy prediction parameters can be divided into six main groups, namely; building features, time, outdoor weather conditions, occupancy/occupant energy usage patterns, indoor environmental conditions and historical energy consumption. More than 50 features were identified from the primary studies captured in this review as depicted in Table 4 . In order to visualize the most 
widely applied features, Figures 12-15 show the historical trends of parameter classes adopted by the 4 prediction methods and building types from which the data were acquired. In Figure 12, it can be deduced that outdoor weather conditions were the dominant parameter class adopted by all 4 prediction methods, which is closely followed by indoor environmental conditions and building characteristics respectively. It was also observed that historical energy consumption rates, time and occupancy/occupant energy use behaviour are the least applied parameters when employing physical methods. With regards to the application of the parameters to building types, Figure 13 shows that outdoor weather conditions and historical consumption data are two of the most widely applied parameter classes for all 3 types of buildings. Owing to the availability of relevant energy management systems and sensors, commercial and educational buildings offer more information for indoor environmental conditions. On the contrary, building characteristics is the most adopted parameter when studying energy consumption of residential buildings, due to the ease of their measurements. Figure 14 shows that solar radiation, relative humidity and outdoor air temperature are the most frequently used outdoor weather conditions by all the prediction methods, owing to the maturity of meteorological studies and availability of several open source weather databases. However, classifications according to individual methods further depicts that predictions based on physical and statistical methods are often performed using features such as building geometry, energy consumption and equipment load data while AI and hybrid methods have mostly relied on energy consumption data alone. The trend among the reviewed studies also suggests that the randomness of occupancy patterns makes it very challenging feature to accurately quantify especially for mixed purpose buildings. The elemental distribution in Figure 15 indicates that approximately $60 \%$ of features applied to all building classifications are related to building characteristics and outdoor weather.

\subsection{Identification of influential studies and interrelation network}

Irrespective of the field of study, researchers expend immense proportions of their time and efforts on the compilation and analysis of existing studies. The emergence of advanced computational technology and the recent push for environmental sustainability around the globe has immensely increased the rates at which research articles associated with the different facets of energy are published. While the rationale behind interactions with existing studies is unquestionable, it is vital to understand how researchers are able to fairly establish balance between quantity, quality and influence of such studies. This study has already exposed the unavailability of SR studies related to building energy consumption prediction 
but besides just compiling relevant studies and presenting their core findings, a bibliometric network analysis is used to highlight the interrelationship that exists among the included articles. For instance, the 158 articles used here represent the most relevant to the defined research protocol, but their individual influence on the field cannot be easily ascertained from a traditional systematic review alone. Bibliometric analysis typically enables the mapping of interdisciplinary research on the basis of selected keywords in a specific database (for example WoS, Compendex, InSpec, GeoRef, Scopus and GeoBase) or within field-specific articles or a fusion of all approaches [123].

Several earlier bibliometric analyses were based on the application of manually generated binary strings for articles encoding [123]. In this study however, Vosviewer is used to automatically construct the bibliometric network of the data downloaded from well-known multidisciplinary databases (i.e. WoS, Compendex, InSpec and GeoBase). The constructed network then establishes concept-similarity among the 158 included primary articles through pair-wise comparisons of their keywords. The greater the commonality between two publications, the higher their correlation on the basis of concept-similarity which in turn determines their sub-field or cluster as depicted in Figure 16. The magnitude of a particular sub-field is a representation of the proportion of articles that belong to an entire field while the connecting lines indicate strong correlation between two sub-fields. Also, similar subfields or clusters are positioned in close proximity and dissimilar ones far from each other. With reference to Figure 16, some of the most influential sub-fields are energy consumption, energy efficiency, machine learning, sensitivity analysis, residential buildings, data mining, retrofit, occupant behaviour. Through a combination of the keywords, it is possible to create a dynamic strategic map that can illustrate the strengths of knowledge in a particular field and where such is domiciled in the world. Finally, one article was selected from each of the 19 most influential clusters and its major findings detailed in Table 5. Both Figure 16 and Table 5 provide a quick guidance of research hotspots for building energy consumption prediction, so as to aid research planning, future directions and cross disciplinary collaborations. The keywords distribution depicted in Figure 16 adequately demonstrates the main focal points of research within the studied discipline, which makes it easier to understand areas of strengths and underrepresentation at a glance.

This SR did not dwell on the underlying principles of individual methods or their applications, since such generic information are readily obtainable from the background reviews of several 
existing articles and textbooks. The primary articles indicate that 6 types of variables (i.e. building features, time, outdoor weather conditions, occupancy/occupant energy usage patterns, indoor environmental conditions and historical energy consumption) are mostly applied. It is worth noting that the statistics of variables in this SR only reflected the frequency of variables applied within included primary articles, therefore, it is difficult to accurately evaluate the impact of each class of variables on the prediction process. For example, when using any of the four methods for prediction irrespective of building type, outdoor weather conditions are the most commonly used, while occupants' behaviour data is a rare parameter. The skewness in application towards outdoor weather conditions does not necessarily indicate its superiority as a parameter over occupants' behaviour but rather highlights availability. For instance, outdoor weather conditions can be obtained from various public databases, while variables such as occupant behaviour are particularly difficult to obtain due to privacy policies. In general, research on the influence of data types on prediction methods is still in its infancy. The SR indicates that current research efforts appear to be overwhelmingly directed towards implementation of AI methods which have been previously compared to black box models because of the difficulties associated with understanding the intermediate processes of their associated algorithms, which has been identified as a reason for the stratification of input variables and algorithms. Therefore, unless AI-based research paradigms shift towards developing deeper understanding of underlying governing principles, the representativeness of building energy predictions may still continue to rely on professional knowledge of building thermodynamics.

\section{Limitations of the study}

Some of the papers published on building energy prediction may have been left out of this SR owing to the inclusion and exclusion criteria that were defined as part of the research protocol to focus only on primary articles published in English language and accessible within Web of Science, Compendex, InSpec, GeoBase, GeoRef, Scopus databases. Also, the inclusion of ageing, existing, retrofit and old in the search string can be perceived as a limitation, since it can be argued that this approach potentially excludes articles that considered the sophistications associated with modern-day buildings. However, the authors believe that most building energy inefficiencies, data collection difficulties and prediction inaccuracies are more attributable to older buildings, thereby making the chosen study group substantial and very relevant. Besides, the lack of standard and universally agreed definition of what 
constitutes old or ageing or existing building within existing body of knowledge is believed to have significantly broadened the review scope beyond that which was originally intended.

\section{Concluding remarks and future considerations}

A combination of population growths and rapid depletion of traditional energy resources in recent decades is continuously influencing energy planning and management research across the globe. The need to increase energy sustainability, while correspondingly reducing carbon footprints has led to enactment of various regulations that often rely on accurate predictions of current energy usage under varying scenarios. This has led to the emergence of numerous approaches within a spate of research contributions which must be collated for better optimization of the valuable information domiciled within individual primary article. This paper provides a systematic knowledge trend for building energy prediction, through the application of well-founded principles of PRISMA and PPSR methodologies for conducting systematic reviews. The paper compiles various descriptions of building energy prediction as well as reflecting their spread, principles and scope. This paper also presents a review of 240 primary research articles on building energy prediction over the past century, based on a rigorously defined research protocol. The review analyses articles' time distribution, author profiles, energy prediction methodologies, input data types, data sample sizes, sampling frequencies and building characteristics. Based on the synthesis of the findings extracted from individual articles, these conclusions can be inferred from this SR:

- Judging from the viewpoint of the immense global drive for energy conservation and carbon footprint reduction, one would assume that building energy prediction related literature reviews should account for a significant proportion of existing literature especially owing to the fact that buildings consume up to $40 \%$ of primary energy in some countries. However, based on the adopted search string for this systematic review, only 24 literature review articles were found and none of which is a systematic review. While traditional literature reviews also contribute significantly to the understanding of research trends, the decision to include or exclude certain articles is sometimes viewed as opinionated. Also, the lack of bibliometric analysis in such review articles limit the ability of researchers to swiftly ascertain answers to crucial research planning questions such as "who's doing what, when and where"

- During articles retrieval, it was observed that search sensitivity and precision is not always a function of the database size. Engineering Village databases especially Compendex and InSpec returned the highest percentage as well as volume of relevant primary articles in 
comparison to significantly larger databases such as WoS and Scopus. Additionally, the bibliometric network analysis provides a dynamic and strategic map of the interrelationship and frequency of research keywords utilised by the primary articles. A combination of these could be very valuable time-saving mechanism during future research planning activities.

- There are 4 dominant classes of building energy consumption prediction methodologies, namely: physical, statistical, artificial intelligence and hybrid methods. The physical methods are mainly based on the application of physical laws for modelling building systems and their associated components as well as estimating thermal dynamics and energy patterns. Statistical methods (also known as statistical regression or regression methods) are the most widely applied in practice, due to their computational ease, speed and reasonably acceptable degree of accuracy but often criticized for their inabilities to adequately show the underlying relationships that exist between inputs and outputs. AI based techniques such as Bayesian networks, deep learning, decision trees, ensemble algorithms, ANN, SVM and clustering algorithms are becoming more and more influential in the field, due to their ability to self-learn from historical data. Hybrid methods combine various heterogeneous machine learning methods into a single unified framework, thereby allowing the strengths of one class of techniques to compensate for the limitations of others. However, the confidence level in the technique is often undermined by the risk of overfitting and computational intensiveness. This is perhaps the reason for a lack of in-depth knowledge about hybrid methods within existing literature.

- Fundamental developments in building energy consumption prediction research can be traced back to 2001, but research publications were quite limited until 2010 after which a significant rise was observed, especially in 2018 when as much as 40 articles were obtained. This trend is believed to have been triggered by rises in total energy consumption resulting from building operational activities as well as the implementation of initiatives such as the Kyoto protocol. Also, sustained growth in educational expenditures and contributions of various governments since 2009 is adjudged a positive catalyst for the experienced publication trends.

- The emergence of research articles from different countries including USA, China, South Korea, UK, Malaysia, Spain, the Netherlands, Canada, India, Turkey, etc., suggests that building energy consumption prediction research is conducted across the globe. The distribution of articles by country also indicates that the two largest economies (i.e. USA and China) account for most of the published articles. Malaysia and India are also active contributors, perhaps owing to their currently erratic power supplies. 
- Commercial buildings are widely used case studies, which is perhaps owing to the existence of relevant energy management systems and sensors that provide superior opportunities for research over educational and/or residential buildings.

- Historic energy usage, time, occupant energy usage patterns, outdoor weather conditions, building features and indoor environmental conditions are the six main groups of prediction parameters or features. Artificial intelligence, statistical and hybrid methods are heavily reliant on historical energy consumption data but on the average, outdoor weather condition is the most dominant parameter across all four classes of prediction methods, closely followed by indoor environmental conditions and building characteristics.

It is glaring that the quantity of published building energy usage prediction research is on an upward trajectory but future research endeavours need to also focus on diversity of data collection case studies and parameters. For instance, there is a stack under-representation of research on mixed purpose buildings, despite their popularity across the globe. Also, the use of building characteristics as a feature needs further attention especially for older buildings whereby energy management systems, sensors and building details are non-existent. So far, the application of AI and hybrid methods still highly relies on personal experience and preference. The SR reveals the application of multi-farious types and varying amounts of input data for prediction, which are very promising but it still remains a challenge to standardise the input variables to match different practical scenarios. Also, there is an underrepresentation of studies applying occupants' behaviours data when compare to publicly available information such as meteorological data, which may undermine the representativeness of existing outcomes. Perhaps one viable approach to the aforementioned challenges would be detailed exploration of the wider role of emerging approaches such as building information modelling within the premise of building energy consumption analyses, with keen interests on incorporating human factor analysis. 


\section{Reference}

[1] D. Pimentel and M. Burgess, World Human Population Problems «ै, no. September 2014. Elsevier Inc., 2017.

[2] S. Kan, B. Chen, and G. Chen, "Worldwide energy use across global supply chains: Decoupled from economic growth?," Appl. Energy, vol. 250, no. April, pp. 1235-1245, 2019, doi: 10.1016/j.apenergy.2019.05.104.

[3] W. Feist and J. Schnieders, "Energy efficiency - A key to sustainable housing," Eur. Phys. J. Spec. Top. vol. 176, no. 1, pp. 141-153, 2009, doi: 10.1140/epjst/e2009-01154-y.

[4] H. Zhong, J. Wang, H. Jia, Y. Mu, and S. Lv, "Vector field-based support vector regression for building energy consumption prediction,” Appl. Energy, 2019, doi: 10.1016/j.apenergy.2019.03.078.

[5] A. S. Galadanci, A. Ianakiev, R. Kromanis, and J. Robinson, "Energy investigation framework: Understanding buildings from an energy perspective view," J. Build. Eng., 2020, doi: 10.1016/j.jobe.2019.101046.

[6] DECC, “UK Energy in Brief 2019," p. 48, 2019, [Online]. Available: https://www.gov.uk/government/uploads/system/uploads/attachment_data/file/350941/UK_Energy_in_ Brief_2014_revised.pdf.

[7] T. Huo et al., "China's building stock estimation and energy intensity analysis," J. Clean. Prod., vol. 207, no. 2019, pp. 801-813, 2019, doi: 10.1016/j.jclepro.2018.10.060.

[8] M. Kavgic, A. Mavrogianni, D. Mumovic, A. Summerfield, Z. Stevanovic, and M. Djurovic-Petrovic, "A review of bottom-up building stock models for energy consumption in the residential sector," Build. Environ., vol. 45, no. 7, pp. 1683-1697, 2010, doi: 10.1016/j.buildenv.2010.01.021.

[9] B. Yildiz, J. I. Bilbao, and A. B. Sproul, "A review and analysis of regression and machine learning models on commercial building electricity load forecasting," Renew. Sustain. Energy Rev., vol. 73, no. February, pp. 1104-1122, 2017, doi: 10.1016/j.rser.2017.02.023.

[10] X. Li and J. Wen, "Review of building energy modeling for control and operation," Renewable and Sustainable Energy Reviews. 2014, doi: 10.1016/j.rser.2014.05.056.

[11] M. Ashouri, B. C. M. Fung, F. Haghighat, and H. Yoshino, "Systematic approach to provide building occupants with feedback to reduce energy consumption," Energy, 2020, doi: 10.1016/j.energy.2019.116813.

[12] R. Qiao and T. Liu, "Impact of building greening on building energy consumption : A quantitative computational approach,” J. Clean. Prod., no. xxxx, p. 119020, 2019, doi: 10.1016/j.jclepro.2019.119020.

[13] K. Amasyali and N. M. El-Gohary, "A review of data-driven building energy consumption prediction studies,” Renew. Sustain. Energy Rev., vol. 81, no. September 2017, pp. 1192-1205, 2018, doi: 10.1016/j.rser.2017.04.095.

[14] Y. Wei et al., "A review of data-driven approaches for prediction and classification of building energy consumption," Renew. Sustain. Energy Rev., vol. 82, no. May 2017, pp. 1027-1047, 2018, doi: 10.1016/j.rser.2017.09.108.

[15] A. S. Ahmad et al., "A review on applications of ANN and SVM for building electrical energy consumption forecasting," Renew. Sustain. Energy Rev., vol. 33, pp. 102-109, 2014, doi: 10.1016/j.rser.2014.01.069.

[16] H. Lim and Z. J. Zhai, "Review on stochastic modeling methods for building stock energy prediction," Build. Simul., vol. 10, no. 5, pp. 607-624, 2017, doi: 10.1007/s12273-017-0383-y.

[17] B. Kitchenham, "Procedures for Performing Systematic Literature Reviews," Jt. Tech. Report, Keele Univ. TR/SE-0401 NICTA TR-0400011T.1, p. 33, 2004.

[18] A. Cooke, D. Smith, and A. Booth, "Beyond PICO: The SPIDER tool for qualitative evidence synthesis," Qual. Health Res., vol. 22, no. 10, pp. 1435-1443, 2012, doi: 10.1177/1049732312452938.

[19] S. Sharma and M. Oremus, "PRISMA and AMSTAR show systematic reviews on health literacy and cancer screening are of good quality," J. Clin. Epidemiol., 2018, doi: 10.1016/j.jclinepi.2018.03.012.

[20] J. Runge and R. Zmeureanu, "Forecasting Energy Use in Buildings Using Artificial Neural Networks: A Review," ENERGIES, vol. 12, no. 17, Sep. 2019, doi: 10.3390/en12173254.

[21] L. Suganthi and A. A. Samuel, "Energy models for demand forecasting - A review," Renewable and Sustainable Energy Reviews. 2012, doi: 10.1016/j.rser.2011.08.014.

[22] B. Grillone, S. Danov, A. Sumper, J. Cipriano, and G. Mor, “A review of deterministic and data-driven methods to quantify energy efficiency savings and to predict retrofitting scenarios in buildings," Renew. Sustain. Energy Rev., vol. 131, 2020, doi: 10.1016/j.rser.2020.110027.

[23] Y. Sun, F. Haghighat, and B. C. M. Fung, "A review of the-state-of-the-art in data-driven approaches for building energy prediction," Energy and Buildings. 2020, doi: 10.1016/j.enbuild.2020.110022.

[24] A. A. A. A. A. A. Gassar and S. H. S. H. Cha, "Energy prediction techniques for large-scale buildings 
towards a sustainable built environment: A review," Energy Build., vol. 224, Oct. 2020, doi: 10.1016/j.enbuild.2020.110238.

[25] Z. Wang and R. S. Srinivasan, "A review of artificial intelligence based building energy use prediction: Contrasting the capabilities of single and ensemble prediction models," Renewable and Sustainable Energy Reviews. 2017, doi: 10.1016/j.rser.2016.10.079.

[26] A. Foucquier, S. Robert, F. Suard, L. Stéphan, and A. Jay, "State of the art in building modelling and energy performances prediction: A review," Renewable and Sustainable Energy Reviews. 2013, doi: 10.1016/j.rser.2013.03.004.

[27] M. Bourdeau, X. qiang Zhai, E. Nefzaoui, X. Guo, and P. Chatellier, "Modeling and forecasting building energy consumption: A review of data-driven techniques," Sustainable Cities and Society. 2019, doi: 10.1016/j.scs.2019.101533.

[28] Z. Wang and R. S. Srinivasan, "A review of artificial intelligence based building energy prediction with a focus on ensemble prediction models," in Proceedings - Winter Simulation Conference, 2016, doi: 10.1109/WSC.2015.7408504.

[29] C. Deb, F. Zhang, J. Yang, S. E. Lee, and K. W. Shah, “A review on time series forecasting techniques for building energy consumption," Renewable and Sustainable Energy Reviews. 2017, doi: 10.1016/j.rser.2017.02.085.

[30] D. Ju-Long, “Control problems of grey systems,” Syst. Control Lett., 1982, doi: 10.1016/S01676911(82)80025-X.

[31] L. G. Swan and V. I. Ugursal, "Modeling of end-use energy consumption in the residential sector: A review of modeling techniques," Renewable and Sustainable Energy Reviews. 2009, doi: 10.1016/j.rser.2008.09.033.

[32] K. Li, W. Xue, G. Tan, and A. S. A. S. Denzer, "A state of the art review on the prediction of building energy consumption using data-driven technique and evolutionary algorithms," Build. Serv. Eng. Res. Technol., vol. 41, no. 301, pp. 108-127, 2020, doi: 10.1177/0143624419843647.

[33] M. Gong, J. Wang, Y. Bai, B. Li, and L. Zhang, "Heat load prediction of residential buildings based on discrete wavelet transform and tree-based ensemble learning," J. Build. Eng., 2020, doi: 10.1016/j.jobe.2020.101455.

[34] K. Raoufi, A. K. Wisthoff, B. L. DuPont, and K. R. Haapala, "A questionnaire-based methodology to assist non-experts in selecting sustainable engineering analysis methods and software tools," J. Clean. Prod., vol. 229, pp. 528-541, 2019, doi: 10.1016/j.jclepro.2019.05.016.

[35] R. Lahrech, A. Fery, A. Gautier, W. Lecointre, and C. Marne, "the Use of Yearly in Situ Measurements of a Whole Commercial Building for Sensitivity and Uncertainty Analysis of Energy Performance Assessment," Proc. Build. Simul., pp. 1714-1721, 2013.

[36] S. J. Rees, "Closing the performance gap through better building physics," Build. Serv. Eng. Res. Technol., vol. 38, no. 2, pp. 125-132, 2017, doi: 10.1177/0143624417693711.

[37] T. Ahmad et al., "Supervised based machine learning models for short, medium and long-term energy prediction in distinct building environment," Energy, vol. 158, pp. 17-32, 2018, doi: 10.1016/j.energy.2018.05.169.

[38] C. Robinson et al., "Machine learning approaches for estimating commercial building energy consumption,” Appl. Energy, vol. 208, no. August, pp. 889-904, 2017, doi: 10.1016/j.apenergy.2017.09.060.

[39] L. Wang, R. Kubichek, and X. Zhou, "Adaptive learning based data-driven models for predicting hourly building energy use,” Energy Build., vol. 159, pp. 454-461, 2018, doi: 10.1016/j.enbuild.2017.10.054.

[40] T. Hsueh and E. Oliveira, "Artificial Intelligence: An Overview," in Cutting Edge Technologies and Microcomputer Applications for Developing Countries, 2019.

[41] R. Y. Choi, A. S. Coyner, J. Kalpathy-Cramer, M. F. Chiang, and J. Peter Campbell, "Introduction to machine learning, neural networks, and deep learning," Transl. Vis. Sci. Technol., vol. 9, no. 2, pp. 1-12, 2020, doi: 10.1167/tvst.9.2.14.

[42] M. Varone, D. Mayer, and A. Melegari, "What is Machine Learning? A definition - Expert System," Expert System, vol. 7. p. 1, 2019, [Online]. Available: https://expertsystem.com/machine-learningdefinition/\%0Ahttps://expertsystem.com/machine-learningdefinition/\%0Ahttps://www.expertsystem.com/machine-learning-definition/.

[43] Y. Forghani and H. S. Yazdi, "Robust support vector machine-trained fuzzy system," Neural Networks, vol. 50. pp. 154-165, 2014, doi: 10.1016/j.neunet.2013.11.013.

[44] W. Sun and M. Liu, "Prediction and analysis of the three major industries and residential consumption CO2 emissions based on least squares support vector machine in China," J. Clean. Prod., vol. 122, pp. 144-153, 2016, doi: 10.1016/j.jclepro.2016.02.053.

[45] M. Lin, A. Afshari, and E. Azar, "A data-driven analysis of building energy use with emphasis on operation and maintenance: A case study from the UAE," J. Clean. Prod., vol. 192, pp. 169-178, 2018, 
doi: 10.1016/j.jclepro.2018.04.270.

[46] M. W. Ahmad, M. Mourshed, and Y. Rezgui, "Trees vs Neurons: Comparison between random forest and ANN for high-resolution prediction of building energy consumption," Energy Build., vol. 147, pp. 77-89, 2017, doi: 10.1016/j.enbuild.2017.04.038.

[47] C. Xu et al., "Modal decomposition based ensemble learning for ground source heat pump systems load forecasting," Energy Build., 2019, doi: 10.1016/j.enbuild.2019.04.018.

[48] T. Ahmad and D. Zhang, "Novel deep regression and stump tree-based ensemble models for real-time load demand planning and management," IEEE Access, 2020, doi: 10.1109/ACCESS.2020.2978937.

[49] T. Ahmad and H. Chen, "Potential of three variant machine-learning models for forecasting district level medium-term and long-term energy demand in smart grid environment," Energy, 2018, doi: 10.1016/j.energy.2018.07.084.

[50] Z. Tian, B. Si, X. Shi, and Z. Fang, "An application of Bayesian Network approach for selecting energy efficient HVAC systems," J. Build. Eng., 2019, doi: 10.1016/j.jobe.2019.100796.

[51] B. Abediniangerabi, S. M. Shahandashti, and A. Makhmalbaf, "A data-driven framework for energyconscious design of building facade systems," J. Build. Eng., 2020, doi: 10.1016/j.jobe.2020.101172.

[52] R. Xu and D. Wunsch, "Survey of clustering algorithms," IEEE Transactions on Neural Networks. 2005, doi: 10.1109/TNN.2005.845141.

[53] L. Čuček, J. J. Klemeš, and Z. Kravanja, "Objective dimensionality reduction method within multiobjective optimisation considering total footprints," J. Clean. Prod., vol. 71, pp. 75-86, 2014, doi: 10.1016/j.jclepro.2013.12.035.

[54] X. Goldberg, Introduction to semi-supervised learning, vol. 6. 2009.

[55] Z. Hailat, A. Komarichev, and X. W. Chen, Deep Semi-Supervised Learning, vol. 2018-Augus. 2018.

[56] M. C. B. B, Deep Low-Density Separation for Semi-supervised Classification, vol. 1. Springer International Publishing, 2020.

[57] P. Foggia, G. Percannella, C. Sansone, and M. Vento, A graph-based clustering method and its applications, vol. 4729 LNCS, no. June 2014. 2007.

[58] J. Jang, J. Baek, and S. B. Leigh, "Prediction of optimum heating timing based on artificial neural network by utilizing BEMS data," J. Build. Eng., 2019, doi: 10.1016/j.jobe.2018.11.012.

[59] J. Stefanowski, "Artificial Neural Networks - Basics of MLP , RBF and Kohonen Networks Acknowledgments," 2010.

[60] G. S. Georgiou, P. Christodoulides, and S. A. Kalogirou, "Implementing artificial neural networks in energy building applications - A review," 2018 IEEE Int. Energy Conf. ENERGYCON 2018, pp. 1-6, 2018, doi: 10.1109/ENERGYCON.2018.8398847.

[61] T. T. Truong, D. Dinh-Cong, J. Lee, and T. Nguyen-Thoi, “An effective deep feedforward neural networks (DFNN) method for damage identification of truss structures using noisy incomplete modal data," J. Build. Eng., 2020, doi: 10.1016/j.jobe.2020.101244.

[62] C. Y. Liou, W. C. Cheng, J. W. Liou, and D. R. Liou, "Autoencoder for words," Neurocomputing, 2014, doi: 10.1016/j.neucom.2013.09.055.

[63] E. Mocanu, P. H. Nguyen, M. Gibescu, and W. L. Kling, "Deep learning for estimating building energy consumption," Sustain. Energy, Grids Networks, vol. 6, pp. 91-99, 2016, doi: 10.1016/j.segan.2016.02.005.

[64] J. Kim, J. Moon, E. Hwang, and P. Kang, "Recurrent inception convolution neural network for multi short-term load forecasting," ENERGY Build., vol. 194, pp. 328-341, Jul. 2019, doi: 10.1016/j.enbuild.2019.04.034.

[65] C. Tian, C. Li, G. Zhang, and Y. Lv, "Data Driven Parallel Prediction of Building Energy Consumption Using Generative Adversarial Nets," Energy Build., vol. 186, pp. 230-243, Mar. 2019, doi: 10.1016/j.enbuild.2019.01.034.

[66] Z. kai Feng, W. jing Niu, X. Cheng, J. yang Wang, S. Wang, and Z. guo Song, “An effective three-stage hybrid optimization method for source-network-load power generation of cascade hydropower reservoirs serving multiple interconnected power grids," J. Clean. Prod., no. xxxx, p. 119035, 2019, doi: 10.1016/j.jclepro.2019.119035.

[67] X. Xu et al., "A mixed-mode building energy model for performance evaluation and diagnosis of existing buildings," Build. Serv. Eng. Res. Technol., vol. 29, no. 1, pp. 73-83, 2008, doi: $10.1177 / 0143624407087788$.

[68] Y. Bai, Q. C. Ren, and H. M. Jiang, "The Analysis of Combined Prediction Model of Building Energy Consumption with Grey Theory and RBF Neural Network," Adv. Mater. Res., vol. 374-377, no. 0, pp. 90-93, 2011, doi: 10.4028/www.scientific.net/amr.374-377.90.

[69] H. Son, C. C. C. C. Kim, C. C. C. C. Kim, and Y. Kang, "Prediction of Government-Owned Building Energy Consumption Based on an Rrelieff and Support Vector Machine Model," J. Civ. Eng. Manag., vol. 21, no. 6, pp. 748-760, 2015, doi: 10.3846/13923730.2014.893908. 
[70] H. C. Jung, J. S. Kim, and H. Heo, "Prediction of building energy consumption using an improved real coded genetic algorithm based least squares support vector machine approach," Energy Build., vol. 90, pp. 76-84, 2015, doi: 10.1016/j.enbuild.2014.12.029.

[71] L. C. Harmer and G. P. Henze, "Using calibrated energy models for building commissioning and load prediction," Energy Build., vol. 92, pp. 204-215, 2015, doi: 10.1016/j.enbuild.2014.10.078.

[72] C. Hu, K. Li, G. Liu, and L. Pan, "Forecasting building energy consumption based on hybrid PSO-ANN prediction model," Chinese Control Conf. CCC, vol. 2015-Septe, pp. 8243-8247, 2015, doi: 10.1109/ChiCC.2015.7260948.

[73] Y. K. Jeong, T. Kim, H. S. Nam, and I. W. Lee, "Implementation of energy performance assessment system for existing building," 2016 Int. Conf. Inf. Commun. Technol. Converg. ICTC 2016, no. 20142010102370, pp. 393-395, 2016, doi: 10.1109/ICTC.2016.7763504.

[74] E. Mocanu, P. H. Nguyen, W. L. Kling, and M. Gibescu, "Unsupervised energy prediction in a Smart Grid context using reinforcement cross-building transfer learning," Energy Build., vol. 116, pp. 646-655, 2016, doi: 10.1016/j.enbuild.2016.01.030.

[75] J. Mao, Y. Pan, and Y. Fu, "Towards fast energy performance evaluation: A pilot study for office buildings," Energy Build., vol. 121, pp. 104-113, 2016, doi: 10.1016/j.enbuild.2016.03.077.

[76] C. L. Tsai, W. T. Chen, and C. S. Chang, "Polynomial-Fourier series model for analyzing and predicting electricity consumption in buildings," Energy Build., vol. 127, pp. 301-312, 2016, doi: 10.1016/j.enbuild.2016.05.083.

[77] K. Song, N. Kwon, K. Anderson, M. Park, H. S. Lee, and S. H. Lee, "Predicting hourly energy consumption in buildings using occupancy-related characteristics of end-user groups," Energy Build., vol. 156, pp. 121-133, 2017, doi: 10.1016/j.enbuild.2017.09.060.

[78] S. Banihashemi, G. Ding, and J. Wang, "Developing a Hybrid Model of Prediction and Classification Algorithms for Building Energy Consumption,” Energy Procedia, vol. 110, no. December 2016, pp. 371-376, 2017, doi: 10.1016/j.egypro.2017.03.155.

[79] J. H. Ko, D. S. Kong, and J. H. Huh, "Baseline building energy modeling of cluster inverse model by using daily energy consumption in office buildings," Energy Build., vol. 140, pp. 317-323, 2017, doi: 10.1016/j.enbuild.2017.01.086.

[80] L. Diao, Y. Sun, Z. Chen, and J. Chen, "Modeling energy consumption in residential buildings: A bottom-up analysis based on occupant behavior pattern clustering and stochastic simulation,” Energy Build., vol. 147, pp. 47-66, 2017, doi: 10.1016/j.enbuild.2017.04.072.

[81] M. Nilashi, M. Dalvi-Esfahani, O. Ibrahim, K. Bagherifard, A. Mardani, and N. Zakuan, "A soft computing method for the prediction of energy performance of residential buildings," Meas. J. Int. Meas. Confed., vol. 109, no. October, pp. 268-280, 2017, doi: 10.1016/j.measurement.2017.05.048.

[82] C. Li, Z. Ding, D. Zhao, J. Yi, and G. Zhang, "Building energy consumption prediction: An extreme deep learning approach,” Energies, vol. 10, no. 10, pp. 1-20, 2017, doi: 10.3390/en10101525.

[83] B. Jiang, Z. Cheng, Q. Hao, and N. Ma, “A Building Energy Consumption Prediction Method Based on Random Forest and ARMA,” 2018 Chinese Autom. Congr., pp. 3550-3555, 2018, doi: 10.1109/CAC.2018.8623540.

[84] A. Streltsov, K. Bradbury, and J. Malof, “Automated building energy consumption estimation from aerial imagery," in International Geoscience and Remote Sensing Symposium (IGARSS), 2018, doi: 10.1109/IGARSS.2018.8517624.

[85] M. H. Alobaidi, F. Chebana, and M. A. Meguid, "Robust ensemble learning framework for day-ahead forecasting of household based energy consumption," Appl. Energy, vol. 212, no. May 2017, pp. 9971012, 2018, doi: 10.1016/j.apenergy.2017.12.054.

[86] C. Li, Z. Ding, J. Yi, Y. Lv, and G. Zhang, "Deep belief network based hybrid model for building energy consumption prediction,” Energies, vol. 11, no. 1, pp. 1-26, 2018, doi: 10.3390/en11010242.

[87] R. Gordillo-Orquera et al., "Analyzing and forecasting electrical load consumption in healthcare buildings,” Energies, vol. 11, no. 3, pp. 1-18, 2018, doi: 10.3390/en11030493.

[88] M. Khan, N. Javaid, M. N. Iqbal, M. Bilal, S. F. A. Zaidi, and R. A. Raza, "Load prediction based on multivariate time series forecasting for energy consumption and behavioral analytics," Adv. Intell. Syst. Comput., vol. 772, no. May, pp. 305-316, 2019, doi: 10.1007/978-3-319-93659-8_27.

[89] C. Chang, N. Zhu, K. Yang, and F. Yang, "Data and analytics for heating energy consumption of residential buildings: The case of a severe cold climate region of China," Energy Build., vol. 172, pp. 104-115, 2018, doi: 10.1016/j.enbuild.2018.04.037.

[90] S. Malik and D. H. Kim, "Prediction-learning algorithm for efficient energy consumption in smart buildings based on particle regeneration and velocity boost in particle swarm optimization neural networks," Energies, vol. 11, no. 5, pp. 1-22, 2018, doi: 10.3390/en11051289.

[91] K. Li, X. Xie, W. Xue, X. Dai, X. Chen, and X. Yang, “A hybrid teaching-learning artificial neural network for building electrical energy consumption prediction,” Energy Build., vol. 174, pp. 323-334, 
2018, doi: 10.1016/j.enbuild.2018.06.017.

[92] G. Sha and Q. Qian, "Prediction of commercial building lighting energy consumption based on," 2018 18th Int. Conf. Control. Autom. Syst., vol. 2018-Octob, no. Iccas, pp. 1035-1040, 2018.

[93] R. Niemierko et al., "A D-vine copula quantile regression approach for the prediction of residential heating energy consumption based on historical data," Appl. Energy, vol. 233-234, no. June 2018, pp. 691-708, Jan. 2019, doi: 10.1016/j.apenergy.2018.10.025.

[94] J. Moon, Y. Kim, M. Son, and E. Hwang, "Hybrid Short-Term Load Forecasting Scheme Using Random Forest and Multilayer Perceptron," Energies, vol. 11, no. 12, p. 3283, 2018, doi: 10.3390/en11123283.

[95] S. H. Kim, G. Lee, G. Y. Kwon, D. I. Kim, and Y. J. Shin, "Deep learning based on multidecomposition for short-term load forecasting," Energies, vol. 11, no. 12, pp. 1-17, 2018, doi: 10.3390/en11123433.

[96] B. Ajib, S. Lefteriu, A. Caucheteux, S. Lecoeuche, and J. Gauvrit, "Prediction of Standardized Energy Consumption of Existing Buildings Based on Hybrid Systems Modeling and Control," in Proceedings of the IEEE Conference on Decision and Control, 2019, vol. 2018-Decem, pp. 3880-3886, doi: 10.1109/CDC.2018.8619086.

[97] A. Almalaq and J. J. Zhang, "Evolutionary Deep Learning-Based Energy Consumption Prediction for Buildings," IEEE Access, vol. 7, no. Dl, pp. 1520-1531, 2019, doi: 10.1109/ACCESS.2018.2887023.

[98] P. G. Ferreira, "“Common but Differentiated Responsibilities' in the National Courts: Lessons from Urgenda v. The Netherlands," Transnatl. Environ. Law, 2016, doi: 10.1017/S2047102516000248.

[99] L. N. Dwaikat and K. N. Ali, "The economic benefits of a green building - Evidence from Malaysia," $J$. Build. Eng., 2018, doi: 10.1016/j.jobe.2018.04.017.

[100] T. Ahmad and H. Chen, "A review on machine learning forecasting growth trends and their real-time applications in different energy systems," Sustainable Cities and Society. 2020, doi: 10.1016/j.scs.2019.102010.

[101] T. Ahmad, H. Zhang, and B. Yan, "A review on renewable energy and electricity requirement forecasting models for smart grid and buildings," Sustainable Cities and Society. 2020, doi: 10.1016/j.scs.2020.102052.

[102] Y. Sun, F. Haghighat, and B. C. M. Fung, "A review of the -state-of-the-art in data -driven approaches for building energy prediction," ENERGY Build., vol. 221, Aug. 2020, doi: 10.1016/j.enbuild.2020.110022.

[103] S. R. S. R. S. R. Mohandes et al., "A comprehensive review on the application of artificial neural networks in building energy analysis," Neurocomputing, vol. 340, pp. 55-75, May 2019, doi: 10.1016/j.neucom.2019.02.040.

[104] L. Yang, H. Yan, and J. C. Lam, "Thermal comfort and building energy consumption implications - A review," Appl. Energy, vol. 115, pp. 164-173, 2014, doi: 10.1016/j.apenergy.2013.10.062.

[105] A. C. Menezes, A. Cripps, R. A. Buswell, and D. Bouchlaghem, "Benchmarking small power energy consumption in office buildings in the United Kingdom: A review of data published in CIBSE Guide F," Build. Serv. Eng. Res. Technol., vol. 34, no. 1, pp. 73-86, 2013, doi: 10.1177/0143624412465092.

[106] R. M. Rylatt, S. J. Gadsden, K. J. Lomas, and B. Council, "Methods of predicting urban domestic energy demand with reduced datasets: A review and a new GIS-based approach," Build. Serv. Eng. Res. Technol., vol. 24, no. 2, pp. 93-102, 2003, doi: 10.1191/0143624403bt061oa.

[107] P. S. Iman Asadi,Norhayati Mahyuddin, I. Asadi, N. Mahyuddin, and P. Shafigh, "A review on indoor environmental quality (IEQ) and energy consumption in building based on occupant behavior," Facilities, 2013, doi: http://dx.doi.org/10.1108/MRR-09-2015-0216.

[108] D. H. Chow and G. J. Levermore, "The effects of future climate change on heating and cooling demands in office buildings in the UK," Build. Serv. Eng. Res. Technol., vol. 31, no. 4, pp. 307-323, 2010, doi: $10.1177 / 0143624410371284$.

[109] L. Collins, S. Natarajan, and G. Levermore, "Climate change and future energy consumption in UK housing stock," Build. Serv. Eng. Res. Technol., vol. 31, no. 1, pp. 75-90, 2010, doi: $10.1177 / 0143624409354972$.

[110] D. A. Waddicor et al., "Evaluation of the influence of climate warming and building ageing on building energy consumption," 14th Int. Conf. IBPSA - Build. Simul. 2015, BS 2015, Conf. Proc., pp. 610-617, 2015.

[111] D. Daly, P. Cooper, and Z. Ma, "Implications of global warming for commercial building retrofitting in Australian cities," Build. Environ., vol. 74, pp. 86-95, 2014, doi: 10.1016/j.buildenv.2014.01.008.

[112] K. T. Huang and R. L. Hwang, "Future trends of residential building cooling energy and passive adaptation measures to counteract climate change: The case of Taiwan," Appl. Energy, vol. 184, pp. 1230-1240, 2016, doi: 10.1016/j.apenergy.2015.11.008.

[113] J. M. Rey-Hernández, C. Yousif, D. Gatt, E. Velasco-Gómez, J. San José-Alonso, and F. J. Rey- 
Martínez, "Modelling the long-term effect of climate change on a zero energy and carbon dioxide building through energy efficiency and renewables," Energy Build., vol. 174, pp. 85-96, 2018, doi: 10.1016/j.enbuild.2018.06.006.

[114] Y. H. Yau and S. Hasbi, "A Comprehensive Case Study of Climate Change Impacts on the Cooling Load in an Air-Conditioned Office Building in Malaysia," Energy Procedia, vol. 143, pp. 295-300, 2017, doi: 10.1016/j.egypro.2017.12.687.

[115] S. L. Wong, K. K. W. W. Wan, D. H. W. W. Li, and J. C. Lam, "Impact of climate change on residential building envelope cooling loads in subtropical climates," Energy Build., vol. 42, no. 11, pp. 2098-2103, 2010, doi: 10.1016/j.enbuild.2010.06.021.

[116] T. Ahmad, C. Huanxin, D. Zhang, and H. Zhang, "Smart energy forecasting strategy with four machine learning models for climate-sensitive and non-climate sensitive conditions," Energy, vol. 198, May 2020, doi: 10.1016/j.energy.2020.117283.

[117] V. Dolinay, L. Vasek, J. Novak, P. Chalupa, and E. Kral, "Heat demand model for district heating simulation," MATEC Web Conf., vol. 210, p. 2044, 2018, doi: 10.1051/matecconf/201821002044.

[118] H. Hens, "Energy efficient retrofit of an end of the row house: Confronting predictions with long-term measurements," Energy Build., vol. 42, no. 10, pp. 1939-1947, 2010, doi: 10.1016/j.enbuild.2010.05.030.

[119] W. L. Lee, F. W. H. Yik, and J. Burnett, "Simplifying energy performance assessment in the Hong Kong building environmental assessment method," Build. Serv. Eng. Res. Technol., vol. 22, no. 2, pp. 113-132, 2001, doi: 10.1191/014362401701524172.

[120] Sholahudin, A. G. Alam, C. I. Baek, and H. Han, "Prediction and Analysis of Building Energy Efficiency Using Artificial Neural Network and Design of Experiments," Appl. Mech. Mater., vol. 819, no. January, pp. 541-545, 2016, doi: 10.4028/www.scientific.net/amm.819.541.

[121] S. Kumar, S. K. Pal, and R. P. Singh, "Intra ELM variants ensemble based model to predict energy performance in residential buildings," Sustain. Energy, Grids Networks, vol. 16, pp. 177-187, 2018, doi: 10.1016/j.segan.2018.07.001.

[122] S. Kumar, S. K. Pal, and R. P. Singh, "A novel method based on extreme learning machine to predict heating and cooling load through design and structural attributes," Energy Build., vol. 176, pp. 275-286, 2018, doi: 10.1016/j.enbuild.2018.06.056.

[123] A. Van Raan, "The use of bibliometric analysis in research performance assessment and monitoring of interdisciplinary scientific developments," TATuP - Zeitschrift für Tech. Theor. und Prax., 2003, doi: 10.14512/tatup.12.1.20.

[124] H. M. Faisal et al., "Prediction of Building Energy Consumption Using Enhance Convolutional Neural Network," Adv. Intell. Syst. Comput., vol. 927, pp. 1157-1168, 2019, doi: 10.1007/978-3-030-150358_111.

[125] E. Mocanu, P. H. Nguyen, M. Gibescu, and W. L. Kling, "Comparison of machine learning methods for estimating energy consumption in buildings,” 2014 Int. Conf. Probabilistic Methods Appl. to Power Syst. PMAPS 2014 - Conf. Proc., pp. 1-6, 2014, doi: 10.1109/PMAPS.2014.6960635.

[126] M. W. Ahmad, A. Mouraud, Y. Rezgui, and M. Mourshed, "Deep highway networks and tree-based ensemble for predicting short-term building energy consumption,” Energies, vol. 11, no. 12, 2018, doi: 10.3390/en11123408.

[127] S. Asadi, S. S. Amiri, and M. Mottahedi, "On the development of multi-linear regression analysis to assess energy consumption in the early stages of building design," Energy Build., vol. 85, pp. 246-255, 2014, doi: 10.1016/j.enbuild.2014.07.096.

[128] C. Turhan, T. Kazanasmaz, I. E. Uygun, K. E. Ekmen, and G. G. Akkurt, "Comparative study of a building energy performance software (KEP-IYTE-ESS) and ANN-based building heat load estimation," Energy Build., vol. 85, pp. 115-125, 2014, doi: 10.1016/j.enbuild.2014.09.026.

[129] K. Amasyali and N. El-Gohary, "Building Lighting Energy Consumption Prediction for Supporting Energy Data Analytics,” Procedia Eng., vol. 145, pp. 511-517, 2016, doi: 10.1016/j.proeng.2016.04.036.

[130] T. Ahmad and H. Chen, "Short and medium-term forecasting of cooling and heating load demand in building environment with data-mining based approaches," Energy Build., vol. 166, pp. 460-476, 2018, doi: 10.1016/j.enbuild.2018.01.066.

[131] C. Fan, Y. Sun, Y. Zhao, M. Song, and J. Wang, "Deep learning-based feature engineering methods for improved building energy prediction," Appl. Energy, vol. 240, no. September 2018, pp. 35-45, Apr. 2019, doi: 10.1016/j.apenergy.2019.02.052.

[132] Y. Zhang, Z. O’Neill, B. Dong, and G. Augenbroe, “Comparisons of inverse modeling approaches for predicting building energy performance," Build. Environ., vol. 86, pp. 177-190, 2015, doi: 10.1016/j.buildenv.2014.12.023.

[133] Y. Zhang and Q. Chen, "Prediction of building energy consumption based on PSO - RBF neural 
network," Conf. Proc. - 2014 Int. Conf. Syst. Sci. Eng. ICSSE 2014, no. x, pp. 60-63, 2014, doi: 10.1109/ICSSE.2014.6887905.

[134] K. T. Williams and J. D. Gomez, "Predicting future monthly residential energy consumption using building characteristics and climate data: A statistical learning approach," Energy Build., vol. 128, pp. 1-11, 2016, doi: 10.1016/j.enbuild.2016.06.076.

[135] S. Farzana, M. Liu, A. Baldwin, and M. U. Hossain, "Multi-model prediction and simulation of residential building energy in urban areas of Chongqing, South West China," Energy Build., vol. 81, pp. 161-169, 2014, doi: 10.1016/j.enbuild.2014.06.007.

[136] N. Nassif, "Single and multivariate regression models for estimating monthly energy consumption in schools in hot and humid climates," Energy Eng. J. Assoc. Energy Eng., vol. 110, no. 5, pp. 33-54, 2013, doi: 10.1080/01998595.2013.10750242.

[137] Q. Qian, G. Tang, and G. Zhang, "Real-time prediction of sub-item building energy consumption based on PCA-AR-BP method," IOP Conf. Ser. Mater. Sci. Eng., vol. 366, no. 1, pp. 0-6, 2018, doi: 10.1088/1757-899X/366/1/012043.

[138] A. D. Galasiu and M. R. Atif, “Applicability of daylighting computer modeling in real case studies: Comparison between measured and simulated daylight availability and lighting consumption," Build. Environ., vol. 37, no. 4, pp. 363-377, 2002, doi: 10.1016/S0360-1323(01)00042-7.

[139] H. Sarak and A. Satman, "The degree-day method to estimate the residential heating natural gas consumption in Turkey: A case study," Energy, vol. 28, no. 9, pp. 929-939, 2003, doi: 10.1016/S03605442(03)00035-5.

[140] C. Koroneos and G. Kottas, "Energy consumption modeling analysis and environmental impact assessment of model house in Thessaloniki-Greece," Build. Environ., vol. 42, no. 1, pp. 122-138, 2007, doi: 10.1016/j.buildenv.2005.08.009.

[141] J. Yang, H. Rivard, and R. Zmeureanu, "On-line building energy prediction using adaptive artificial neural networks," Energy Build., vol. 37, no. 12, pp. 1250-1259, 2005, doi: 10.1016/j.enbuild.2005.02.005.

[142] S. P. Corgnati, V. Corrado, and M. Filippi, "A method for heating consumption assessment in existing buildings: A field survey concerning 120 Italian schools,” Energy Build., vol. 40, no. 5, pp. 801-809, 2008, doi: 10.1016/j.enbuild.2007.05.011.

[143] M. Yalcintas, "Energy-savings predictions for building-equipment retrofits," Energy Build., vol. 40, no. 12, pp. 2111-2120, 2008, doi: 10.1016/j.enbuild.2008.06.008.

[144] A. H. Neto and F. A. S. Fiorelli, "Comparison between detailed model simulation and artificial neural network for forecasting building energy consumption," Energy Build., vol. 40, no. 12, pp. 2169-2176, 2008, doi: 10.1016/j.enbuild.2008.06.013.

[145] A. Kusiak, M. Li, and Z. Zhang, "A data-driven approach for steam load prediction in buildings,” Appl. Energy, vol. 87, no. 3, pp. 925-933, 2010, doi: 10.1016/j.apenergy.2009.09.004.

[146] J. Bujak, "Heat consumption for preparing domestic hot water in hospitals," Energy Build., vol. 42, no. 7, pp. 1047-1055, 2010, doi: 10.1016/j.enbuild.2010.01.017.

[147] W. Yu, B. Li, Y. Lei, and M. Liu, "Analysis of a residential building energy consumption demand model," Energies, vol. 4, no. 3, pp. 475-487, 2011, doi: 10.3390/en4030475.

[148] V. Cheng and K. Steemers, "Modelling domestic energy consumption at district scale: A tool to support national and local energy policies," Environ. Model. Softw., vol. 26, no. 10, pp. 1186-1198, 2011, doi: 10.1016/j.envsoft.2011.04.005.

[149] N. Li, N. Zhu, J. Zhao, and N. Zhu, "Building Energy Consumption Prediction Evaluation Model," Adv. Mater. Res., vol. 280, pp. 101-105, 2011, doi: 10.4028/www.scientific.net/amr.280.101.

[150] M. Sterman and M. Baglione, "“DESIGN OF ARTIFICIAL NEURAL NETWORK USING SOLAR INPUTS FOR ASSESSING ENERGY CONSUMPTION IN A HIGH PERFORMANCE ACADEMIC BUILDING,"” ASME Int. Mech. Eng. Congr. Expo. Proc., pp. 1-7, 2012, doi: 10.1115/IMECE201286976.

[151] R. E. Edwards, J. New, and L. E. Parker, "Predicting future hourly residential electrical consumption: A machine learning case study," Energy Build., vol. 49, pp. 591-603, 2012, doi: 10.1016/j.enbuild.2012.03.010.

[152] B. Yan and A. M. A. A. M. Malkawi, "A Bayesian Approach for Predicting Building Cooling and Heating Consumption," Build. Simul. 2013, pp. 3137-3144, 2013, [Online]. Available: http://www.ibpsa.org/proceedings/BS2013/p\%7B\%5C_\%7D1344.pdf.

[153] I. Alanqar, A. Mohammadpour, J. Srebric, and C. Anumba, "Accurate simulation of metered electricity usage of a leed ${ }^{\circledR}$ certified cancer institute," in Proceedings of BS 2013: 13th Conference of the International Building Performance Simulation Association, 2013.

[154] A. P. A. P. Melo, R. Lamberts, D. Cóstola, and J. L. M. M. J. L. M. M. Hensen, "Development of a method to predict building energy consumption through an artificial neural network approach," Proc. BS 
2013 13th Conf. Int. Build. Perform. Simul. Assoc., no. May 2017, pp. 644-651, 2013, [Online]. Available: www.ibpsa.org/proceedings/BS2013/p\%7B\%5C_\%7D2016.pdf.

[155] D. Majcen, L. C. M. M. Itard, and H. Visscher, "Theoretical vs. actual energy consumption of labelled dwellings in the Netherlands: Discrepancies and policy implications," Energy Policy, vol. 54, pp. 125136, 2013, doi: 10.1016/j.enpol.2012.11.008.

[156] T. Kazanasmaz, I. E. Uygun, G. G. Akkurt, C. Turhan, and K. E. Ekmen, "On the relation between architectural considerations and heating energy performance of Turkish residential buildings in Izmir," Energy Build., vol. 72, pp. 38-50, 2014, doi: 10.1016/j.enbuild.2013.12.036.

[157] Z. Verbai, Á. Lakatos, and F. Kalmár, "Prediction of energy demand for heating of residential buildings using variable degree day," Energy, vol. 76, pp. 780-787, 2014, doi: 10.1016/j.energy.2014.08.075.

[158] X. Lü, T. Lu, C. J. Kibert, and M. Viljanen, "A novel dynamic modeling approach for predicting building energy performance," Appl. Energy, vol. 114, pp. 91-103, 2014, doi: 10.1016/j.apenergy.2013.08.093.

[159] L. Ming-Hai and L. Min, "Prediction of public building energy consumption by using artificial fishswarm algorithm," Proc. - 2015 Chinese Autom. Congr. CAC 2015, pp. 2043-2047, 2016, doi: 10.1109/CAC.2015.7382840.

[160] L. C. C. C. Fiocchi et al., "Matching Building Energy Simulation Results against Measured Data with Weather File Compensation Factors," ASHRAE Trans., vol. 120, no. 2, pp. 397-404, 2014.

[161] A. Ingle, M. Moezzi, L. Lutzenhiser, and R. Diamond, "Better home energy audit modelling: Incorporating inhabitant behaviours," Build. Res. Inf., vol. 42, no. 4, pp. 409-421, 2014, doi: 10.1080/09613218.2014.890776.

[162] C. Peng, L. Wang, and X. Zhang, "DeST-based dynamic simulation and energy efficiency retrofit analysis of commercial buildings in the hot summer/cold winter zone of China: A case in Nanjing," Energy Build., vol. 78, pp. 123-131, 2014, doi: 10.1016/j.enbuild.2014.04.023.

[163] C. Fan, F. Xiao, and S. Wang, "Development of prediction models for next-day building energy consumption and peak power demand using data mining techniques," Appl. Energy, vol. 127, pp. 1-10, 2014, doi: 10.1016/j.apenergy.2014.04.016.

[164] L. Friedrich, P. Armstrong, and A. Afshari, "Mid-term forecasting of urban electricity load to isolate airconditioning impact,” Energy Build., vol. 80, pp. 72-80, 2014, doi: 10.1016/j.enbuild.2014.05.011.

[165] R. Mena, F. Rodríguez, M. Castilla, and M. R. Arahal, "A prediction model based on neural networks for the energy consumption of a bioclimatic building," Energy Build., vol. 82, pp. 142-155, 2014, doi: 10.1016/j.enbuild.2014.06.052.

[166] D. Lv, B. Zhong, and J. Luo, "Application of GLBP Algorithm in the Prediction of Building Energy Consumption," Int. J. Adv. Comput. Sci. Appl., vol. 6, no. 6, pp. 45-48, 2015, doi: 10.14569/ijacsa.2015.060607.

[167] J. Yang, H. Fu, and M. Qin, "Evaluation of Different Thermal Models in EnergyPlus for Calculating Moisture Effects on Building Energy Consumption in Different Climate Conditions," Procedia Eng., vol. 121, pp. 1635-1641, 2015, doi: 10.1016/j.proeng.2015.09.194.

[168] C. Yang and J. H. Choi, "Energy Use Intensity Estimation Method Based on Façade Features," Procedia Eng., vol. 118, pp. 842-852, 2015, doi: 10.1016/j.proeng.2015.08.522.

[169] M. Mottahedi, A. Mohammadpour, S. S. Amiri, D. Riley, and S. Asadi, "Multi-linear Regression Models to Predict the Annual Energy Consumption of an Office Building with Different Shapes," Procedia Eng., vol. 118, pp. 622-629, 2015, doi: 10.1016/j.proeng.2015.08.495.

[170] S. Paudel et al., "Support Vector Machine in Prediction of Building Energy Demand Using Pseudo Dynamic Approach," ECOS 2015 - 28th Int. Conf. Effic. Cost, Optim. Simul. Environ. Impact Energy Syst., no. 2015, 2015, [Online]. Available: http://arxiv.org/abs/1507.05019.

[171] E. Hüllermeier and M. Minor, "CBR Model for Predicting a Building's Electricity Use: On-Line Implementation in the Absence of Historical Data," Lect. Notes Comput. Sci. (including Subser. Lect. Notes Artif. Intell. Lect. Notes Bioinformatics), vol. 9343, no. February, 2015, doi: 10.1007/978-3-31924586-7.

[172] M. Castelli, L. Trujillo, L. Vanneschi, and A. Popovič, "Prediction of energy performance of residential buildings: A genetic programming approach,” Energy Build., vol. 102, no. January 2019, pp. 67-74, 2015, doi: 10.1016/j.enbuild.2015.05.013.

[173] D. Liu, Q. Chen, and K. Mori, "Time series forecasting method of building energy consumption using support vector regression,” 2015 IEEE Int. Conf. Inf. Autom. ICIA 2015 - conjunction with 2015 IEEE Int. Conf. Autom. Logist., no. August, pp. 1628-1632, 2015, doi: 10.1109/ICInfA.2015.7279546.

[174] J. W. Moon, S. K. Jung, Y. O. Lee, and S. Choi, "Prediction performance of an artificial neural network model for the amount of cooling energy consumption in hotel rooms," Energies, vol. 8, no. 8, pp. 82268243, 2015, doi: 10.3390/en8088226.

[175] A. Tascikaraoglu and B. M. Sanandaji, "Short-term residential electric load forecasting: A compressive 
spatiooral approach," Energy Build., vol. 111, pp. 380-392, 2016, doi: 10.1016/j.enbuild.2015.11.068.

[176] D. Caicedo and A. Pandharipande, "Energy performance prediction of lighting systems," IEEE Int.

Work. Mach. Learn. Signal Process. MLSP, vol. 2016-Novem, pp. 1-6, 2016, doi: 10.1109/MLSP.2016.7738858.

[177] Z. Du, S. Zhu, W. Shao, and S. Sui, "Study on energy consumption of hotel based on extended STIRPAT model," Proc. 28th Chinese Control Decis. Conf. CCDC 2016, pp. 2052-2056, 2016, doi: 10.1109/CCDC.2016.7531322.

[178] F. Magoulès, M. Piliougine, and D. Elizondo, "Support Vector Regression for Electricity Consumption Prediction in a Building in Japan," Proc. - 19th IEEE Int. Conf. Comput. Sci. Eng. 14th IEEE Int. Conf. Embed. Ubiquitous Comput. 15th Int. Symp. Distrib. Comput. Appl. to Business, Engi, pp. 189-196, 2017, doi: 10.1109/CSE-EUC-DCABES.2016.184.

[179] S. Naji et al., "Estimating building energy consumption using extreme learning machine method," Energy, vol. 97, pp. 506-516, 2016, doi: 10.1016/j.energy.2015.11.037.

[180] D. Zhao, M. Zhong, X. Zhang, and X. Su, "Energy consumption predicting model of VRV (Variable refrigerant volume) system in office buildings based on data mining," Energy, vol. 102, pp. 660-668, 2016, doi: 10.1016/j.energy.2016.02.134.

[181] Y. Yang, Q. S. Jia, and X. Guan, "Improving the prediction accuracy of building energy consumption using location of occupant - A case study," Proc. IEEE Int. Conf. Ind. Technol., vol. 2016-May, no. 61174072, pp. 1550-1555, 2016, doi: 10.1109/ICIT.2016.7474991.

[182] Y. M. Kim, K. U. Ahn, and C. S. Park, "Issues of application of machine learning models for virtual and real-life buildings," Sustain., vol. 8, no. 6, pp. 1-15, 2016, doi: 10.3390/su8060543.

[183] J. Kneifel and D. Webb, "Predicting energy performance of a net-zero energy building: A statistical approach," Appl. Energy, vol. 178, pp. 468-483, 2016, doi: 10.1016/j.apenergy.2016.06.013.

[184] G. Shi, D. Liu, and Q. Wei, "Energy consumption prediction of office buildings based on echo state networks," Neurocomputing, vol. 216, pp. 478-488, 2016, doi: 10.1016/j.neucom.2016.08.004.

[185] X. Liang, T. Hong, and G. Q. Shen, "Improving the accuracy of energy baseline models for commercial buildings with occupancy data," Appl. Energy, vol. 179, pp. 247-260, 2016, doi: 10.1016/j.apenergy.2016.06.141.

[186] M. A. R. Biswas, M. D. Robinson, and N. Fumo, "Prediction of residential building energy consumption: A neural network approach," Energy, vol. 117, pp. 84-92, 2016, doi: 10.1016/j.energy.2016.10.066.

[187] F. Ascione, N. Bianco, C. De Stasio, G. M. Mauro, and G. P. Vanoli, "Artificial neural networks to predict energy performance and retrofit scenarios for any member of a building category: A novel approach,” Energy, vol. 118, pp. 999-1017, 2017, doi: 10.1016/j.energy.2016.10.126.

[188] D. Long, N. Nassif, and A. S. Ours, "Prediction of energy consumption in buildings by system identification," FTC 2016 - Proc. Futur. Technol. Conf., no. December, pp. 701-705, 2017, doi: 10.1109/FTC.2016.7821681.

[189] C. Carpino, R. Bruno, and N. Arcuri, "Statistical analysis of the heating demand in residential buildings located in Mediterranean climate and proposals for refurbishment," Energy Procedia, vol. 133, pp. 1627, 2017, doi: 10.1016/j.egypro.2017.09.365.

[190] K. P. Amber et al., "Energy consumption forecasting for university sector buildings," Energies, vol. 10, no. 10 , pp. 1-18, 2017, doi: 10.3390/en10101579.

[191] A. Prashant et al., "Improving the Accuracy of Building Energy Simulation Using Real-Time Occupancy Schedule and Metered Electricity Consumption Data," ASHRAE Annu. Conf, no. June, 2017.

[192] M. Manivannan, B. Najafi, and F. Rinaldi, "Machine learning-based short-term prediction of airconditioning load through smart meter analytics," Energies, vol. 10, no. 11, 2017, doi: 10.3390/en10111905.

[193] S. Zabada and I. Shahrour, "Analysis of heating expenses in a large social housing stock using artificial neural networks," Energies, vol. 10, no. 12, pp. 1-8, 2017, doi: 10.3390/en10122086.

[194] H. Deng, D. Fannon, and M. J. Eckelman, "Predictive modeling for US commercial building energy use: A comparison of existing statistical and machine learning algorithms using CBECS microdata," Energy Build., vol. 163, pp. 34-43, 2018, doi: 10.1016/j.enbuild.2017.12.031.

[195] Q. Dong, K. Xing, and H. Zhang, "Artificial neural network for assessment of energy consumption and cost for cross laminated timber office building in severe cold regions," Sustain., vol. 10, no. 1, 2017, doi: $10.3390 / \mathrm{su} 10010084$.

[196] Y. Gao, X. Liu, X. Li, L. Gu, J. Cui, and X. Yang, "A prediction approach on energy consumption for public buildings using mind evolutionary algorithm and bp neural network," Proc. 2018 IEEE 7th Data Driven Control Learn. Syst. Conf. DDCLS 2018, pp. 385-389, 2018, doi: 10.1109/DDCLS.2018.8516017.

[197] P. Dinarvand, L. L. Han, A. Coates, and L. L. Han, "Automatic Real-Time Prediction of Energy Consumption Based on Occupancy Pattern for Energy Efficiency Management in Buildings," 2018 
IEEE 20th Int. Conf. High Perform. Comput. Commun. IEEE 16th Int. Conf. Smart City; IEEE 4th Int. Conf. Data Sci. Syst., pp. 1299-1304, 2018, doi: 10.1109/HPCC/SmartCity/DSS.2018.00217.

[198] J. Singh, S. S. Mantha, and V. M. Phalle, "Characterizing domestic electricity consumption in the Indian urban household sector," Energy Build., vol. 170, pp. 74-82, 2018, doi: 10.1016/j.enbuild.2018.04.002.

[199] M. Kim, J. Jun, N. Kim, Y. Song, and C. S. Pyo, "Sequence-to-Sequence model for Building Energy Consumption Prediction," 9th Int. Conf. Inf. Commun. Technol. Converg. ICT Converg. Powered by Smart Intell. ICTC 2018, pp. 1243-1245, 2018, doi: 10.1109/ICTC.2018.8539597.

[200] A. Streltsov, K. Bradbury, and J. Malof, “AUTOMATED BUILDING ENERGY CONSUMPTION ESTIMATION FROM AERIAL IMAGERY Energy Initiative , Duke University, Durham , NC 27708 Department of Electrical \{\\&\} Computer Engineering, Duke University, Durham , NC 27708," pp. $1676-1679,2018$.

[201] A. Naug and G. Biswas, "A Data Driven Method for Prediction of Energy Demand in Commercial Buildings," IEEE Int. Conf. Autom. Sci. Eng., vol. 2018-Augus, pp. 335-340, 2018, doi: 10.1109/COASE.2018.8560520.

[202] E. Ruiz, R. Pacheco-Torres, and J. Casillas, "Energy consumption modeling by machine learning from daily activity metering in a hospital," IEEE Int. Conf. Emerg. Technol. Fact. Autom. ETFA, pp. 1-7, 2018, doi: 10.1109/ETFA.2017.8247667.

[203] A. Tahmassebi and A. H. Gandomi, "Building energy consumption forecast using multi-objective genetic programming," Meas. J. Int. Meas. Confed., vol. 118, no. October 2017, pp. 164-171, 2018, doi: 10.1016/j.measurement.2018.01.032.

[204] I. Ullah, R. Ahmad, and D. H. Kim, "A prediction mechanism of energy consumption in residential buildings using hidden markov model," Energies, vol. 11, no. 2, pp. 1-20, 2018, doi: 10.3390/en11020358.

[205] G. D. Nugraha, A. Musa, J. Cho, K. Park, and D. Choi, "Lambda-based data processing architecture for two-level load forecasting in residential buildings," Energies, vol. 11, no. 4, pp. 1-20, 2018, doi: 10.3390/en11040772.

[206] A. K. Prakash, S. Xu, R. Rajagopal, and H. Y. Noh, "Robust building energy load forecasting using physically-based kernel models," Energies, vol. 11, no. 4, pp. 1-21, 2018, doi: 10.3390/en11040862.

[207] S. Dongmei, "Research and application of energy consumption benchmarking method for public buildings based on actual energy consumption," Energy Procedia, vol. 152, pp. 475-483, 2018, doi: 10.1016/j.egypro.2018.09.256.

[208] S. Al Qadi, B. Sodagar, and A. Elnokaly, "Estimating the heating energy consumption of the residential buildings in Hebron, Palestine,” J. Clean. Prod., vol. 196, no. June, pp. 1292-1305, 2018, doi: 10.1016/j.jclepro.2018.06.059.

[209] Z. Ma, C. Ye, H. Li, and W. Ma, “Applying support vector machines to predict building energy consumption in China," Energy Procedia, vol. 152, pp. 780-786, 2018, doi: 10.1016/j.egypro.2018.09.245.

[210] V. Ciancio, S. Falasca, I. Golasi, G. Curci, M. Coppi, and F. Salata, "Influence of Input Climatic Data on Simulations of Annual Energy Needs of a Building: EnergyPlus and WRF Modeling for a Case Study in Rome (Italy)," Energies, vol. 11, no. 10, p. 2835, 2018, doi: 10.3390/en11102835.

[211] A. Alhamwi, W. Medjroubi, T. Vogt, and C. Agert, "Modelling urban energy requirements using open source data and models," Appl. Energy, vol. 231, no. December 2017, pp. 1100-1108, 2018, doi: 10.1016/j.apenergy.2018.09.164.

[212] Z. Liu, O. L. Kafka, C. Yu, and W. K. Liu, "Hybrid Models for Short-Term Load Forecasting Using Clustering and Time Series Wael,” vol. 840, pp. 221-242, 2019, doi: 10.1007/978-3-319-97982-3.

[213] F. Amara et al., "A residual load modeling approach for household short-term load forecasting application,” Energy Build., vol. 187, no. February, pp. 132-143, 2019, doi: 10.1016/j.enbuild.2019.01.009.

[214] H. Shen, K. Xu, and J. Freihaut, "A statistical study on energy performance of U.S. convenience stores: Investigation of factors and bench marking on store energy use," Energy Build., vol. 183, pp. 792-802, 2019, doi: 10.1016/j.enbuild.2018.10.018.

[215] S. Lee, S. Jung, and J. Lee, "Prediction model based on an artificial neural network for user-based building energy consumption in South Korea," Energies, vol. 12, no. 4, p. 608, Feb. 2019, doi: 10.3390/en12040608.

\section{Appendix A}




\section{List of Abbreviations}

AI

ARIMA

ANFIS

BPNN

BoostedT

BaggedT

CFD

$\mathrm{CNN}$

CRBM

DT

DBN

DA

DHN

ERT

ELM

EM

GIS

GA

GAN

GMMR

GPR

IPCC

$\mathrm{k}-\mathrm{NN}$

LSSVM

LOESS

LEAP

LSTM

MARS

MLR

MA\&ES

OLSR

OEM

OPLS

PWARX

PCA

PICO

PSO

PRISMA

PPSR

QP

RBFN

SAE

SARSA
Artificial intelligence

Autoregressive integrated moving average model

Adaptive neuro-fuzzy inference system

Backward propagation neural network

Boosted tree

Bagged tree

Computational flow dynamics

Convolutional neural network

Conditional restricted Boltzmann machine

Decision tree

Deep belief network

Discriminant analysis

Deep highway network

Extremely randomized trees

Extreme learning machine

Expectation maximization

Geographical information systems

Genetic algorithm

Generative adversarial net

Gaussian mixture regression

Gaussian process regression

Intergovernmental panel on climate change

$\mathrm{k}$ - Nearest neighbor

Least square support vector machine

Locally estimated scatterplot smoothing

Long-range energy alternatives planning system

Long short-term memory

Multivariate adaptive regression splines

Multiple linear regression

Moving average and exponential smoothing

Ordinary least squares regression

Original equipment manufacturers

Orthonormal partial least squares

Piece wise auto-regressive eXogeneous inputs

Principal component analysis

Problem, intervention, comparison and

outcomes

Particle swarm optimization

Preferred reporting items for systematic reviews and meta-analyses

Procedures for performing systematic reviews

Quadratic programming

Radial basis function network

Stacked auto-encoders

State-action-reward-state-action 
SPIDER

SVM

TB

TLBO
Sample, phenomenon of interest, design, evaluation and research type Support vector machine Tree bagger Teaching learning-based optimization

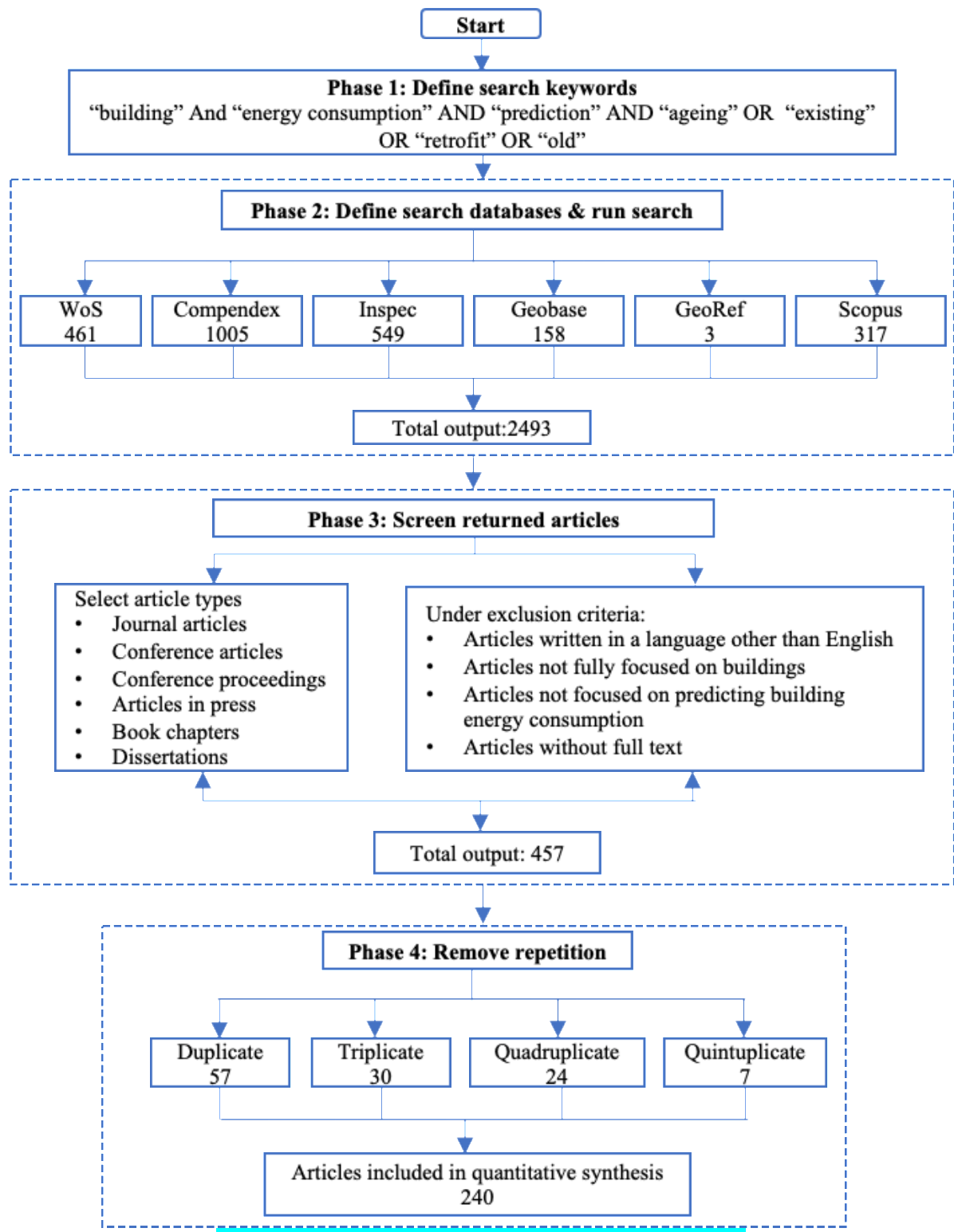

Fig.1. Systematic review process flow diagram. 


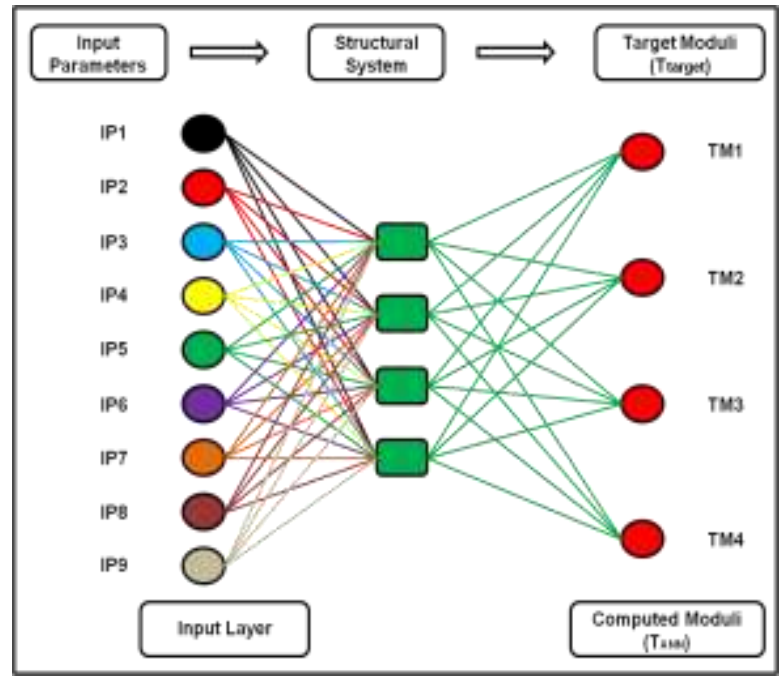

Fig.2. Typical ANN-based model

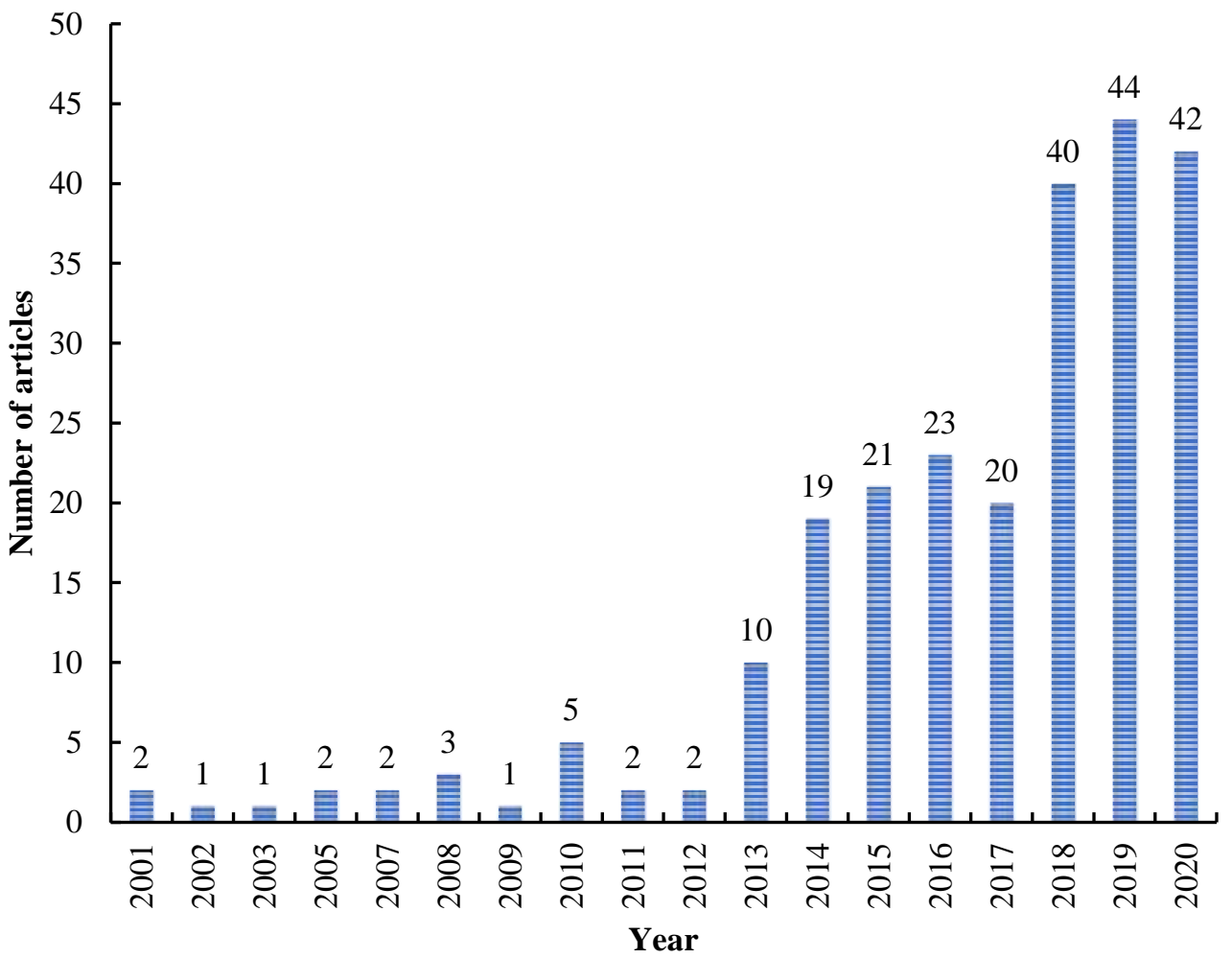

Fig.3. Number of the articles found using research keywords 


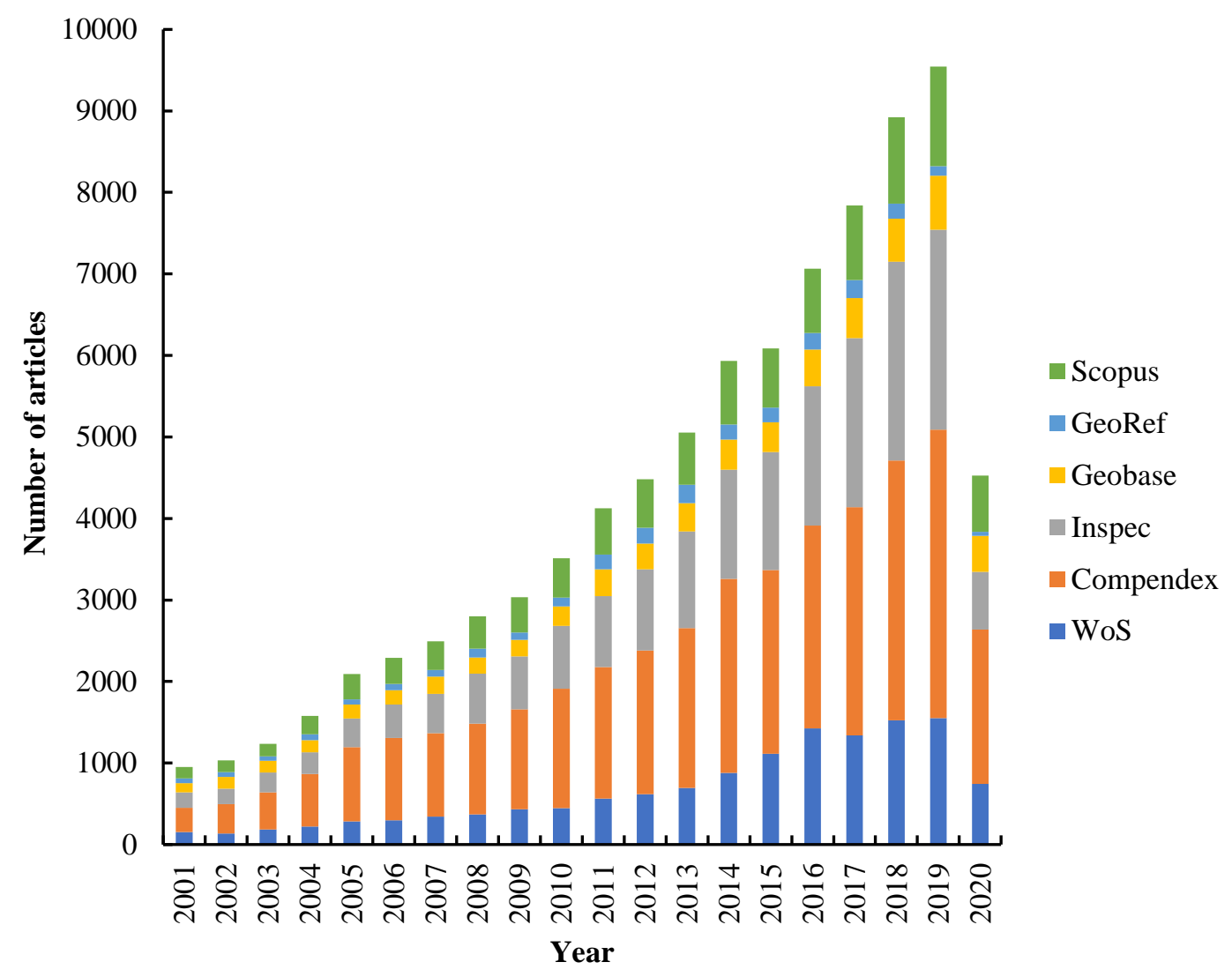

Fig.4. Number of articles found using building data collection as search term

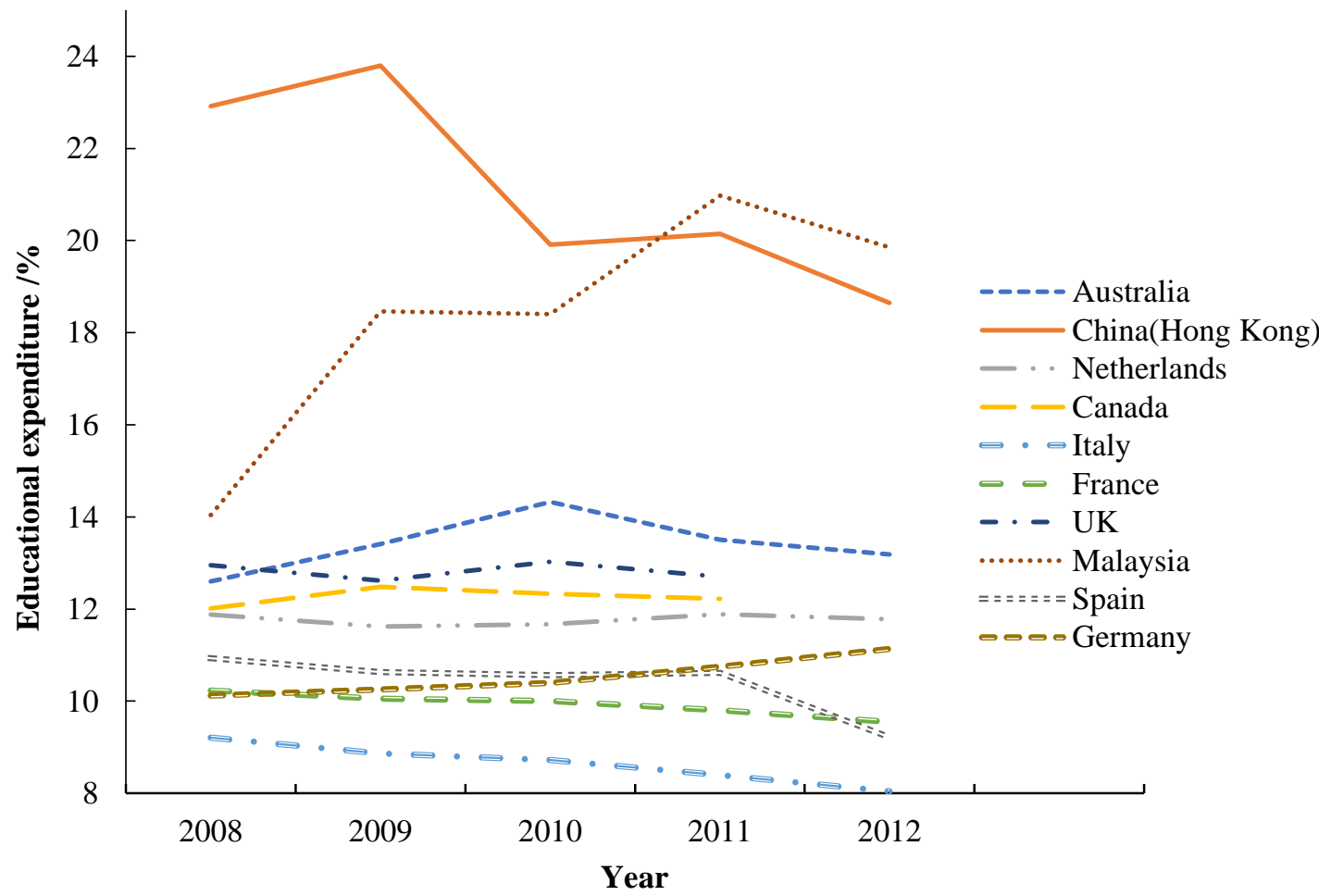

Fig.5. Government expenditure on education 


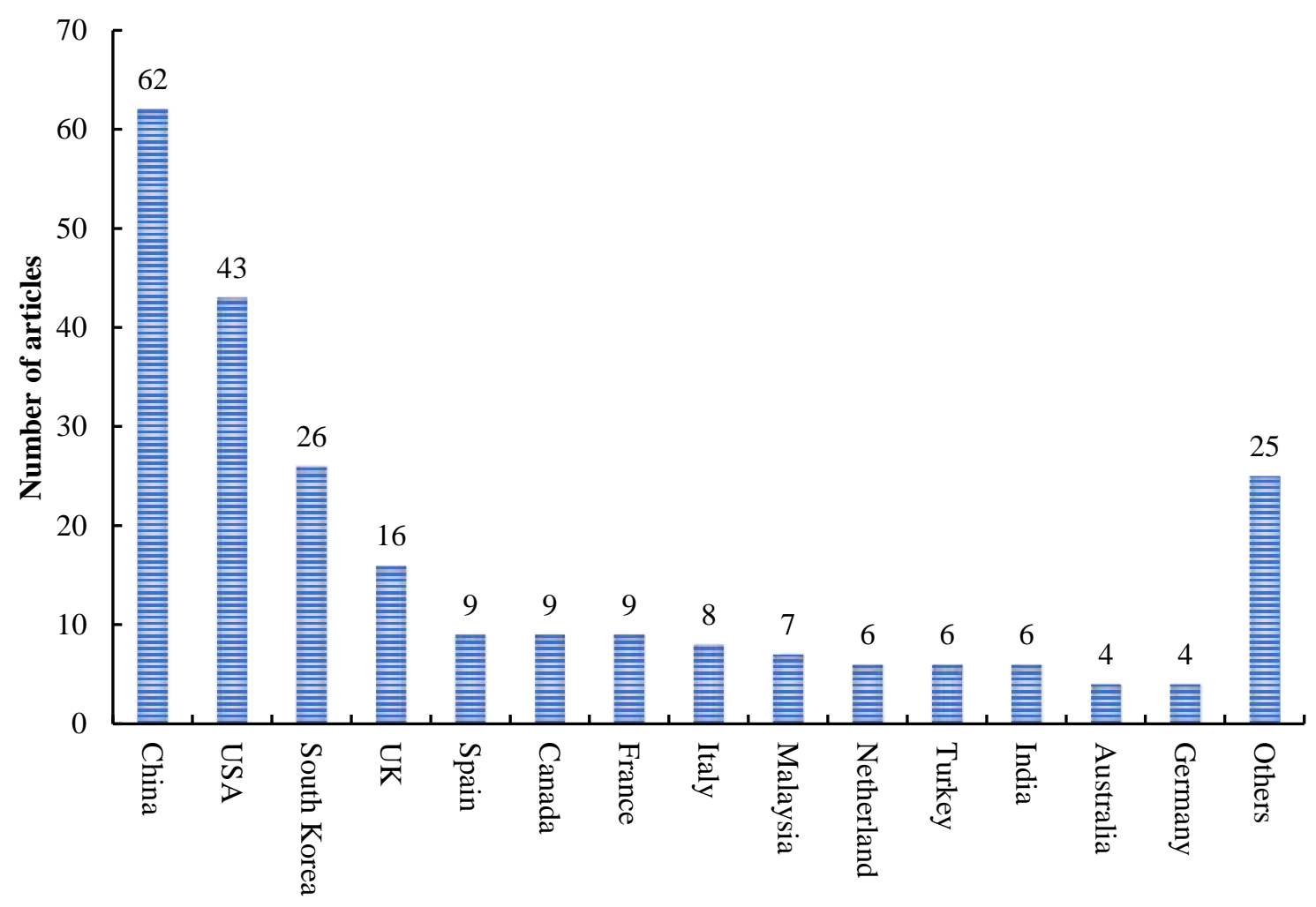

Country

Fig.6. Distribution of articles by country of origin from 2001 to 2020
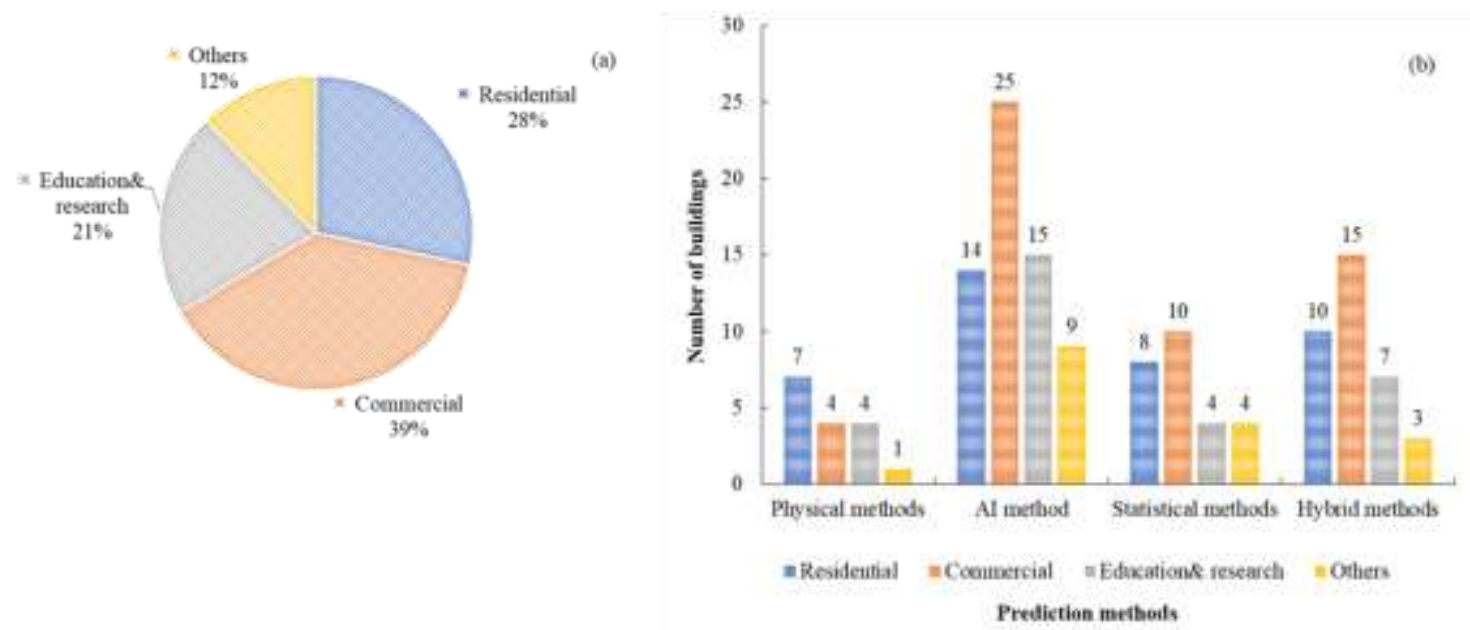

Fig.7. (a) composition of the building type. (b) prediction methods for each building type 


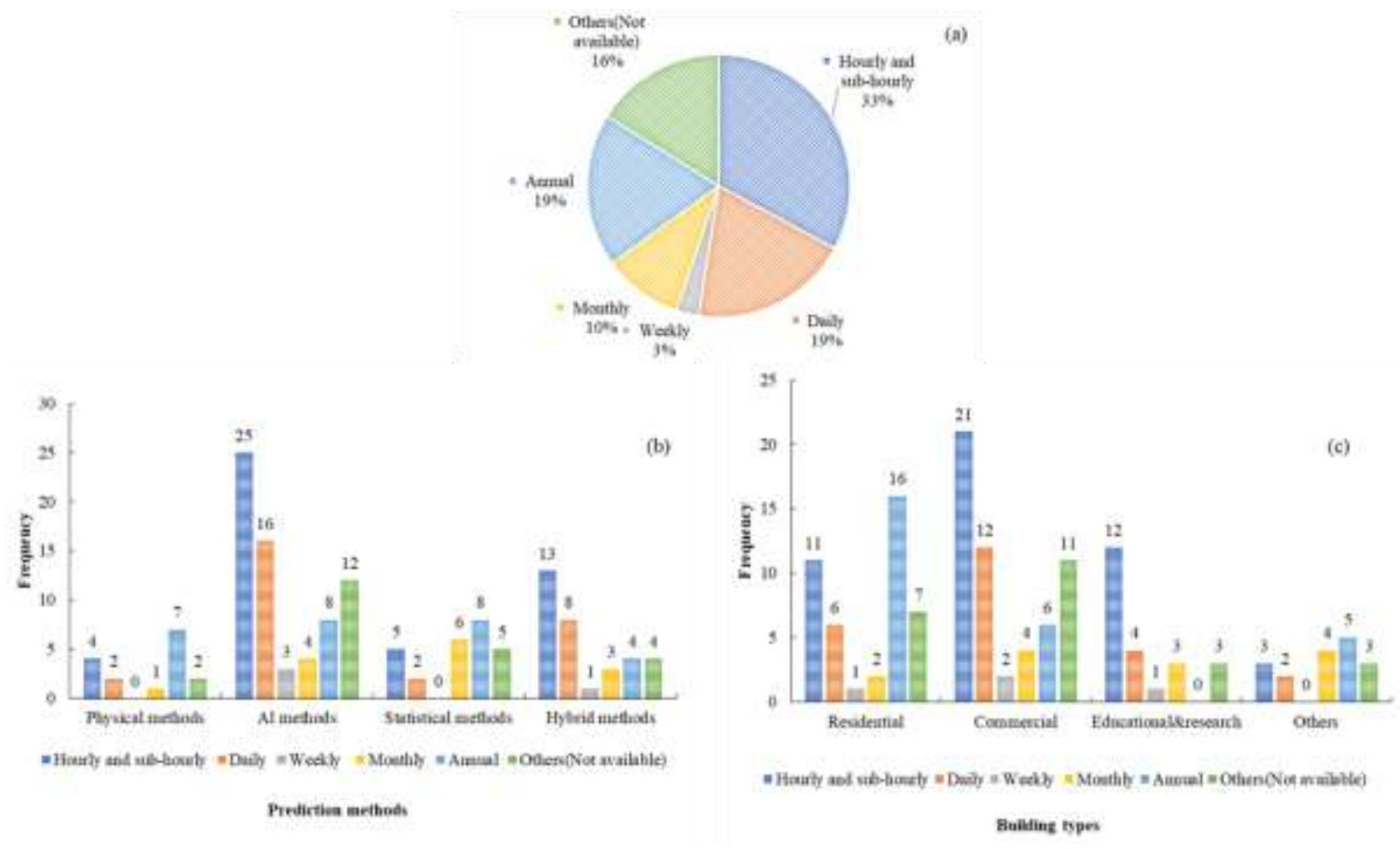

Fig.8. (a) Temporal granularity, (b) Temporal granularity with different prediction methods, (c) Temporal granularity with different building types

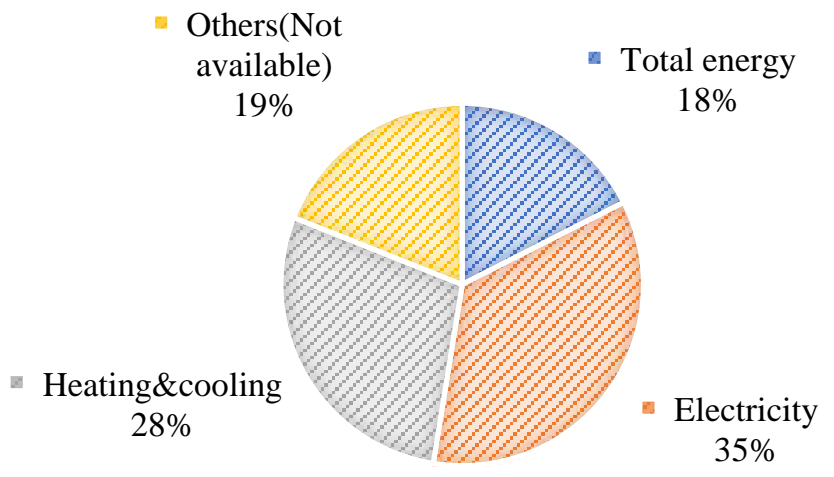

Fig.9. Composition of energy type

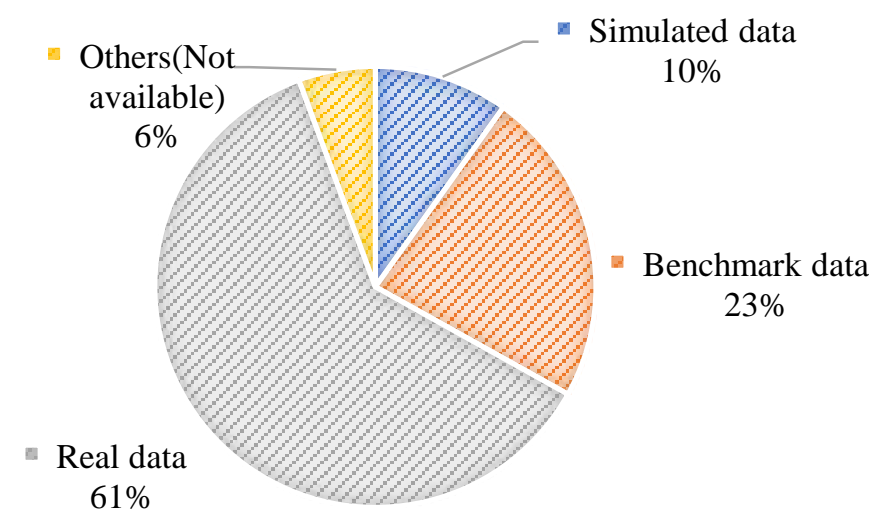

Fig.10. Types of data 
- Within one week

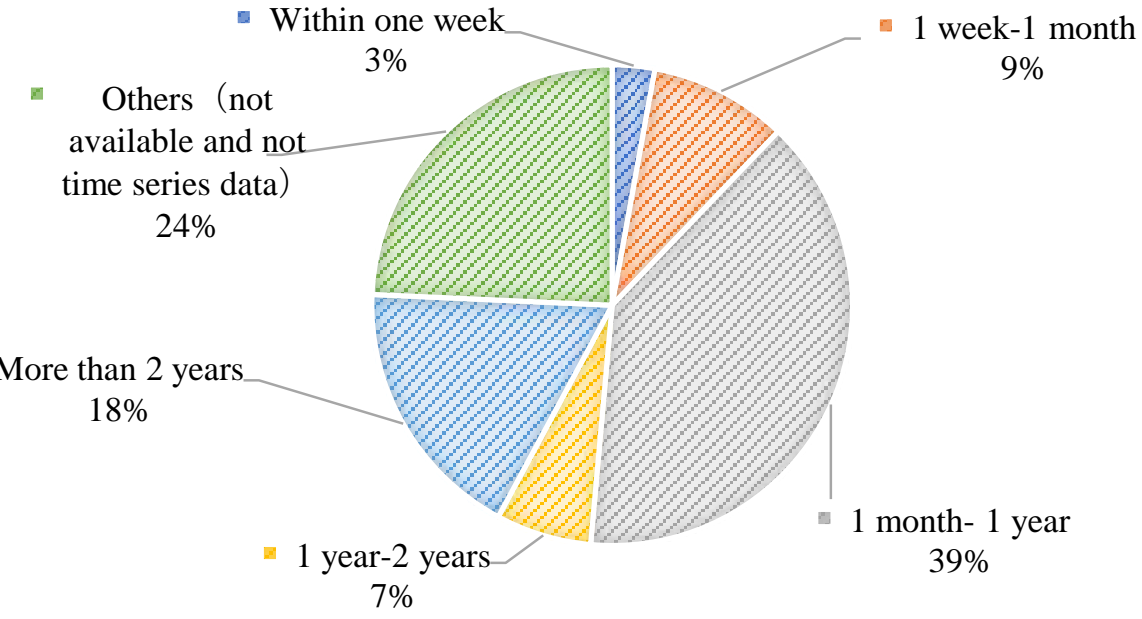

Fig.11. Size of datasets

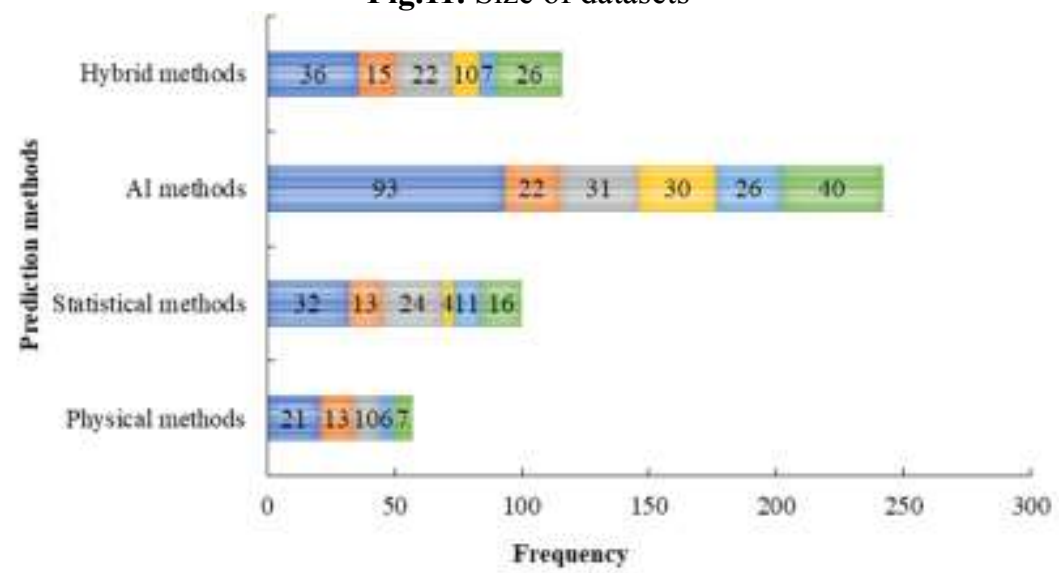

$\begin{array}{ll}\text { = Outdoor weather coeditions } & \text { "Indoor enviroumental coeditions } \\ =\text { Building charactenstics } & =\text { Time } \\ \text { s Occumancy and occupant energy use behavior } & \text { " Historical consumption }\end{array}$

Fig.12. Distribution of the usage of 6 main classes of parameters by common prediction methods 


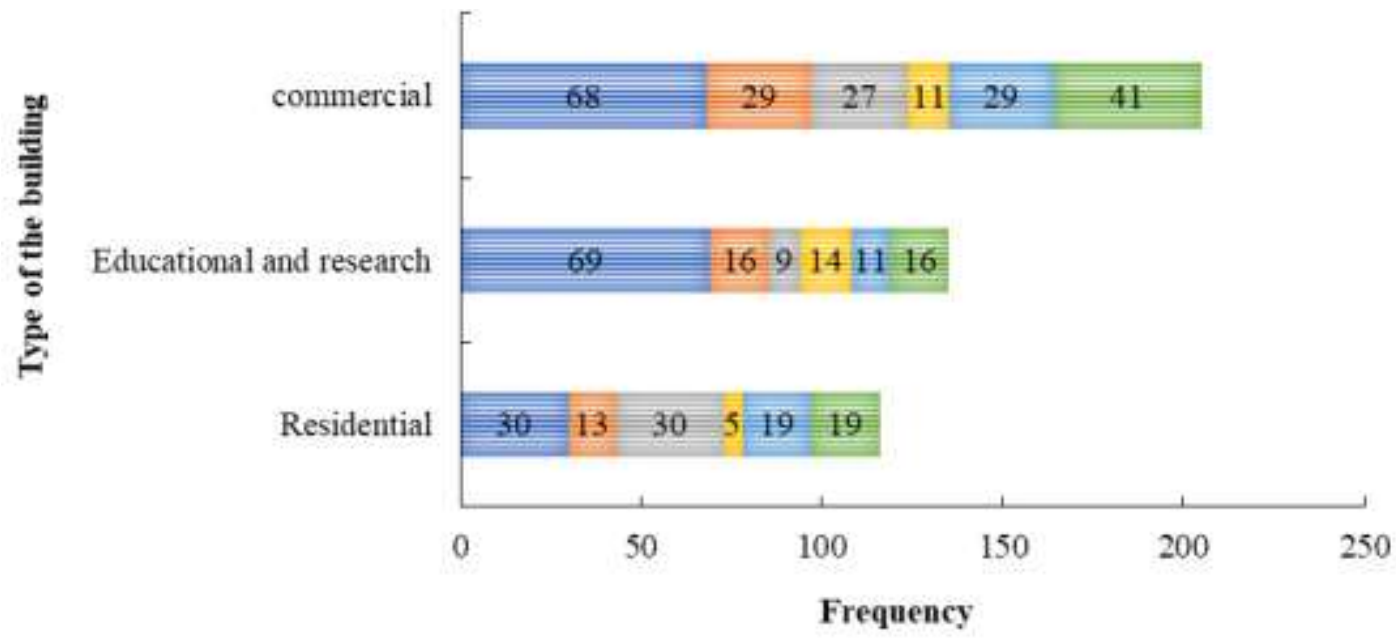

= Outdoor weather conditions

Building characteristics

"Indoor envirommental conditions

= Occupancy and occupant energy use behavior 


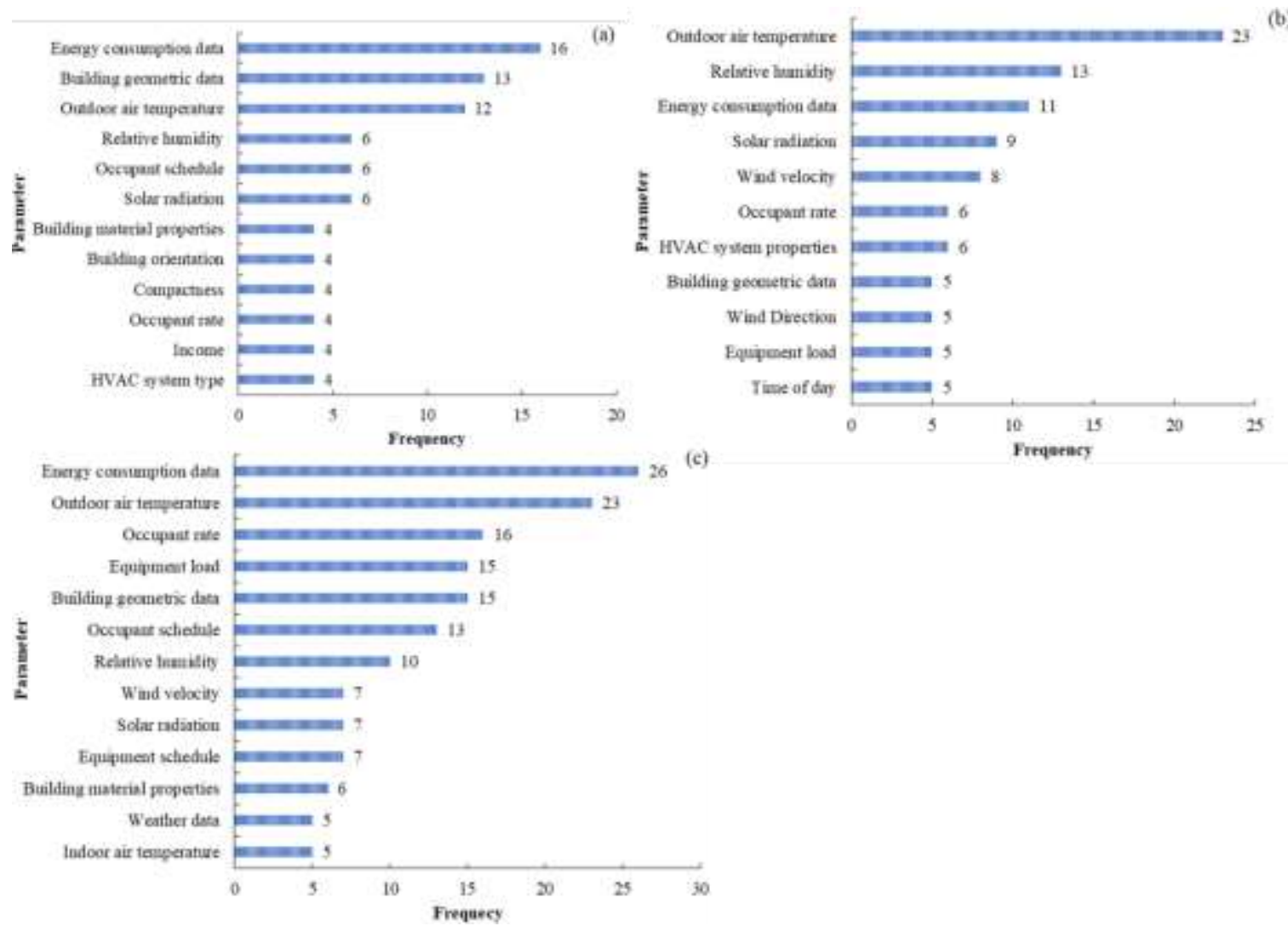

(b)

Fig.15. Frequency of parameters used in a) Residential building, b) Educational and research building, c) Commercial building 


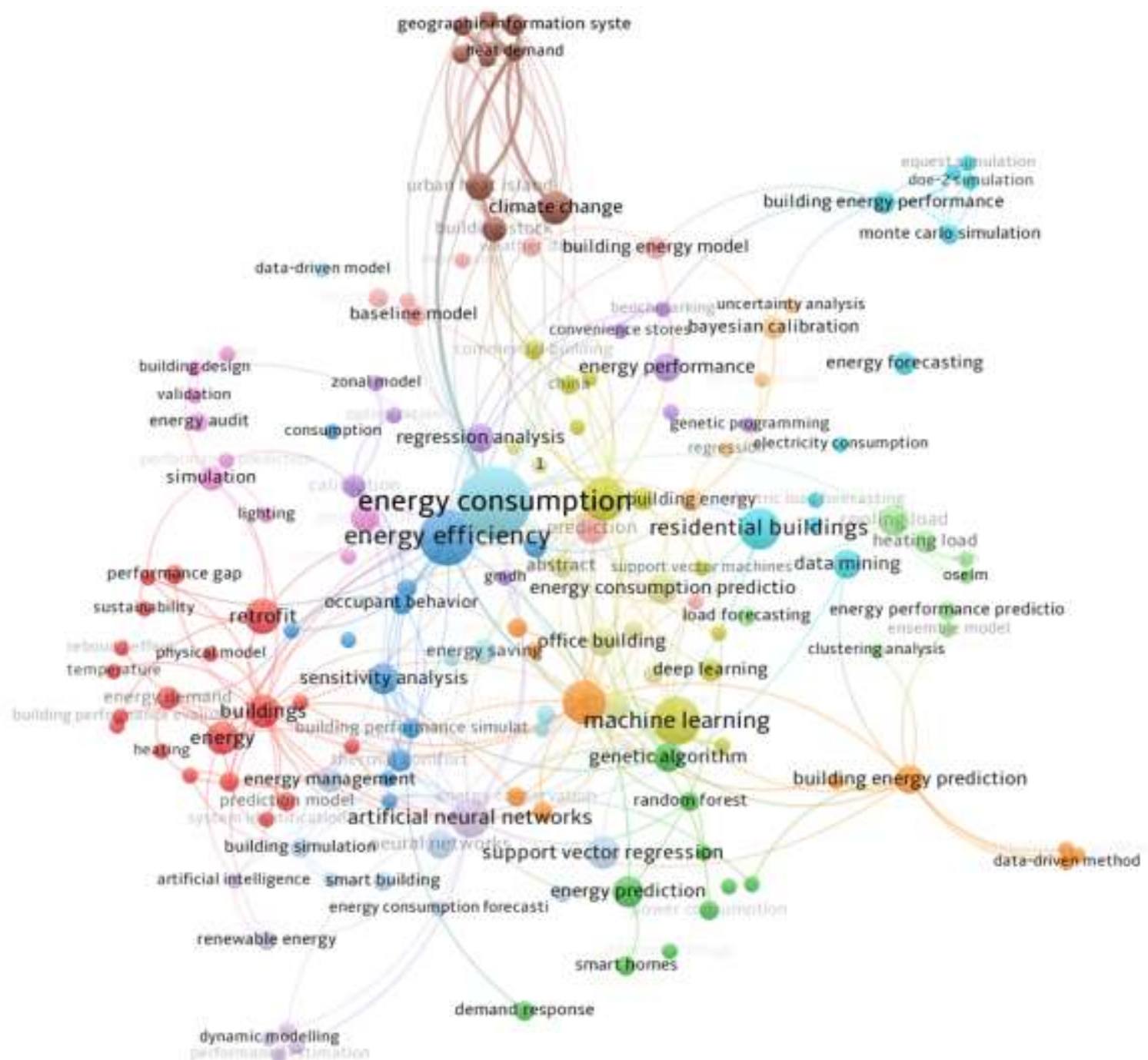

Fig.16. Cluster of influential building energy consumption prediction keywords 
Table 1. Review Protocol for the systematic review

\begin{tabular}{ll}
\hline Item & Description \\
\hline Keywords & $\begin{array}{l}\text { Building AND energy consumption AND prediction AND ageing OR existing OR } \\
\text { retrofit OR old }\end{array}$ \\
\hline Search fields & All fields \\
\hline Inclusion criteria & $\begin{array}{l}\text { In English language; focus on buildings; aimed at predicting building energy } \\
\text { consumption; full text is available. }\end{array}$ \\
\hline Publication type & $\begin{array}{l}\text { Journal articles, conference articles, conference proceedings, articles in press, book } \\
\text { chapters, dissertations }\end{array}$ \\
\hline Time window & $1990-$ \\
\hline
\end{tabular}

Table2. Summary of core characteristics of the prediction methods and examples

Method Advantages Disadvantages

- Assumptions

- The relationship between input and output variables is very clear.

Physical methods[8], [9], [13], [14], [16], [26], [27], [31]

- Good at simulating the energy consumption at the design phase.

- The physically-based model may not be appropriate for all scenarios

- Often requires detailed/exhaustive building information

- Time-consuming and laborintensive

Statistical methods: [8], [14], [16], [21], [26], [31], [32]

Ordinary Least squares regression [41], Linear regression [37], [121], [163], Logistic regression [41], [101], Stepwise regression, Multivariate adaptive regression splines [128], Locally estimated scatterplot smoothing.

Hybrid method[14], [26], [27], [29]

Can be used to harmonise the strengths of individual methods
- The relationship between input and output variables are unknown

- The input data have a significant influence on the prediction results

- Requires precise assumptions

- Lack of tolerance for uncorrelated noise

- Overfitting problems

- May also incorporate the weaknesses of individual methods if not adequately processed

Artificial intelligence:[9],

[13], [32], [14], [21], [25]-

[29], [31]

Machine learning:

\begin{tabular}{|c|c|c|}
\hline $\begin{array}{l}\text { Support vector machine [61], } \\
\text { [116], [164] [167], [187], } \\
{[189],[204]}\end{array}$ & $\begin{array}{l}\text { Outperforms other } \\
\text { methods on linearly } \\
\text { separable problems }\end{array}$ & $\begin{array}{l}\text { Challenging to train and } \\
\text { interpret information }\end{array}$ \\
\hline $\begin{array}{l}\text { Decision trees: } \\
\text { Classification tree [41], [199], } \\
\text { Regression tree [9], [33], } \\
\text { [124], [199] Boosted tree } \\
\text { [33], [41] [124] }\end{array}$ & $\begin{array}{l}\text { Easy to interpret and non- } \\
\text { parametric }\end{array}$ & $\begin{array}{l}\text { - Tends to over-fit } \\
\text { - May get stuck in local } \\
\text { minima } \\
\text { - Not an online learning }\end{array}$ \\
\hline $\begin{array}{l}\text { Ensemble algorithms: } \\
\text { Boosting [4], [33], [38], [41], } \\
\text { [48], [90], [125], [139] } \\
\text { Bootstrapped aggregation } \\
\text { [21], AdaBoost [48], [196], } \\
\text { Stacked generalization [41], }\end{array}$ & $\begin{array}{l}\text { Capitalises on the merits } \\
\text { of individual methods }\end{array}$ & $\begin{array}{l}\text { Adequate combination and } \\
\text { refinement of different } \\
\text { methods is often } \\
\text { challenging }\end{array}$ \\
\hline
\end{tabular}


Gradient boosting machines,

Random forest [45], [75],

[85] [86], [116], [187], [195]

Clustering algorithms:

k-Means [41], [50], [69],

[71], [207], k-Medians,

Expectation maximization

[50], [73], Hierarchical

clustering [41], [50], [207]

Dimensionality reduction

algorithms:

Principal component analysis

[41], [64], [73], [79], [83],

[131], [135], [165], Principal

component regression [41],

Partial least squares

regression [21]

Bayesian algorithms:

Naive Bayes [41], Gaussian

naive Bayes [37]

Multinomial naive Bayes,

Bayesian belief network [46],

Bayesian network [9], [52],

[146]

\section{Neural network:}

Artificial neural network:

Back-propagation [45], [122],

[137], [141], [204], Hopfield network [54],

Radial basis function network

[54], [74], [78], [116]

- Superior in solving nonlinear problems with high-dimensional datasets

- Can handle large and incomplete datasets

- Self-adapting, selforganizing and real-time learning network

- Easy to construct the network models

- Superior in solving non-

Deep learning:

Deep Boltzmann machine [41], [57], [174], Deep belief networks [41], [61]

Convolutional neural network [41], [118], Stacked autoencoders [41], [74] [125]
Good for handling large necessarily making assumptions on data
- Results are sometimes difficult to interpret

- Very limited when dealing with unfamiliar datasets
- Not effective when dealing with non-linear data

- It is sometimes difficult to understand the meaning of the results
Fast and easy to train

Could be extremely

challenging when the input variables are correlated
- Requires large amount of data

- Extremely computationally expensive to train

- Full details of the internal working principles could be challenging to understand

- The meta parameter and network topology selection is challenging

- Requires a large amount of data

- Extremely computationally expensive to train

- The internal working is unknown

- The meta parameter and network topology selection is hard

- Easy to construct the network models

Table 3. Summary of articles that explored hybrid methods, their associated sub-methods and functions

\begin{tabular}{cll}
\hline Reference & Algorithm & Function \\
\hline \multirow{2}{*}[67]{} & Physical & Simulates the building energy performance \\
\cline { 2 - 3 } & Genetic Algorithm & Identifies the buildings' internal mass model parameters \\
\hline \multirow{2}{*}[68]{} & GM (1,1) & Predicts the buildings' energy consumption \\
\cline { 2 - 3 } & $\begin{array}{l}\text { Radial basis neural } \\
\text { network }\end{array}$ & Revises the residual errors of the grey model \\
\hline$[69]$ & RReliefF & Accounts for interdependencies between variables so as to select the optimal variable \\
\hline
\end{tabular}




\begin{tabular}{|c|c|c|}
\hline & & subset \\
\hline & SVM & Predicts the buildings' energy consumption \\
\hline \multirow[b]{2}{*}{ [70] } & $\begin{array}{l}\text { Improved real coded } \\
\text { genetic algorithm }\end{array}$ & $\begin{array}{l}\text { Determines the free parameters of LSSVM in a more effective manner by optimizing } \\
\text { free parameters simultaneously from the training data }\end{array}$ \\
\hline & $\begin{array}{l}\text { Least squares support } \\
\text { vector machine } \\
\text { approach }\end{array}$ & $\begin{array}{l}\text { LSSVM solves a set of linear equations instead of the QP problems solved in standard } \\
\text { SVM, thereby significantly reducing the computational time of the learning process }\end{array}$ \\
\hline \multirow[t]{2}{*}{ [71] } & $\begin{array}{l}\text { Latin Hypercube } \\
\text { Monte Carlo sampling } \\
\text { algorithm }\end{array}$ & Obtains a set of plausible solutions by varying each key building parameter \\
\hline & Physical & Simulates the buildings' energy performance \\
\hline \multirow[t]{2}{*}{ [72] } & $\begin{array}{l}\text { Particle Swarm } \\
\text { Optimization }\end{array}$ & Trains and adjusts the weights and threshold values of ANN model \\
\hline & ANN & Predicts the buildings' energy consumption \\
\hline \multirow[b]{2}{*}{ [73] } & Physical & Simulates the buildings' energy performance \\
\hline & Bayesian calibration & $\begin{array}{l}\text { Effectively derives the coefficient of performance and deterioration, as well as applies } \\
\text { such to building energy models when calculating building energy consumption }\end{array}$ \\
\hline \multirow{2}{*}{ [74] } & $\begin{array}{l}\text { Reinforcement } \\
\text { learning }\end{array}$ & Predicts the energy consumption at the building level using unlabelled historical data \\
\hline & Deep Belief Network & $\begin{array}{l}\text { For continuous states estimation and automatic features extraction in a unified } \\
\text { framework }\end{array}$ \\
\hline \multirow{2}{*}{ [75] } & SVM & Predicts the buildings' energy consumption \\
\hline & Genetic algorithm & Optimizes the performance of SVM based on radial basis function kernel \\
\hline \multirow[t]{2}{*}{ [76] } & $\begin{array}{l}\text { Least square curve } \\
\text { fitting method }\end{array}$ & Fits the polynomial to the preceding part of the analysed data set \\
\hline & Fourier series & Refines all the parameters to yield the best data fit \\
\hline \multirow{3}{*}{ [77] } & K-means algorithm & Investigates representative end-user groups within buildings \\
\hline & ANN & Predicts energy usage for the identified end-user groups \\
\hline & K-nearest neighbour & Selects an appropriate set of historical data for network training \\
\hline \multirow{2}{*}{ [78] } & ANN & Predicts the energy consumption based on continuous inputs \\
\hline & Decision tree & Predicts the energy consumption based on discrete inputs \\
\hline \multirow{2}{*}{ [79] } & Statistical method & Predicts the buildings' energy consumption \\
\hline & K-means algorithm & Classifies the electricity and gas consumption data into groups \\
\hline \multirow{3}{*}{ [80] } & $\mathrm{k}$-modes clustering & Derives behaviour patterns directly from the database \\
\hline & $\begin{array}{l}\text { Probability neural } \\
\text { network }\end{array}$ & Associates occupants' characteristics with the clustered behaviour types \\
\hline & $\begin{array}{l}\text { First-order } \\
\text { inhomogeneous } \\
\text { Markov chain }\end{array}$ & Synthesizes the occupants' activity schedules \\
\hline \multirow{3}{*}{ [81] } & $\begin{array}{l}\text { Expectation } \\
\text { Maximization (EM), }\end{array}$ & Data clustering \\
\hline & $\begin{array}{l}\text { Principal Component } \\
\text { Analysis (PCA) and }\end{array}$ & $\begin{array}{l}\text { Extracts the most significant information from the data, reducing the dimensions of } \\
\text { data and dealing with the multi-collinearity issues within the experimental data-set }\end{array}$ \\
\hline & $\begin{array}{l}\text { Adaptive Neuro-Fuzzy } \\
\text { Inference System }\end{array}$ & Predicts the buildings' energy consumption \\
\hline \multirow[b]{2}{*}{ [82] } & Stacked autoencoders & Extracts the buildings' energy consumption features \\
\hline & $\begin{array}{l}\text { Extreme learning } \\
\text { machine }\end{array}$ & Functions as a predictor for obtaining accurate prediction results \\
\hline \multirow[b]{2}{*}{ [83] } & Random Forest & $\begin{array}{l}\text { Aids the building of forecasting models based on historical data. It includes working- } \\
\text { day and non-working day modes }\end{array}$ \\
\hline & $\begin{array}{l}\text { Auto Regressive } \\
\text { Moving Average } \\
\text { algorithm }\end{array}$ & $\begin{array}{l}\text { Serves as the benchmark for improving the presented model as well as addresses the } \\
\text { challenges of switching between working mode and non-working modes }\end{array}$ \\
\hline \multirow{2}{*}{ [84] } & $\begin{array}{l}\text { Convolutional neural } \\
\text { networks }\end{array}$ & $\begin{array}{l}\text { Detects buildings in the imagery forms and then extracts features from those building } \\
\text { annotations }\end{array}$ \\
\hline & $\begin{array}{l}\text { Random forests } \\
\text { regression }\end{array}$ & Estimates building energy consumption \\
\hline \multirow[b]{2}{*}{ [85] } & ANN & Predicts the building energy consumption \\
\hline & $\begin{array}{l}\text { Minute-controlled } \\
\text { resampling }\end{array}$ & Generates the training data for ANN \\
\hline \multirow[t]{2}{*}{ [86] } & $\begin{array}{l}\text { Energy-consuming } \\
\text { pattern }\end{array}$ & $\begin{array}{l}\text { Represents the periodicity property of building energy consumption and can be } \\
\text { extracted from the observed historical energy consumption data }\end{array}$ \\
\hline & Deep belief network & Predicts the building energy consumption \\
\hline \multirow{2}{*}{ [87] } & $\begin{array}{l}\text { Principal component } \\
\text { analysis }\end{array}$ & $\begin{array}{l}\text { Reduces the dimensionality of the data to create an efficient and low-complexity data } \\
\text { representation as well as eliminates subspaces occupied by uncorrelated noises }\end{array}$ \\
\hline & $\begin{array}{l}\text { Orthonormal partial } \\
\text { least squares }\end{array}$ & $\begin{array}{l}\text { Reduces the dimensionality of the data to create an efficient and low-complexity data } \\
\text { representation as well as eliminates subspaces occupied by uncorrelated noises }\end{array}$ \\
\hline \multirow{2}{*}[88]{} & SVM & Predicts the building energy consumption \\
\hline & Jaya algorithm & Determines the resultant weights of SVM configurations \\
\hline \multirow{2}{*}{ [89] } & K-means clustering & Classifies the electricity and gas consumption data into groups \\
\hline & Discriminant analysis & Features recognition and text mining \\
\hline$[90]$ & $\begin{array}{l}\text { Particle swarm } \\
\text { optimization }\end{array}$ & $\begin{array}{l}\text { Determines optimal weights and bias values for neural network training so as to } \\
\text { provide the most accurate prediction results }\end{array}$ \\
\hline
\end{tabular}




\begin{tabular}{|c|c|c|}
\hline & ANN & Predicts the building energy consumption \\
\hline \multirow[t]{2}{*}{ [91] } & $\begin{array}{l}\text { Teaching learning- } \\
\text { based optimization }\end{array}$ & Searches for globally optimised weights and threshold values of the ANN models \\
\hline & ANN & Predicts the building energy consumption \\
\hline \multirow[t]{2}{*}{ [92] } & $\begin{array}{l}\text { Particle swarm } \\
\text { optimization }\end{array}$ & $\begin{array}{l}\text { Optimal weights and bias values for neural network training to hence the most } \\
\text { accurate prediction results }\end{array}$ \\
\hline & BPNN & Predict the building energy consumption \\
\hline \multirow{2}{*}{ [93] } & Quantile regression & $\begin{array}{l}\text { Estimate arbitrary intervals instead of single values to forecast the building energy } \\
\text { consumption }\end{array}$ \\
\hline & D-vine copula method & $\begin{array}{l}\text { Predict conditional quantiles of heating energy consumption after retrofitting is } \\
\text { presented and implemented }\end{array}$ \\
\hline \multirow{2}{*}{ [94] } & Random forest & Classifies the electrical load data based on pattern similarity \\
\hline & Multilayer Perceptron & Predicts the building energy consumption \\
\hline \multirow{2}{*}{ [95] } & Multi-Decomposition & Analyses similar signals and extracts features \\
\hline & Deep Learning & Predicts the building energy consumption \\
\hline \multirow[t]{2}{*}{ [96] } & $\begin{array}{l}\text { Piece Wise Auto- } \\
\text { Regressive } \\
\text { eXogeneous inputs }\end{array}$ & $\begin{array}{l}\text { Extracts the discrete modes from the collected measurements and associates each } \\
\text { regression data to one of these functioning modes. }\end{array}$ \\
\hline & $\begin{array}{l}\text { Support Vector } \\
\text { Machine }\end{array}$ & Identifies the optimum hyperplanes that separate the data within the regression space \\
\hline \multirow{2}{*}{ [97] } & $\begin{array}{l}\text { Long short-term } \\
\text { memory }\end{array}$ & Predicts the building energy consumption \\
\hline & Genetic algorithm & $\begin{array}{l}\text { Improves accuracy of prediction of LSTM method by searching for fine window sizes } \\
\text { and appropriate number of hidden neurons. }\end{array}$ \\
\hline \multirow[t]{2}{*}{ [65] } & $\begin{array}{l}\text { Generative } \\
\text { Adversarial Nets }\end{array}$ & Applies small proportions of the original data series to generate parallel data sets \\
\hline & BPNN/SVM/ELM & Predicts the building energy consumption \\
\hline
\end{tabular}

Table 4. Main classes of building energy prediction parameters and their associated features/variables

\begin{tabular}{ll}
\hline Category & Variable \\
\hline Outdoor weather conditions & $\begin{array}{l}\text { Air pressure, climate zone, cloud cover, daylight level, illuminance contribution, dimming level, } \\
\text { dew point temperature, dry-bulb temperature, ground temperature, monthly degree days, relative } \\
\text { humidity, solar radiation, visibility, wet-bulb temperature, wind direction, wind velocity. }\end{array}$ \\
\hline $\begin{array}{l}\text { Indoor environmental } \\
\text { conditions }\end{array}$ & $\begin{array}{l}\text { Equipment schedule, gas volume, pressure, gas temperature, heated area, heating/cooling set- } \\
\text { point, humidity set-point, HVAC system properties, HVAC system type, indoor air temperature, } \\
\text { indoor CO2 concentration, indoor humidity latent heat gain from people, sensible heat gained } \\
\text { from people, ventilation rates. }\end{array}$ \\
\hline Building characteristics & $\begin{array}{l}\text { Building age, building geometry, building material properties, building orientation, building type, } \\
\text { compactness, air infiltration rate. }\end{array}$ \\
\hline Time & Date, day of the week, day of the month, holidays, time of day. \\
\hline $\begin{array}{l}\text { Occupancy and occupant } \\
\text { energy use behavior }\end{array}$ & Education level, family size, gender, occupant rate, occupant schedule, occupation, age, income. \\
\hline Historical consumption & Energy consumption, sub energy consumption \\
\hline
\end{tabular}

Table 5. Findings and limitations of the articles from clusters

\begin{tabular}{|c|c|c|c|c|}
\hline Reference & $\begin{array}{ll}\text { e } & \begin{array}{l}\text { Prediction } \\
\text { methods }\end{array} \\
\end{array}$ & $\begin{array}{c}\text { Building } \\
\text { types }\end{array}$ & Findings & Limitations \\
\hline [124] & ANN & $\begin{array}{l}\text { Office } \\
\text { building }\end{array}$ & $\begin{array}{l}\text { 1) The number of parameters } \\
\text { used in the prediction has a } \\
\text { significant impact on the } \\
\text { accuracy of prediction. Too many } \\
\text { parameters may lead to } \\
\text { overfitting problems and in turn } \\
\text { diminish accuracy of prediction. } \\
\text { 2) Integrating occupancy as an } \\
\text { input can improve the accuracy of } \\
\text { the proposed models. }\end{array}$ & $\begin{array}{l}\text { The lack of indoor sensors made it } \\
\text { difficult to capture the dynamics of } \\
\text { the entire indoor environment. The } \\
\text { model performance was only } \\
\text { validated during the summer. }\end{array}$ \\
\hline [82] & $\begin{array}{l}\text { Hybrid method } \\
\text { (stacked autoencoders } \\
\text { and the extreme } \\
\text { learning machine) }\end{array}$ & Retail & $\begin{array}{l}\text { 1) The proposed extreme SAEs } \\
\text { approach has the greatest ability } \\
\text { to deal with uncertainties } \\
\text { associated with building energy } \\
\text { consumption data. } \\
\text { 2) In comparison to other } \\
\text { methods, the residual errors of } \\
\text { extreme SAE approach are } \\
\text { usually the lowest. }\end{array}$ & $\begin{array}{l}\text { The simultaneous utilization of data } \\
\text { and prior knowledge of periodicity } \\
\text { to construct the DNN is extremely } \\
\text { difficult. }\end{array}$ \\
\hline$[125]$ & Stochastic method & $\begin{array}{c}\text { Office } \\
\text { building }\end{array}$ & $\begin{array}{l}\text { CRBM is a powerful probabilistic } \\
\text { method which outperformed other }\end{array}$ & $\begin{array}{l}\text { The determination of parameters } \\
\text { such as number of hidden units and }\end{array}$ \\
\hline
\end{tabular}




\begin{tabular}{|c|c|c|c|c|}
\hline & & & $\begin{array}{l}\text { state-of-the-art prediction } \\
\text { methods (including ANN and } \\
\text { hidden Markov models). }\end{array}$ & $\begin{array}{l}\text { learning rates must be carefully } \\
\text { managed. }\end{array}$ \\
\hline [74] & $\begin{array}{l}\text { Hybrid method (Deep } \\
\text { belief network with } \\
\text { Reinforcement } \\
\text { learning) }\end{array}$ & $\begin{array}{l}\text { Residential } \\
\text { and } \\
\text { commercial } \\
\text { buildings }\end{array}$ & $\begin{array}{l}\text { The extension of SARSA and Q- } \\
\text { learning by incorporating DBN } \\
\text { for states estimation is more } \\
\text { robust as well as offers lower } \\
\text { prediction error (approximately } \\
20 \text { times lower that obtainable } \\
\text { from un-extended versions }\end{array}$ & $\begin{array}{l}\text { A more extensive investigation still } \\
\text { needs to be conducted at different } \\
\text { Smart Grid levels prior to full } \\
\text { transition to future energy systems. }\end{array}$ \\
\hline [126] & $\begin{array}{l}\text { Deep highway } \\
\text { networks (DHN) and } \\
\text { extremely randomized } \\
\text { trees (ERT) }\end{array}$ & Hotel & $\begin{array}{l}\text { Both ERT and DHN models } \\
\text { marginally outperform the SVR } \\
\text { algorithm in predicting hourly } \\
\text { heating, ventilation and air } \\
\text { conditioning (HVAC) energy } \\
\text { consumption of a hotel building }\end{array}$ & $\begin{array}{l}\text { 1) Obtained performance is optimal } \\
\text { and no further improvements could } \\
\text { be achieved } \\
\text { 2) Network complexity significant } \\
\text { influences performance } \\
\text { 3) Some variables of interest are } \\
\text { missing } \\
\text { 4) Historical data is required for } \\
\text { reliable training of deep learning } \\
\text { models, which could be challenging } \\
\text { when dealing with new buildings. }\end{array}$ \\
\hline$[127]$ & Statistical methods & $\begin{array}{l}\text { Office } \\
\text { buildings }\end{array}$ & $\begin{array}{l}\text { Glass type, building occupancy } \\
\text { schedule and shape of buildings } \\
\text { have the highest influence on } \\
\text { energy consumption. H-shaped } \\
\text { buildings recorded the highest } \\
\text { consumptions, based on results } \\
\text { from } 7 \text { different regression } \\
\text { models. }\end{array}$ & $\begin{array}{l}\text { The effects of building design } \\
\text { parameters and shapes in different } \\
\text { climate regions still needs to be } \\
\text { investigated }\end{array}$ \\
\hline [122] & $\begin{array}{l}\text { Extreme learning } \\
\text { machine and Online } \\
\text { sequential ELM }\end{array}$ & N/A & $\begin{array}{l}\text { The proposed models learn better } \\
\text { and outperform other popular } \\
\text { machine learning approaches } \\
\text { (including ANNs, SVM, RBFN } \\
\text { and RF). }\end{array}$ & $\begin{array}{l}\text { Some improvements can still be } \\
\text { achieved by incorporating more } \\
\text { information about building } \\
\text { structure/attributes. It is also } \\
\text { envisaged that gradual migration } \\
\text { from shallow to deep architectures } \\
\text { of deep learning prediction models } \\
\text { would enhance accuracy. }\end{array}$ \\
\hline [128] & ANN & $\begin{array}{l}\text { Residential } \\
\text { buildings }\end{array}$ & $\begin{array}{l}\text { This study stipulates that ANN } \\
\text { models can accurately (i.e. R2 = } \\
97.7 \% \text { ) predict heating loads of } \\
\text { buildings, based on just four input } \\
\text { data. With the exception of the U- } \\
\text { value, all other parameters are } \\
\text { geometric properties which are } \\
\text { still obtainable even in the } \\
\text { absence of architectural details of } \\
\text { the buildings. }\end{array}$ & N/A \\
\hline [129] & $\begin{array}{l}\text { Support vector } \\
\text { machine }\end{array}$ & $\begin{array}{l}\text { Office } \\
\text { building }\end{array}$ & $\begin{array}{l}\text { A comparison between the SVM } \\
\text { model predictions and actual } \\
\text { energy consumption figures were } \\
\text { very identical. }\end{array}$ & N/A \\
\hline [130] & $\begin{array}{l}\text { Tree bagger, Gaussian } \\
\text { process regression, } \\
\text { multiple linear } \\
\text { regression, bagged } \\
\text { tree, boosted tree and } \\
\text { neural network. }\end{array}$ & $\begin{array}{l}\text { Office } \\
\text { building }\end{array}$ & $\begin{array}{l}\text { The simulation results implied } \\
\text { that the precisions of TB, } \\
\text { BoostedT, GPR, NN and } \\
\text { BaggedT are better than the MLR } \\
\text { model. The prediction } \\
\text { performance was better in case of } \\
\text { 7-day and 14- day period and the } \\
\text { model can predict short-term } \\
\text { energy consumption accurately. }\end{array}$ & $\begin{array}{l}\text { This performance can further be } \\
\text { improved by taking occupant } \\
\text { behavior into account due to } \\
\text { occupant behavior has a very } \\
\text { dominant impact on lighting energy } \\
\text { consumption }\end{array}$ \\
\hline [37] & $\begin{array}{l}\text { Binary decision tree, } \\
\text { Compact regression, } \\
\text { Gaussian process, } \\
\text { Stepwise Gaussian } \\
\text { processes regression } \\
\text { and Generalized linear } \\
\text { regression. }\end{array}$ & $\begin{array}{l}\text { Office } \\
\text { building }\end{array}$ & $\begin{array}{l}\text { 1) The multi linear regression } \\
\text { performed worse than other } \\
\text { methods. } \\
\text { 2) The prediction performance is } \\
\text { more suitable for short-term } \\
\text { rather than long-term. }\end{array}$ & $\begin{array}{l}\text { This method is most suitable for } \\
\text { buildings that possess adequate } \\
\text { monitoring and meteorological data. } \\
\text { Additionally, such buildings } \\
\text { shouldn't have undergone any form } \\
\text { of retrofitting during the period of } \\
\text { estimation. }\end{array}$ \\
\hline [91] & $\begin{array}{l}\text { Hybrid method } \\
\text { Teaching learning- } \\
\text { based optimization and } \\
\text { ANN }\end{array}$ & $\begin{array}{l}\text { School } \\
\text { library }\end{array}$ & $\begin{array}{l}\text { The proposed model performed } \\
\text { better than previously reported } \\
\text { GA-ANN and PSO-ANN } \\
\text { methods, especially with regards } \\
\text { to convergence speed and } \\
\text { prediction accuracy. }\end{array}$ & $\begin{array}{l}\text { The algorithms developed in this } \\
\text { research rely heavily on the degree } \\
\text { of correlation that exists among } \\
\text { days to be predicted and the } \\
\text { historical reference data }\end{array}$ \\
\hline [131] & $\begin{array}{l}\text { Fully connected auto- } \\
\text { encoders, }\end{array}$ & $\begin{array}{c}\text { Educational } \\
\text { building }\end{array}$ & $\begin{array}{l}\text { The features extracted by the } \\
\text { fully connected autoencoders are }\end{array}$ & $\begin{array}{l}\text { Most of the outliers identified were } \\
\text { due to public holidays, excluding }\end{array}$ \\
\hline
\end{tabular}




\begin{tabular}{|c|c|c|c|c|}
\hline & $\begin{array}{l}\text { Convolutional auto- } \\
\text { encoders and } \\
\text { Generative adversarial } \\
\text { networks }\end{array}$ & & $\begin{array}{l}\text { nonlinear transformations of the } \\
\text { original data. One-dimensional } \\
\text { convolutional autoencoders are } \\
\text { capable of extracting useful } \\
\text { temporal relationships in time } \\
\text { series data used for predictive } \\
\text { modeling, while the GAN-based } \\
\text { feature engineering method } \\
\text { adopts a generative approach for } \\
\text { feature extraction. }\end{array}$ & $\begin{array}{l}\text { Sundays and the days adjacent to } \\
\text { those public holidays. While the } \\
\text { approach eases prediction, its } \\
\text { overall outcomes could become less } \\
\text { representative. }\end{array}$ \\
\hline$[132]$ & $\begin{array}{l}\text { Change-point } \\
\text { regression, Gaussian } \\
\text { process regression, } \\
\text { ANN and Gaussian } \\
\text { mixture regression }\end{array}$ & $\begin{array}{l}\text { Office } \\
\text { building }\end{array}$ & $\begin{array}{l}\text { 1) The accuracy of ANN was the } \\
\text { least, due to lack of sufficient } \\
\text { training data. } \\
\text { 2) Besides ANN, all the methods } \\
\text { can be used as baseline models } \\
\text { since they meet the criteria } \\
\text { stipulated by ASHREA } \\
\text { Guidelines }\end{array}$ & $\begin{array}{l}\text { The obtained outcomes can be } \\
\text { further improved by accounting for } \\
\text { occupants' behavior, owing to its } \\
\text { dominant impact on energy } \\
\text { consumption }\end{array}$ \\
\hline [133] & $\begin{array}{l}\text { Hybrid method } \\
\text { (Particle swarm } \\
\text { optimization + Radial } \\
\text { basis function NN) }\end{array}$ & National & $\begin{array}{l}\text { Through the incorporation of } \\
\text { PSO for RBFNN optimization, } \\
\text { the prediction accuracy of the } \\
\text { hybrid method was far superior to } \\
\text { that of RBFNN alone. }\end{array}$ & N/A \\
\hline [134] & Statistical methods & $\begin{array}{l}\text { Residential } \\
\text { building }\end{array}$ & $\begin{array}{l}\text { The study identified inaccuracies } \\
\text { within application of climatic } \\
\text { data, especially when such data } \\
\text { are obtained from limited } \\
\text { locations within a given region. } \\
\text { Therefore, the influence of } \\
\text { variability on prediction accuracy } \\
\text { can be alleviated by collecting } \\
\text { weather data from different } \\
\text { locations within the studied } \\
\text { region }\end{array}$ & $\begin{array}{l}\text { Accessible network of } \\
\text { meteorological sensors that are } \\
\text { capable of collecting and sharing } \\
\text { weather data required for energy } \\
\text { consumption prediction is scarce. }\end{array}$ \\
\hline$[135]$ & $\begin{array}{l}\text { GM }(1,1) \text { model, } \\
\text { DGM }(2,1) \text { model, } \\
\text { Regression, } \\
\text { Polynomial model, } \\
\text { Polynomial regression } \\
\text { and ANN }\end{array}$ & $\begin{array}{c}\text { Residential } \\
\text { building }\end{array}$ & $\begin{array}{l}\text { The ANN model outperformed all } \\
\text { other five models in terms of } \\
\text { MRPE and other statistical } \\
\text { results. }\end{array}$ & N/A \\
\hline [136] & Statistical method & $\begin{array}{c}\text { School } \\
\text { buildings }\end{array}$ & $\begin{array}{l}\text { Including the school schedule as a } \\
\text { regressor in the model can } \\
\text { improve the accuracy of } \\
\text { prediction results significantly. } \\
\text { Including the dew point } \\
\text { temperature did not improve the } \\
\text { results. In contrast, the results } \\
\text { deteriorated in some school. }\end{array}$ & $\begin{array}{l}\text { There are no established standards } \\
\text { for selecting input parameters, } \\
\text { which implies that the adequacy of } \\
\text { the fewer parameters applied here } \\
\text { couldn't be established. }\end{array}$ \\
\hline [137] & $\begin{array}{l}\text { Hybrid methods } \\
\text { (Principal component } \\
\text { analysis + Auto } \\
\text { regression) }\end{array}$ & N/A & $\begin{array}{l}\text { Principal component analysis was } \\
\text { used to reduce data } \\
\text { dimensionality; thereby retaining } \\
\text { only datasets that contain the } \\
\text { highest variability. The } \\
\text { harmonization of PCA and } \\
\text { autoregressive approaches } \\
\text { improved computational speed as } \\
\text { well as prediction accuracy. }\end{array}$ & N/A \\
\hline [89] & $\begin{array}{l}\text { K-means clustering } \\
\text { algorithm and } \\
\text { Discriminant analysis }\end{array}$ & $\begin{array}{c}\text { Residential } \\
\text { buildings }\end{array}$ & $\begin{array}{l}\text { 1) The combination of K-means } \\
\text { clustering and discriminant } \\
\text { analysis achieved a very } \\
\text { impressive } 97.9 \% \text { classification } \\
\text { accuracy. } \\
\text { 2) Occupant behaviors was } \\
\text { observed to greatly impact } \\
\text { building energy consumption }\end{array}$ & N/A \\
\hline
\end{tabular}


Appendix B

Table 1. Scope, data properties, algorithms and performance of the energy consumption prediction models

\begin{tabular}{|c|c|c|c|c|c|c|c|c|c|}
\hline Reference & Country & Building type & Scale & Prediction method & Energy type & Date source & $\begin{array}{l}\text { Date } \\
\text { size/Time } \\
\text { scale } \\
\end{array}$ & $\begin{array}{l}\text { Temporal } \\
\text { granularity }\end{array}$ & Performance metric \\
\hline [119] & China & Office & Single & $\begin{array}{l}\text { Multiple linear } \\
\text { regression }\end{array}$ & Cooling load & N/A & 173 & Annual & $\mathrm{R} 2$ \\
\hline [138] & Canada & Office & Singe & Physical & Lighting & Measured & 2 months & Daily & N/A \\
\hline [139] & Turkey & Residential & Single & Physical & $\begin{array}{l}\text { Heating natural } \\
\text { gas consumption }\end{array}$ & BOTAS database & 2 years & Annual & N/A \\
\hline [140] & Greece & N/A & N/A & Physical & $\begin{array}{l}\text { Heating oil and } \\
\text { electricity } \\
\text { consumption }\end{array}$ & Simulated & 1 year & Annual & N/A \\
\hline [141] & Canada & Office & Single & ANN & Electricity & Simulated & & $\begin{array}{l}\text { Hourly } \\
\end{array}$ & CV 0.25-0.46 \\
\hline [142] & Italy & School & 138 & Statistical & Heating load & Measured/database & 6 months & Seasonal/monthly & Deviation $95 \%$ \\
\hline [67] & China & Office & Single & Hybrid (Physical+ GA) & $\begin{array}{l}\text { Cooling/heating } \\
\text { load }\end{array}$ & Survey/database & 2 weeks & Weekly & Relative error $8 \%$ \\
\hline \multirow{2}{*}{ [143] } & \multirow{2}{*}{ USA } & \multirow{2}{*}{ Hotel } & \multirow{2}{*}{ Single } & \multirow{2}{*}{ ANN } & \multirow{2}{*}{ Equipment load } & \multirow{2}{*}{ Measured } & \multirow{2}{*}{3 weeks } & \multirow{2}{*}{ Hourly } & Case1 R 0.912-0.957 \\
\hline & & & & & & & & & Case2 R 0.822-0.917 \\
\hline \multirow{2}{*}{ [144] } & \multirow{2}{*}{ Brazil } & \multirow{2}{*}{ School } & \multirow{2}{*}{ Single } & Physical & \multirow{2}{*}{$\begin{array}{l}\text { Total energy } \\
\text { consumption }\end{array}$} & \multirow{2}{*}{ Measured } & \multirow{2}{*}{4 months } & \multirow{2}{*}{ Daily } & Relative error $13 \%$ \\
\hline & & & & ANN & & & & & Relative error $10 \%$ \\
\hline [145] & USA & School & Over 100 & ANN & Steam load & School department & 3 years & Daily & N/A \\
\hline [146] & Poland & Hospital & 2 & Statistical & Heating load & Measured & 4 years & Monthly & N/A \\
\hline [118] & Belgium & Residential & Single & Physical & Heating load & Measured & 30 years & Annual & N/A \\
\hline [68] & China & Building sector & National & $\begin{array}{l}\text { Hybrid (GM+ Radial } \\
\text { basis NN) }\end{array}$ & $\begin{array}{l}\text { Total energy } \\
\text { consumption }\end{array}$ & $\begin{array}{l}\text { China Statistical } \\
\text { Yearbook from } \\
2001 \text { to } 2008\end{array}$ & 7 years & Annual & Relative error $0.906 \%$ \\
\hline [147] & China & Residential & City & ANN & $\begin{array}{l}\text { Total energy } \\
\text { consumption }\end{array}$ & Database & 8 years & Annual & Relative error 3\% \\
\hline [148] & UK & Residential & National & Statistical & $\begin{array}{l}\text { Total energy } \\
\text { consumption }\end{array}$ & $\begin{array}{l}\text { The household } \\
\text { employment status } \\
\text { data }\end{array}$ & N/A & Annual & MAE $9.4 \%$ \\
\hline [149] & China & N/A & N/A & ANN & $\begin{array}{l}\begin{array}{l}\text { Equipment } \\
\text { electricity load }\end{array} \\
\end{array}$ & Measured & 1 year & Monthly & N/A \\
\hline [150] & USA & School & Single & ANN & Electricity & Measured & 20 days & Hourly & $\begin{array}{l}\text { MAE 33.4 MAPE 5\% } \\
\text { standard deviation } 34.9\end{array}$ \\
\hline [151] & USA & Residential & 3 & $\begin{array}{l}\text { Linear } \\
\text { regression/SVM/Least } \\
\text { squares-SVM }\end{array}$ & Electricity & $\begin{array}{l}\text { Tennessee Valley } \\
\text { Authority }\end{array}$ & 1 year & Hourly & N/A \\
\hline [152] & USA & School & Single & Gaussian process & $\begin{array}{l}\text { Chilled water and } \\
\text { steam use }\end{array}$ & Measured & 9 days & Hourly & R2 0.82-0.9 \\
\hline [69] & South Korea & Government & 175 & $\begin{array}{l}\text { Hybrid (RReliefF+ } \\
\text { SVM) }\end{array}$ & Electricity & $\begin{array}{l}2003 \text { Commercial } \\
\text { Buildings Energy } \\
\text { Consumption }\end{array}$ & 1 year & Hourly & $\begin{array}{l}\text { N/A } \\
\text { MAE 12.3333, RMSE } \\
\text { 16.74, MAPE } 34.88\end{array}$ \\
\hline
\end{tabular}


Survey (CBECS)

database

\begin{tabular}{|c|c|c|c|c|c|c|c|c|c|}
\hline & & & & & & & \multirow{2}{*}{ Relative error $12 \%$} \\
\hline [153] & USA & Hospital & Single & Physical EnergyPlus & Electricity & Measured & N/A & N/A & \\
\hline$[154]$ & $\begin{array}{l}\text { Brazil/The } \\
\text { Netherlands }\end{array}$ & Commercial & Single & ANN & N/A & Simulated & N/A & N/A & $\begin{array}{l}\text { R2 } 0.99 \text { Mean error } 0.7 \\
\text { standard deviation } 5.1\end{array}$ \\
\hline [155] & The Netherlands & Residential & National & Physical (energy label) & Total energy & AgentschapNL & 1 year & yearly & $\mathrm{N} / \mathrm{A}$ \\
\hline [156] & Turkey & Residential & National & Physical & Heating load & Database & N/A & Yearly & N/A \\
\hline [157] & Hungary & Residential & National & Physical (degree day) & Heating load & $\begin{array}{l}\text { Agro- } \\
\text { Meteorological } \\
\text { Observatory } \\
\text { Debrecen }\end{array}$ & 20 years & yearly & N/A \\
\hline [136] & USA & School & 225 & Statistical & N/A & $\begin{array}{l}\text { Web-based energy } \\
\text { information system }\end{array}$ & 2 years & Monthly & R2 2\% \\
\hline$[158]$ & $\begin{array}{l}\text { Finland/China/U } \\
\text { SA }\end{array}$ & Swim center & Single & Physical & N/A & Measured & 13 months & Daily & $\mathrm{R} 2>0.9$ \\
\hline$[159]$ & China & Public & Single & Artificial fish swarm & N/A & N/A & 131 days & & Relative error $1 \%$ \\
\hline$[160]$ & USA & School & Single & Physical eQuest & Heating load & TMY & 2 years & Monthly & RMSE $1.1 \%$ \\
\hline$[125]$ & The Netherlonds & Office & Single & Conditional restricted & Electricity & Mercured & 7 weelse & Hourly & $\begin{array}{l}\text { Lighting RMSE 1.11 R } \\
0.96\end{array}$ \\
\hline [125] & The Netherlands & Office & Single & Boltzmann machine & Electricity & Measured & 7 weeks & Hourly & $\begin{array}{l}\text { Total energy RMSE } \\
1.76 \quad \text { R } 0.98 \\
\end{array}$ \\
\hline [161] & USA & Residential & 1355 & Physical & Total energy & Survey & 1 year & Hourly & $\begin{array}{l}\text { Natural gas R2 } 0.31 \\
\text { Electricity R2 } 0.65\end{array}$ \\
\hline [162] & China & Commercial & Single & Physical DeST & $\begin{array}{l}\text { Cooling/heating } \\
\text { load }\end{array}$ & Database/TMY & 1 year & Hourly & N/A \\
\hline & & & & & Electricity & & & & MAPE $2.32 \%$ \\
\hline [163] & China & Mixed function & Single & Ensemble model & $\begin{array}{l}\text { Peak power } \\
\text { demand }\end{array}$ & $\begin{array}{l}\text { Measured/Hong } \\
\text { Kong Observatory }\end{array}$ & 1 year & Daily & MAPE $2.85 \%$ \\
\hline [164] & $\begin{array}{l}\text { United Arab } \\
\text { Emirates }\end{array}$ & N/A & City & Multiple regression & Peak load & Database & 1 year & Hourly & RMSE $1.54 \%$ \\
\hline [135] & China & Residential & City & $\begin{array}{l}\text { GM }(1,1) \text { model } \\
\text { DGM }(2,1) \text { model } \\
\text { Regression analysis } \\
\text { polynomial model } \\
\text { polynomial regression } \\
\text { ANN }\end{array}$ & Total energy & $\begin{array}{l}\text { The Statistical } \\
\text { Yearbook of } \\
\text { Chongqing } \\
\text { Questionnaire } \\
\text { Survey }\end{array}$ & 12 years & Annual & $\begin{array}{l}\text { MAPE } 0.47 \% \\
0.85 \% \\
0.44 \% \\
0.65 \% \\
0.91 \% \\
0.09 \% \\
\end{array}$ \\
\hline$[165]$ & Spain & Bioclimatic & Single & ANN & Electricity & Measured & 17months & Hourly & Mean error $11.48 \%$ \\
\hline [127] & USA & Office & & $\begin{array}{l}\text { Multiple linear } \\
\text { regressions }\end{array}$ & Total energy & Simulated & N/A & Annual & R2 0.94-0.95 \\
\hline$[128]$ & Turkey & Residential & 148 & ANN & Heating load & Simulated & & Annual & R2 $97.7 \%$ \\
\hline [133] & China & Building sector & National & $\begin{array}{l}\text { Hybrid } \\
(\mathrm{PSO}+\mathrm{RBF}+\mathrm{NN})\end{array}$ & Electricity & $\begin{array}{l}\text { Chinese society } \\
\text { database }\end{array}$ & 2 years & Monthly & MSRE $0.139 \%$ \\
\hline$[166]$ & China & School & & Hybrid (GA+BPNN) & N/A & Simulated & 3 months & Daily & $\begin{array}{l}\text { Average relative error } \\
1.37 \%\end{array}$ \\
\hline [167] & China & Experiment & Single & $\begin{array}{l}\text { Physical Conditional } \\
\text { transfer function model } \\
\text { Physical Combined }\end{array}$ & Total energy & $\begin{array}{l}\text { EnergyPlus Weather } \\
\text { Data }\end{array}$ & 1 year & hourly & $\begin{array}{l}\text { Relative error-1.3\%- } \\
6.3 \% \\
4.4 \%-8.7 \%\end{array}$ \\
\hline
\end{tabular}




\begin{tabular}{|c|c|c|c|c|c|c|c|c|c|}
\hline & & & & $\begin{array}{l}\text { heat and moisture } \\
\text { transfer model }\end{array}$ & & & & & \\
\hline & & & & $\begin{array}{l}\text { Physical Effective } \\
\text { moisture penetration } \\
\text { depth model }\end{array}$ & & & & & N/A \\
\hline \multirow{2}{*}{ [168] } & \multirow{2}{*}{ USA } & \multirow{2}{*}{ School } & \multirow{2}{*}{ Single } & $\begin{array}{l}\text { Hybrid (Bayesian } \\
\text { inference +LRM) } \\
\text { +Calibration }\end{array}$ & \multirow{2}{*}{ Total energy } & \multirow{2}{*}{ Measured } & \multirow{2}{*}{35 months } & \multirow{2}{*}{ Daily } & $\begin{array}{l}\text { NMBE } 0.01 \text { CVRMSE } \\
0.12\end{array}$ \\
\hline & & & & $\begin{array}{l}\text { Hybrid (Bayesian } \\
\text { inference +LRM) }\end{array}$ & & & & & $\begin{array}{l}\text { NMBE 0.18 CVRMSE } \\
0.45\end{array}$ \\
\hline [169] & USA & Office & & Multi linear regression & $\begin{array}{l}\text { Heating/cooling } \\
\text { load }\end{array}$ & Simulated & & Annual & Maximum error 5\% \\
\hline$[170]$ & France & Office & Single & SVM & Heating load & $\begin{array}{l}\text { Data acquisition } \\
\text { system }\end{array}$ & 7 months & Hourly & $\begin{array}{l}\text { R2 0.69-0.88 RMSE 50- } \\
140\end{array}$ \\
\hline [171] & Canada & Institutional & Single & Case-based reasoning & Electricity & Measured & 4 months & Hourly & $\begin{array}{l}\text { Relative error } 12.79 \%- \\
44.42 \%\end{array}$ \\
\hline [70] & South Korea & Business & Single & $\begin{array}{l}\text { Hybrid (Least-squares } \\
\text { SVM+ direct search } \\
\text { optimization) }\end{array}$ & N/A & $\begin{array}{l}\text { Telecommunication } \\
\text { Corporation's } \\
\text { building energy } \\
\text { management system } \\
\text { (BEMS) }\end{array}$ & 4 weekdays & Hourly & $\begin{array}{l}\text { Average RMSE 7.5994- } \\
11.1758\end{array}$ \\
\hline \multirow{4}{*}{ [71] } & \multirow{4}{*}{ USA } & \multirow{4}{*}{ School } & \multirow{4}{*}{ Single } & $\begin{array}{l}\text { Change-point } \\
\text { regression }\end{array}$ & \multirow{4}{*}{$\begin{array}{l}\text { HVAC hot water } \\
\text { energy }\end{array}$} & \multirow{4}{*}{$\begin{array}{l}\text { Energy } \\
\text { Management and } \\
\text { Control System } \\
\text { (EMCS). }\end{array}$} & \multirow{4}{*}{55 days } & \multirow{4}{*}{ Daily/ Hourly } & $\begin{array}{l}\text { R2 } 0.550 .88 \text { CV-RMSE } \\
14.96 \% 28.32 \% \text { NMBE } \\
1.79 \% 5.31\end{array}$ \\
\hline & & & & $\begin{array}{l}\text { Gaussian process } \\
\text { regression }\end{array}$ & & & & & $\begin{array}{l}0.620 .87 ; 13.90 \% \\
28.66 \% ; 0.29 \% 2.8 \% \\
\end{array}$ \\
\hline & & & & $\begin{array}{l}\text { Gaussian Mixture } \\
\text { Regression }\end{array}$ & & & & & $\begin{array}{l}0.580 .88 ; 14.60 \% \\
27.90 \% ; 1.87 \% 4.30 \% \\
\end{array}$ \\
\hline & & & & ANN & & & & & $\begin{array}{l}0.540 .86 ; 15.47 \% \\
32.35 \% ; 2.76 \% 4.8 \%\end{array}$ \\
\hline \multirow{2}{*}{ [172] } & \multirow{2}{*}{$\begin{array}{l}\text { Portugal/Mexico } \\
\text { /Slovenia }\end{array}$} & \multirow{2}{*}{ Residential } & \multirow{2}{*}{768} & \multirow{2}{*}{ Genetic programming } & Heating load & \multirow{2}{*}{ N/A } & \multirow{2}{*}{ N/A } & \multirow{2}{*}{ N/A } & MAE 1.02-1.31 \\
\hline & & & & & Cooling load & & & & MAE $1.47-5.55$ \\
\hline [72] & China & N/A & N/A & Hybrid (PSO + ANN) & Electricity & $\begin{array}{l}\text { the Great Building } \\
\text { Energy Predictor } \\
\text { Shootout }\end{array}$ & 5 months & Hourly & $\begin{array}{l}\text { CV 0.0259-0.0268 } \\
\text { MAPE } 0.0169-0.0177\end{array}$ \\
\hline$[173]$ & China & N/A & N/A & SVM & N/A & Measured & 1 month & Hourly & $\begin{array}{l}\text { MSE 0.0186-0.091 R2 } \\
82.17-84.27\end{array}$ \\
\hline$[174]$ & South Korea & Hotel & Single & ANN & Cooling load & N/A & N/A & N/A & CVRMSE $21.32 \%$ \\
\hline [175] & USA & Residential & 173 & $\begin{array}{l}\text { Multivariate } \\
\text { Autoregressive (M- } \\
\text { AR) }\end{array}$ & Electricity & Pecan Street data & 3 months & Hourly & $\begin{array}{l}\text { MAE 0.8287-1.1196 } \\
\text { RMSE 1.1928-1.3549 } \\
\text { NRMSE 11.88\%- } \\
14.06 \%\end{array}$ \\
\hline [176] & The Netherlands & Office & Single & SVM & Lighting & Measured & 5days & Daily & $\begin{array}{l}\text { Relative error less than } \\
0.05\end{array}$ \\
\hline$[177]$ & China & Hotel & Single & Statistical STIRPAT & $\begin{array}{l}\text { Energy use } \\
\text { intensity }\end{array}$ & Hotel system & 1 year & Monthly & Average error $1.415 \%$ \\
\hline [129] & USA & Office & Single & SVM & Lighting & Database & 60 days & Daily & CV 6.83\% \\
\hline
\end{tabular}




\begin{tabular}{|c|c|c|c|c|c|c|c|c|c|}
\hline [73] & South Korea & Commercial & 3 & $\begin{array}{l}\text { Hybrid (Physical+ } \\
\text { Bayesian calibration) }\end{array}$ & N/A & Database & N/A & Monthly & Error $1.52 \%$ \\
\hline [178] & $\begin{array}{l}\text { France/SPAIN/ } \\
\text { UK }\end{array}$ & Experiment & Single & SVM & Electricity & Measured & I year & Monthly & $\begin{array}{l}\text { NRMSE } 14.88 \%- \\
15.75 \%\end{array}$ \\
\hline [120] & South Korea & N/A & N/A & ANN & $\begin{array}{l}\text { Heating load } \\
\text { Cooling load }\end{array}$ & Reference & 768 datasets & N/A & $\begin{array}{l}\text { RMS } 0.19 \\
\text { RMS } 1.42\end{array}$ \\
\hline [179] & Malaysia/Iran & Residential & N/A & $\begin{array}{l}\text { Extreme learning } \\
\text { machine }\end{array}$ & $\begin{array}{l}\text { Heating and } \\
\text { cooling load }\end{array}$ & Simulated & N/A & Annual & R2 0.9958-0.998777 \\
\hline [74] & The Netherlands & $\begin{array}{l}\text { Residential and } \\
\text { commercial }\end{array}$ & 5 & $\begin{array}{l}\text { Hybrid (reinforcement } \\
\text { learning + Deep belief } \\
\text { network) }\end{array}$ & $\begin{array}{l}\text { Total energy } \\
\text { consumption }\end{array}$ & $\begin{array}{l}\text { Baltimore Gas and } \\
\text { Electric Company }\end{array}$ & $\begin{array}{l}7 \text { years } \\
25 \text { days } \\
\end{array}$ & N/A & RMSE $96.5 \%$ \\
\hline [63] & The Netherlands & Residential & Single & $\begin{array}{l}\text { Conditional Restricted } \\
\text { Boltzmann } \\
\text { Machined/Factored } \\
\text { Conditional Restricted } \\
\text { Boltzmann Machine } \\
\end{array}$ & Electricity & $\begin{array}{l}\text { Individual } \\
\text { residential customer }\end{array}$ & 4 years & $15 \mathrm{~min} /$ hour/daily & N/A \\
\hline \multirow{3}{*}[180]{} & \multirow{3}{*}{ China } & \multirow{3}{*}{ Office } & \multirow{3}{*}{ Single } & ANN & \multirow{3}{*}{ N/A } & \multirow{3}{*}{ Database } & \multirow{3}{*}{2 months } & \multirow{3}{*}{ Hourly } & $\begin{array}{l}\text { RMSE, MSE, MAPE } \\
0.0681,0.0045,0.1710 \\
\end{array}$ \\
\hline & & & & SVM & & & & & 0.07140 .00510 .2030 \\
\hline & & & & ARIMA & & & & & 0.07110 .00510 .2071 \\
\hline [75] & China & Office & Single & Hybrid (GA+ SVM) & Electricity & Simulated & N/A & Annual & R2 0.987 \\
\hline$[181]$ & China & Laboratory & Single & $\begin{array}{l}\text { Markov decision } \\
\text { processes }\end{array}$ & Electricity & Measured & 4 days & Hourly & Average error $52.4 \%$ \\
\hline [76] & China & $\begin{array}{l}\text { Library/office/re } \\
\text { sidential }\end{array}$ & 3 & $\begin{array}{l}\text { Hybrid (polynomial- } \\
\text { Fourier series model) }\end{array}$ & Electricity & Measured & 4 years & Monthly & $\begin{array}{l}\text { Variation of roughly } 5 \% \\
\text { to } 17 \% \text {. }\end{array}$ \\
\hline \multirow{3}{*}[182]{} & \multirow{3}{*}{ South Korea } & \multirow{3}{*}{ Office } & \multirow{3}{*}{ Single } & ANN & \multirow{3}{*}{$\begin{array}{l}\text { Chiller electricity } \\
\text { demand }\end{array}$} & \multirow{3}{*}{ Measured } & \multirow{3}{*}{8 days } & \multirow{3}{*}{ Daily } & $\begin{array}{l}\text { RMSE, CVRMSE, } \\
\text { MBE 9.6, } 10.5 \%, 2.2 \%\end{array}$ \\
\hline & & & & SVM & & & & & $10.2,11.2 \%, 0.8 \%$ \\
\hline & & & & Gaussian Process & & & & & $10.0,11.0 \%, 1.4 \%$ \\
\hline [183] & USA & N/A & N/A & Statistical & N/A & $\begin{array}{l}\text { the National } \\
\text { Institute of } \\
\text { Standards/ } \\
\text { Technology (NIST) } \\
\text { Net-Zero Energy } \\
\text { Residential Test } \\
\text { Facility (NZERTF) } \\
\end{array}$ & 1 year & N/A & Relative error $3.0 \%$ \\
\hline [134] & USA & Residential & 426305 & Statistical & $\begin{array}{l}\text { natural gas } \\
\text { /electricity }\end{array}$ & $\begin{array}{l}\text { Database/weather } \\
\text { station }\end{array}$ & 3 years & Monthly & N/A \\
\hline [184] & China & Office & Single & Echo state networks & N/A & Measured & 4 years & Hourly & $\begin{array}{l}\text { CVRMSEs 3.72\%- } \\
4.97 \%\end{array}$ \\
\hline [185] & China/USA & Office & Single & Statistical & Total energy & Measured & 1 year & Hourly & CVRMSE $15 \%$ \\
\hline [186] & USA & Residential & Single & ANN & $\begin{array}{l}\text { House and heat } \\
\text { pump energy } \\
\text { consumption }\end{array}$ & Measured & 72 days & Daily & $\begin{array}{l}\text { Coefficients of } \\
\text { determination within } \\
0.87-0.91\end{array}$ \\
\hline [187] & Italy & Office & Single & ANN & $\begin{array}{l}\text { Heating load } \\
\text { Cooling load }\end{array}$ & Simulated & N/A & N/A & $\begin{array}{l}\text { Relative errors } 8.0 \% \\
8.1 \%\end{array}$ \\
\hline [188] & USA & Commercial & Single & System Identification & $\mathrm{N} / \mathrm{A}$ & Measured/local & 50 months & daily & R2 $74.77 \%$ \\
\hline
\end{tabular}




\begin{tabular}{|c|c|c|c|c|c|c|c|c|c|}
\hline & & & & Process & & airport & & & \\
\hline [77] & South Korea & School & 7 & $\begin{array}{l}\text { Hybrid(k- } \\
\text { means+ANN+k- } \\
\text { nearest) }\end{array}$ & Total energy & Survey/measured & 145 days & Hourly & CV-RMSE $7.5 \%-20 \%$ \\
\hline [189] & Italy & Residential & 363 & Multiple regression & Heating load & Survey & 4 years & Annual & $\begin{array}{l}\text { Relative error } \\
\text { apartments } 12.46 \% / \\
\text { detached houses } 9.71 \%\end{array}$ \\
\hline [190] & Egypt & $\begin{array}{l}\text { Office } \\
\text { Academic }\end{array}$ & 2 & Multiple Regression & Electricity & Database & 5 years & Hourly & $\begin{array}{l}\text { NRMSE } 12 \% \\
13 \%\end{array}$ \\
\hline [78] & Australia & Residential & Single & Hybrid (ANN+ DT) & N/A & Simulated & 4435 datasets & Annual & MSE 0.6 \\
\hline [191] & Singapore & School & Single & Physical EnergyPlus & $\begin{array}{l}\text { Plug and lighting } \\
\text { load }\end{array}$ & Measured & 180 days & hourly & CV-RMSE 6.9-7.7\% \\
\hline \multirow[t]{2}{*}{ [79] } & \multirow[t]{2}{*}{ South Korea } & \multirow[t]{2}{*}{ Office } & \multirow[t]{2}{*}{ Single } & \multirow{2}{*}{$\begin{array}{l}\text { Hybrid (regression+ } \\
\text { clustering) }\end{array}$} & electricity & \multirow{2}{*}{$\begin{array}{l}\text { Meteorological } \\
\text { Agency }\end{array}$} & \multirow[t]{2}{*}{1 year } & \multirow[t]{2}{*}{ Daily } & $\begin{array}{l}\text { R2, MBE, CV 0.8623, } \\
3.96 \%, 8.65 \%\end{array}$ \\
\hline & & & & & gas & & & & $0.9766,-0.67 \%, 17.62 \%$ \\
\hline \multirow[b]{2}{*}{ [46] } & \multirow[b]{2}{*}{ UK } & \multirow[b]{2}{*}{ Hotel } & \multirow[b]{2}{*}{ Single } & ANN & \multirow[b]{2}{*}{$\begin{array}{l}\text { HVAC energy } \\
\text { consumption }\end{array}$} & \multirow{2}{*}{$\begin{array}{l}\text { Building energy } \\
\text { management } \\
\text { system/reservation } \\
\text { system/a nearby } \\
\text { weather station }\end{array}$} & \multirow[b]{2}{*}{$\begin{array}{l}1 \text { year } 106 \\
\text { days }\end{array}$} & \multirow[b]{2}{*}{ Hourly } & RMSE 4.97 \\
\hline & & & & Random Tree & & & & & Relative error $6.10 \%$ \\
\hline [80] & China & Residential & city & $\begin{array}{l}\text { Hybrid (the k-modes } \\
\text { clustering } \\
\text { +demographic-based } \\
\text { probability neural } \\
\text { networks) }\end{array}$ & N/A & $\begin{array}{l}\text { American time use } \\
\text { survey/Residential } \\
\text { energy consumption } \\
\text { survey/weather } \\
\text { station }\end{array}$ & 1 year & Monthly & N/A \\
\hline \multirow{2}{*}{ [81] } & \multirow{2}{*}{ Malaysia/Iran } & \multirow{2}{*}{ Residential } & \multirow{2}{*}{ Single } & \multirow{2}{*}{$\begin{array}{l}\text { Hybrid (Adaptive } \\
\text { Neuro-Fuzzy Inference } \\
\text { System+ clustering) }\end{array}$} & Heating load & \multirow{2}{*}{$\begin{array}{l}\text { Energy Efficiency } \\
\text { dataset }\end{array}$} & \multirow{2}{*}{768 datasets } & \multirow{2}{*}{ N/A } & MAE 0.16 \\
\hline & & & & & Cooling load & & & & 0.52 \\
\hline$[82]$ & China & Retail & Single & $\begin{array}{l}\text { Hybrid (Stacked } \\
\text { autoencoders }+ \text { the } \\
\text { extreme learning } \\
\text { machine) }\end{array}$ & N/A & Website database & $\begin{array}{l}34939 \\
\text { datasets }\end{array}$ & 30min/hourly & $\begin{array}{l}\text { MAE, MRE, RMSE } \\
33.7168,3.642 \% \text {, } \\
59.1812\end{array}$ \\
\hline [38] & USA & Commercial & 73388 & $\begin{array}{l}\text { Gradient boosting } \\
\text { regression }\end{array}$ & $\begin{array}{l}\text { Fuel, or the } \\
\text { combination of } \\
\text { electricity, natural } \\
\text { gas, and fuel oil, } \\
\text { consumption }\end{array}$ & $\begin{array}{l}\text { the Commercial } \\
\text { Buildings Energy } \\
\text { Consumption } \\
\text { Survey } \\
\text { (CBECS)/The New } \\
\text { York City } \\
\text { Benchmarking Law. }\end{array}$ & $\begin{array}{l}6720 / 13,223 \\
\text { datasets }\end{array}$ & Annual & R2 0.82 \\
\hline \multirow{4}{*}{ [192] } & \multirow{4}{*}{ Italy } & & & Linear regression & & & & & R2 $84.7 \% / 74.4 \%$ \\
\hline & & & & SVM & air-conditioning & Pecan Street Inc.'s & & & $85.6 \% / 79.7 \%$ \\
\hline & & Residential & Single & Random Tree & (AC) load & Data port & 1 year & Hourly/daily & $87.3 \% / 83.2 \%$ \\
\hline & & & & MLP Neural Networks & & & & & $87.3 \% / 80.6 \%$ \\
\hline [193] & France/Palestine & Residential & 84 & ANN & $\begin{array}{l}\text { Heating } \\
\text { consumption }\end{array}$ & $\begin{array}{l}\text { Lille Metropole } \\
\text { Habitat }\end{array}$ & 4 years & Annual & R2 0.58-0.74 \\
\hline [194] & USA & Office & N/A & $\begin{array}{l}\text { Linear Regression } \\
\text { Lasso Regression }\end{array}$ & $\begin{array}{l}\text { Energy Use } \\
\text { Intensity, HVAC, }\end{array}$ & $\begin{array}{l}\text { Commercial } \\
\text { Building Energy }\end{array}$ & 1 year & N/A & N/A \\
\hline
\end{tabular}




\begin{tabular}{|c|c|c|c|c|c|c|c|c|c|}
\hline & & & & $\begin{array}{l}\text { Support Vector } \\
\text { Machine Artificial } \\
\text { Neural Network } \\
\text { Gradient Boosting } \\
\text { Random Forest }\end{array}$ & $\begin{array}{l}\text { plug and lighting } \\
\text { load }\end{array}$ & $\begin{array}{l}\text { Consumption } \\
\text { Survey (CBECS) } \\
2012 \text { microdata }\end{array}$ & & & \\
\hline [195] & USA & Office & 3 & ANN & N/A & $\begin{array}{l}\text { the local standards } \\
\text { and survey }\end{array}$ & simulated & N/A & r 0.9985-0.9995 \\
\hline [95] & South Korea & Commercial & Single & $\begin{array}{l}\text { Hybrid (Deep learning } \\
\text { +multi-decomposition) }\end{array}$ & Electrical & Measured & N/A & Daily & MAPE $0.71 \%-5.96 \%$ \\
\hline \multirow{2}{*}[122]{} & \multirow{2}{*}{ India } & \multirow{2}{*}{ N/A } & \multirow{2}{*}{$\mathrm{N} / \mathrm{A}$} & \multirow{2}{*}{$\begin{array}{l}\text { Extreme learning } \\
\text { machine }\end{array}$} & Heating load & \multirow{2}{*}{ Database } & \multirow{2}{*}{768 datasets } & \multirow{2}{*}{ N/A } & MAE 0.1433 \\
\hline & & & & & Cooling load & & & & 0.2548 \\
\hline [137] & China & Experience & Single & ANN & Lighting & Measured & 1 Month & Hourly & $\begin{array}{l}\text { MAE 0.0249 RMSE } \\
5.6778,\end{array}$ \\
\hline [196] & China & Public & Single & ANN & Electricity & Measured & 42 days & Hourly & Relative error 1.4 \\
\hline [83] & China & Commercial & Single & $\begin{array}{l}\text { Hybrid (Random } \\
\text { Forest+ Auto } \\
\text { Regressive Moving } \\
\text { Average) }\end{array}$ & & Measured & 23 days & Hourly & \\
\hline [197] & UK & School & Single & Bayesian networks & Electricity & Measured & 11 days & N/A & MEA 30.73-35.898 \\
\hline [93] & Germany & Residential & N/A & $\begin{array}{l}\text { Hybrid (D-vine copula } \\
\text { method+ quantile } \\
\text { regression) }\end{array}$ & Heating load & $\begin{array}{l}\text { German EN-OP- } \\
\text { Institute }\end{array}$ & N/A & N/A & N/A \\
\hline [198] & India & Residential & City & Statistical & Electricity & Survey & 1 year & Yearly & $\begin{array}{l}\text { percentage deviation } \\
1.2 \%-5 \%, 7 \%-9 \% \\
\end{array}$ \\
\hline [199] & South Korea & N/A & N/A & $\begin{array}{l}\text { Recurrent Neural } \\
\text { Network }\end{array}$ & N/A & N/A & 3 months & Daily & RMSE 0.1335 \\
\hline [200] & USA & Community & 30000 & $\begin{array}{l}\text { Hybrid (CNNs+ } \\
\text { Random Forest } \\
\text { Regression) }\end{array}$ & $\begin{array}{l}\text { Total energy } \\
\text { consumption }\end{array}$ & $\begin{array}{l}\text { the Alachua County } \\
\text { Property Appraiser }\end{array}$ & 1 year & Yearly & R2 0.95 \\
\hline [201] & USA & School & Single & $\begin{array}{l}\text { Long Short-Term } \\
\text { Memory (LSTM) } \\
\text { neural networks }\end{array}$ & $\begin{array}{l}\text { HVAC energy } \\
\text { consumption }\end{array}$ & BAS system & 3 months & N/A & $\begin{array}{l}\text { CVRMSE LSTM } \\
11.17 \% \\
\text { AdaBoost } \\
22.63 \% \\
\text { SVM } \\
29.50 \% \\
\end{array}$ \\
\hline \multirow[b]{2}{*}{ [117] } & \multirow[b]{2}{*}{ Czech Republic } & \multirow[b]{2}{*}{ Experiment } & \multirow[b]{2}{*}{2} & Auto Regressive & \multirow[b]{2}{*}{ Heating load } & \multirow[b]{2}{*}{ Measured } & \multirow[b]{2}{*}{3 days } & \multirow[b]{2}{*}{ Daily } & Relative error $0.3-1.6$ \\
\hline & & & & $\begin{array}{l}\text { Particle swarm } \\
\text { algorithm }\end{array}$ & & & & & $0.1-1.1$ \\
\hline \multirow{2}{*}{ [202] } & \multirow{2}{*}{ Spain } & \multirow{2}{*}{ Hospital } & \multirow{2}{*}{ Single } & $\begin{array}{l}\text { Multilayer perceptron } \\
(\text { MLP) }\end{array}$ & \multirow{2}{*}{ Electrical } & \multirow{2}{*}{ Database } & \multirow{2}{*}{5 years } & \multirow{2}{*}{ Daily } & R2 0.6614-0.9015 \\
\hline & & & & $\begin{array}{l}\text { M5Rules algorithm } \\
\text { Tree ensemble learner }\end{array}$ & & & & & \begin{tabular}{|l|}
$0.6713-0.9930$ \\
$0.6529-0.9434$
\end{tabular} \\
\hline [85] & Canada & Residential & Single & $\begin{array}{l}\text { Hybrid (Ensemble- } \\
\text { based ANN framework } \\
\text { with minute-controlled } \\
\text { re-sampling technique } \\
\text { and robust integration) }\end{array}$ & Electrical & Database & $\begin{array}{l}2 \text { years } 9 \\
\text { months }\end{array}$ & Daily & $\begin{array}{l}\text { MAPE } 11.3952 \%- \\
15.9396 \%\end{array}$ \\
\hline
\end{tabular}




\begin{tabular}{|c|c|c|c|c|c|c|c|c|c|}
\hline \multirow{2}{*}{ [86] } & \multirow{2}{*}{ China } & Retail & \multirow{2}{*}{ Single } & \multirow{2}{*}{$\begin{array}{l}\text { Hybrid (the contrastive } \\
\text { divergence algorithm } \\
\text { +deep belief network) }\end{array}$} & \multirow{2}{*}{ N/A } & \multirow{2}{*}{ Measured } & \multirow{2}{*}{$\begin{array}{l}1 \text { year } \\
2 \text { years } 4 \\
\text { months }\end{array}$} & \multirow{2}{*}{ Hourly } & \multirow{2}{*}{$\begin{array}{l}\text { MRE, R, R2 5.03\%, } \\
0.94,0.89 \\
11.62 \%, 0.97,0.93\end{array}$} \\
\hline & & Office & & & & & & & \\
\hline [203] & USA & Residential & N/A & $\begin{array}{l}\text { Multi-objective } \\
\text { genetic } \\
\text { programming }\end{array}$ & $\begin{array}{l}\text { Heating/cooling } \\
\text { load }\end{array}$ & Simulated & 768 datasets & N/A & R 0.8 \\
\hline \multirow{3}{*}{ [204] } & \multirow{3}{*}{$\begin{array}{l}\text { Pakistan/South } \\
\text { Korea }\end{array}$} & \multirow{3}{*}{ Residential } & \multirow{3}{*}{ N/A } & \multirow{3}{*}{ Hidden Markov Model } & \multirow{3}{*}{ N/A } & \multirow{3}{*}{ Measured } & \multirow{3}{*}{1 years } & Hourly & RMSE 2.62 \\
\hline & & & & & & & & Daily & 1.54 \\
\hline & & & & & & & & Weekly & 0.46 \\
\hline \multirow{6}{*}[130]{} & \multirow{6}{*}{ China } & \multirow{6}{*}{ Office } & \multirow{6}{*}{ Single } & Tree bagger & \multirow{6}{*}{$\begin{array}{l}\text { heating and } \\
\text { cooling load }\end{array}$} & \multirow{6}{*}{ Measured } & \multirow{6}{*}{1 month } & \multirow{6}{*}{ Weekly } & MAPE $3.544 \%$ \\
\hline & & & & $\begin{array}{l}\text { Gaussian process } \\
\text { regression }\end{array}$ & & & & & $0.405 \%$ \\
\hline & & & & $\begin{array}{l}\text { Multiple linear } \\
\text { regression }\end{array}$ & & & & & $1.703 \%$ \\
\hline & & & & Bagged tree & & & & & $1.928 \%$ \\
\hline & & & & Boosted tree & & & & & $2.592 \%$ \\
\hline & & & & Neural network & & & & & $13.503 \%$ \\
\hline [87] & Spain & Healthcare & 2 & $\begin{array}{l}\text { Hybrid (PCA+ } \\
\text { Autoregressive } \\
\text { orthonormal partial } \\
\text { least squares }\end{array}$ & Electrical & Database & 8 years & Daily & $\begin{array}{l}\text { MAPE 5.06\%- } \\
5.96 \%\end{array}$ \\
\hline [205] & South Korea & South Korea & N/A & $\begin{array}{l}\text { Lambda-based data } \\
\text { processing }\end{array}$ & Electricity & Database & 2 years & Hourly & N/A \\
\hline \multirow{2}{*}{ [206] } & \multirow{2}{*}{ USA } & \multirow{2}{*}{ School } & \multirow{2}{*}{ N/A } & \multirow{2}{*}{$\begin{array}{l}\text { Gaussian Process } \\
\text { Regression }\end{array}$} & \multirow{2}{*}{ Total energy } & & & Weekly & $94.38 \%$ \\
\hline & & & & & & Database & N/A & Hourly & $99.26 \%$ \\
\hline [88] & Pakistan & Residential & N/A & Hybrid (SVM+ Jaya & Flectricity & Database & 1 year & Daily & MAPE 5.521 \\
\hline$[88]$ & Pak1stan & Residential & N/A & algorithm) & Electricity & Database & 9 days & Hourly & 3.769 \\
\hline [89] & China & Residential & 40 & $\begin{array}{l}\text { Hybrid (K-means } \\
\text { clustering+ } \\
\text { discriminant analysis) }\end{array}$ & Heating load & Measured & 1 year & Daily & $\begin{array}{l}\text { MBE } 6.5 \% \text { CVRMSE } \\
6.59 \%\end{array}$ \\
\hline [90] & South Korea & Residential & 4 & $\begin{array}{l}\text { Hybrid (PSO-based } \\
\text { neural networks) }\end{array}$ & Electricity & Measured & 1 year & Hourly & $99.45 \%$ \\
\hline & & & & Binary Decision Tree & & & & & $\begin{array}{l}\text { MAPE, CV } 0.601 \% \text {, } \\
0.873 \%\end{array}$ \\
\hline & & & & $\begin{array}{l}\text { Compact Regression } \\
\text { Gaussian Process }\end{array}$ & & Datahase & 2 vears & Monthly & $1.058 \%, 1.402 \%$ \\
\hline [37] & China & N/A & City & $\begin{array}{l}\text { Stepwise Gaussian } \\
\text { Processes Regression }\end{array}$ & Total energy & Database & 2 years & Monthly & $1.529 \%, 1.983 \%$ \\
\hline & & & & $\begin{array}{l}\text { Generalized Linear } \\
\text { Regression }\end{array}$ & & & & & $1.784 \%, 2.333 \%$ \\
\hline$[207]$ & China & Office & 2 & $\begin{array}{l}\text { Multiple regression } \\
\text { model }\end{array}$ & N/A & Database & 1 year & N/A & R 1.11-1.24 \\
\hline$[208]$ & UK & Residential & 322 & Regression & Heating load & Survey & N/A & Yearly & R2 60.6 \\
\hline$[91]$ & China & Library & Single & $\begin{array}{l}\text { Hybrid (teaching } \\
\text { learning-based }\end{array}$ & Electricity & Measured & 1 month & Monthly & CV 0.0733 \\
\hline
\end{tabular}




\begin{tabular}{|c|c|c|c|c|c|c|c|c|c|}
\hline \multirow{2}{*}{ [121] } & \multirow{2}{*}{ India } & \multirow{2}{*}{ Residential } & \multirow{2}{*}{ N/A } & \multirow{2}{*}{$\begin{array}{l}\text { Online sequential } \\
\text { extreme learning } \\
\text { machine }\end{array}$} & Heating load & \multirow{2}{*}{ N/A } & \multirow{2}{*}{768 datasets } & \multirow{2}{*}{ N/A } & $\begin{array}{l}\text { MAE, RMSE 0.3229, } \\
0.7772\end{array}$ \\
\hline & & & & & Cooling load & & & & $0.2746,0.3243$ \\
\hline [209] & China & Building sector & National & SVM & N/A & $\begin{array}{l}\text { Chinese National } \\
\text { Bureau of Statistics }\end{array}$ & 14 years & Yearly & R2 0.991 \\
\hline [92] & China & Commercial & Single & $\begin{array}{l}\text { Hybrid (Enhanced } \\
\text { particle swarm } \\
\text { optimization + ANN) }\end{array}$ & Lighting & Measured & 8 months & Hourly & $\begin{array}{l}\text { MAE 0.7607-4.1532, } \\
\text { RMSE } \quad 0.9947-5.4712\end{array}$ \\
\hline \multirow{4}{*}{ [39] } & \multirow{4}{*}{ USA } & \multirow{4}{*}{ Commercial } & \multirow{4}{*}{2} & Least mean square & \multirow{4}{*}{ N/A } & \multirow{2}{*}{ Simulated } & \multirow{4}{*}{1 years } & \multirow{4}{*}{ Hourly } & $\begin{array}{l}\text { R2(S) } 0.888 \text { R2(M) } \\
0.806\end{array}$ \\
\hline & & & & $\begin{array}{l}\text { Normalized least mean } \\
\text { square }\end{array}$ & & & & & $0.880,0.791$ \\
\hline & & & & Recursive least square & & \multirow[b]{2}{*}{ Measured } & & & $0.893,0.799$ \\
\hline & & & & $\begin{array}{l}\text { Gaussian mixture } \\
\text { model regression }\end{array}$ & & & & & $0.985,0.925$ \\
\hline [210] & Italy & Residential & Single & Physical EnergyPlus & $\begin{array}{l}\text { Heating/cooling } \\
\text { load }\end{array}$ & Database & 1 year & Annual & \\
\hline [211] & Germany & Building sector & City & Statistical & Electricity & Database & N/A & Monthly & $\begin{array}{l}\text { Average coverage error } \\
-0.0231-0.0184\end{array}$ \\
\hline [94] & South Korea & School & Single & $\begin{array}{l}\text { Hybrid (random forest } \\
\text { +multilayer } \\
\text { perceptron) }\end{array}$ & Electricity & Database & 6 years & Daily & N/A \\
\hline \multirow{3}{*}{ [126] } & \multirow{3}{*}{ UK } & \multirow{3}{*}{ Hotel } & \multirow{3}{*}{ Single } & Randomized trees & \multirow{3}{*}{$\begin{array}{l}\text { HVAC energy } \\
\text { consumption }\end{array}$} & \multirow{3}{*}{ Database } & \multirow{3}{*}{1 year } & \multirow{3}{*}{ Hourly } & R2 0.8427 \\
\hline & & & & SVM & & & & & 0.8453 \\
\hline & & & & $\begin{array}{l}\text { Deep highway } \\
\text { networks }\end{array}$ & & & & & 0.8491 \\
\hline [96] & France & Experiment & Single & $\begin{array}{l}\text { Hybrid (Piece Wise } \\
\text { Auto-Regressive } \\
\text { eXogeneous + SVM) }\end{array}$ & Heating load & Measured & 1 year & N/A & $79 \%$ \\
\hline [212] & Germany & Commercial & 59 & $\begin{array}{l}\text { Total Consumption } \\
\text { Pattern Matching } \\
\text { (TCPM)/Hourly } \\
\text { Consumption Pattern } \\
\text { Matching (HCPM) } \\
\text { model }\end{array}$ & N/A & $\begin{array}{l}\text { Commission of } \\
\text { Energy Regulation } \\
(\mathrm{CER}) \text { in Ireland }\end{array}$ & 8 months & Daily/hourly & $\begin{array}{l}\text { Relative error } 17.70 \%- \\
24.02 \%\end{array}$ \\
\hline \multirow{2}{*}{ [97] } & \multirow{2}{*}{ USA } & Residential & \multirow{2}{*}{ Single } & \multirow{2}{*}{$\begin{array}{l}\text { Hybrid (GA+ Long } \\
\text { Short-Term Memory) }\end{array}$} & \multirow{2}{*}{ Electricity } & \multirow{2}{*}{ Database } & 4 years & \multirow{2}{*}{ Hourly } & CV $17.526 \%$ \\
\hline & & Commercial & & & & & 1 year & & $8303 \%$ \\
\hline [213] & Canada & Residential & Single & Statistical & Electrical & Measured & N/A & Hourly & NMAE 75\% \\
\hline [214] & China/USA & $\begin{array}{l}\text { Convenience } \\
\text { store }\end{array}$ & 600 & Multiple regression & Total energy & Database & 1 year & Yearly & R2 0.7 \\
\hline$[65]$ & China & Commercial & 2 & $\begin{array}{l}\text { Hybrid Generative } \\
\text { Adverarial Nets }\end{array}$ & N/A & Database & $\begin{array}{l}24 \text { days } \\
240 \text { davs }\end{array}$ & Daily & R, MAPE $0.940,5.83 \%$ \\
\hline & & & & $\begin{array}{l}\text { Multiple linear } \\
\text { regression }\end{array}$ & & & & & $\begin{array}{l}\text { CV-RMSE 26.4\%- } \\
34.3 \%\end{array}$ \\
\hline [131] & China/Japan & Educational & Single & ANN & Cooling load & Database & 1 year & Daily & $20.2 \%-25.3 \%$ \\
\hline & & & & SVR & & & & & $20.1 \%-25.1 \%$ \\
\hline
\end{tabular}


Extreme gradient

boosting trees

$17.7 \%-19.3 \%$ 